
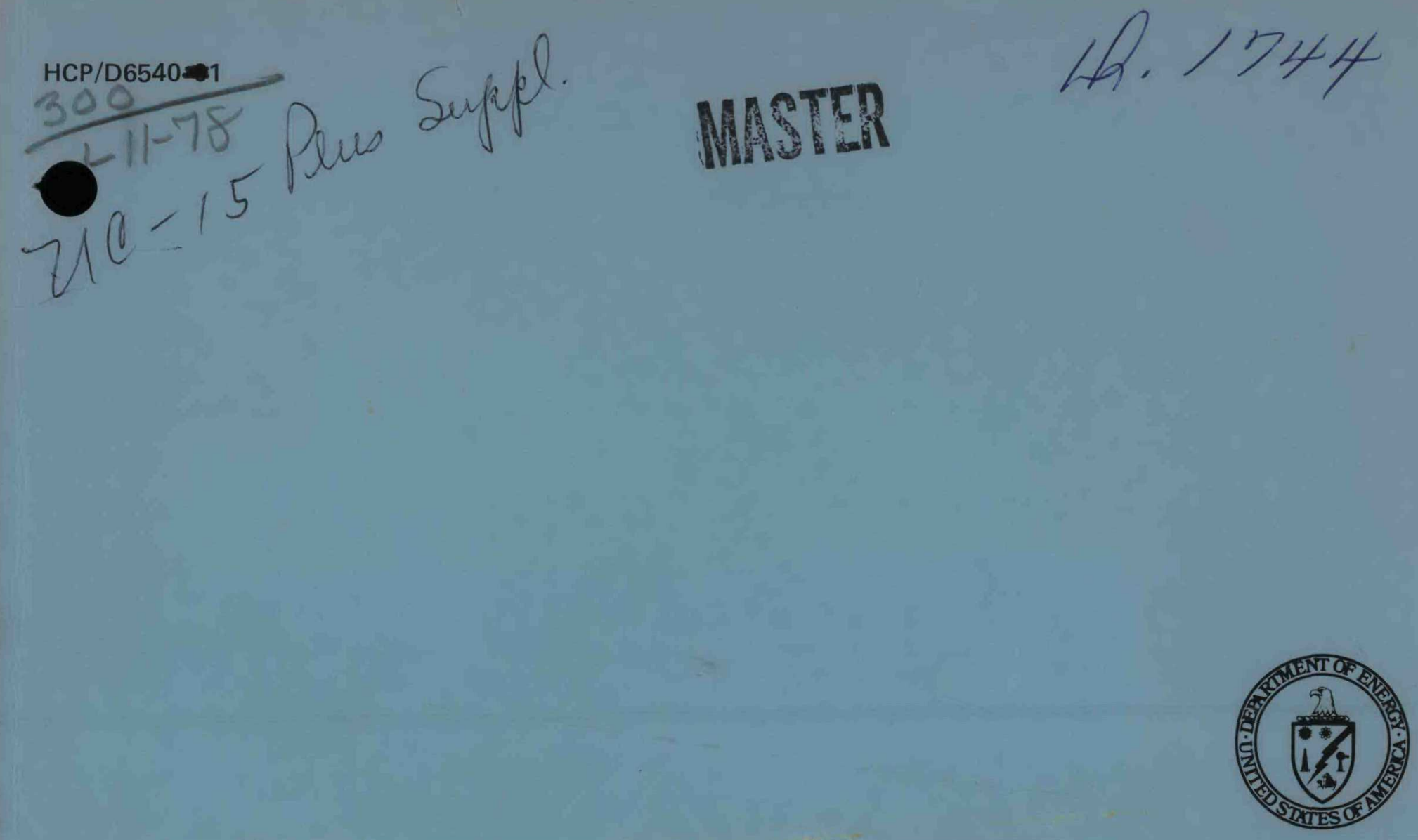

\title{
Nuclear Safeguards Technology Handbook
} December 1977

\author{
Prepared For \\ Sandia Laboratories \\ Under Contract No. 03-6540
}

For

U.S. Department of Energy

Assistant Secretary for Defense Programs

Division of Safeguards and Security 


\section{DISCLAIMER}

This report was prepared as an account of work sponsored by an agency of the United States Government. Neither the United States Government nor any agency Thereof, nor any of their employees, makes any warranty, express or implied, or assumes any legal liability or responsibility for the accuracy, completeness, or usefulness of any information, apparatus, product, or process disclosed, or represents that its use would not infringe privately owned rights. Reference herein to any specific commercial product, process, or service by trade name, trademark, manufacturer, or otherwise does not necessarily constitute or imply its endorsement, recommendation, or favoring by the United States Government or any agency thereof. The views and opinions of authors expressed herein do not necessarily state or reflect those of the United States Government or any agency thereof. 


\section{DISCLAIMER}

Portions of this document may be illegible in electronic image products. Images are produced from the best available original document. 


\section{NOTICE}

This report was prepared as an account of work sponsored by the United States Government. Neither the United States nor the United States Department of Energy, nor any of their employees, nor any of their contractors, subcontractors, or their employees, makes any warranty, express or implied, or assumes any legal liability or responsibility for the accuracy, completeness or usefulness of any information, apparatus, product or process disclosed, or represents that its use would not infringe privately owned rights.

\section{Available from:}

National Technical Information Service (NTIS) U. S. Department of Commerce

5285 Port Royal Road

Springfield, Virginia 22161

\section{Price: Printed Copy: $\$ 10.75$}

Microfiche : $\$ 3.00$ 


\section{Nuclear Safeguards Technology Handbook} December 1977

International Energy Associated Limited 2600 Virginia Avenue, NW.

Washington, DC 20037

Prepared For

Sandia Laboratories

Under Contract No. 03-6540

For

U.S. Department of Energy Assistant Secretary for Defense Programs

Division of Safeguards and Security 


\section{ACKNOWLEDGEMENT}

The following authors from International Energy Associates Limited assisted in the preparation of this handbook: Nancy A. Alikonis, John E. Gray, Joseph W. Harned, John R. Powers, and John C. Young. 
1.0 Preface................................. 1-1

2.0 Introduction and summary.................... 2-1

3.0 The Safeguards Problem...................... 3-1

3.1 International safeguards................. 3-2

3.2 Domestic Safeguards...................... 3-5

3.3 Interrelationship Between International and

4.0 Roles and Missions for Safeguards in the U.S. Government $4 \cdots 1$ 4.1 Nuclear Regulatory Commission (NRC) ............ 4-1

4.2 Department of Energy (DOE) $\ldots \ldots \ldots \ldots \ldots \ldots \ldots \ldots \ldots 4-4$

4.2 .1 Overall DOE Program................ 4-4

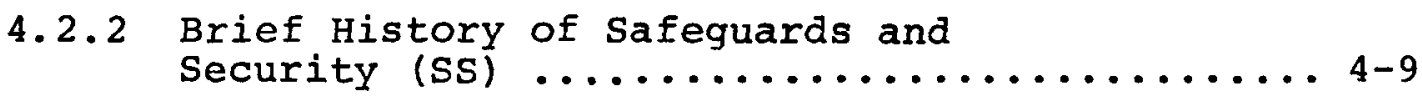

4.2.3 Current DOE/SS Program.............. 4-10

4.3 Complementary Responsibilities to Those of NRC and DOE................................. 4-17

5.0 Application of the DOE Technology Program to Industry Safeguards Planning........................... 5-1

5.1 The DOE Safeguards Technology Program.......... 5-1 Program Principles.$\ldots \ldots \ldots \ldots \ldots \ldots \ldots \ldots \ldots \ldots \ldots \ldots \ldots \ldots$

Safeguards Design Principles................ 5-2

Safeguards Design Sequence................. 5-4

Operational Roles of Facility Safeguards and Process operations Organizations................... 5-7

Safeguards Products...................... 5-8

- Design Tools........................... 5-9

- Engineered Safeguards System Designs........... 5-9

- Equipment, Procedures and Associated specifications......................... 5-10 
5.2 Application of DOE Safeguards Products to Industry

Facility Planning....................... 5-10

Industry Activities in Planning a Facility Safeguards

Program........................... 5-10

Industrial Program Support................. 5-12

Technology Transfer................... 5-17

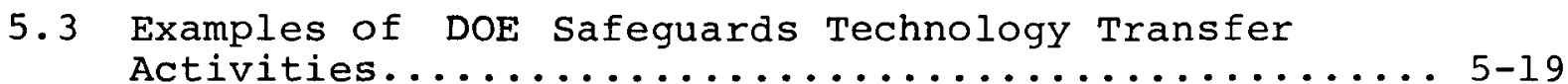

GUIDE TO SOURCES AND PRODUCTS

(information through April 30, 1977)

A. Guide to Sources

A.1 Sandia Laboratories.................... A-1

A. 2 Los Alamos Scientific Laboratory.............. A-10

A.3 Brookhaven National Laboratory.............. A-25

A.4 Lawrence Livermore Laboratory.............. A-34

A. 5 National Bureau of Standards................ A-38

A. 6 Pacific Northwest Laboratory $\ldots \ldots \ldots \ldots \ldots \ldots \ldots$ A-43

A. 7 New Brunswick Laboratory................... A-49

A.8 Idaho Chemical Processing Plant............. A-55

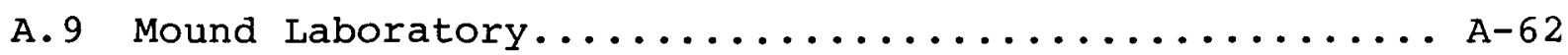

B. Guide to Products

B.1 Safeguards System Design Methodology............ B-3

B.1.1 Threat Considerations................ B-9

B.1.2 Physical Protection System Design and

Evaluation.......................... B-11

B.1.3 Materials Measurement and Accounting

System Design and Evaluation............ B-32 
B. 2 Design Support.......................... B-46

B.2.1 Evaluation Techniques and Models.......... B-46

B.2.2 Physical Protection Equipment Evaluation..... B-54

B.3 Representative system and Subsystem Designs........ B-59

B. 4 Physical Protection Equipment Development.......... B-63

B.5 Material Measurement and Accounting (MMA)......... B-68

B.5.1 NDA Instrumentation..................... 69

B.5.2 Other Physical Techniques for Bulk and Sample Measurement................... B-94

B.5.3 Analytical Chemistry Techniques for Bulk and Sample Measurement.....................101

B.5.4 Storage Vaults and seals................... 105

B. 6 Inter-Facility Transportation................. B-109

B.7 Inspection, Assessment and Verification........... B-110 
1.0 PREFACE

Protection of nuclear materials and facilities against malevolent use and acts is imperative--in order that nuclear power generation and other peaceful nuclear applications can make their proper contribution to U.S. and world needs without unacceptable risks.

Safeguards and Security (SS) of the Department of Energy (DOE) is responsible for developing technology which can be used by industrial and utility organizations to safeguard special nuclear materials and facilities. This technology--which is applicable to safeguarding any nuclear fuel cycle option--is supportive of President Carter's policy to find better answers to the problems and risks of nuclear proliferation.

The purpose of this handbook is to convey an understanding of the current SS safeguards technology development program and its prospective relevance and use to U.S. industrial and utility organizations, as well as to other U.S. government agencies and international organizations. It has been prepared by International Energy Associates Limited (IEAL), working with and under contract to the Sandia Laboratories, and the staff of DOE's SS.

I regard the handbook as an important step in aiding the transfer of DOE-developed technology to those institutions which can make effective use of it. 
I commend the many people in the Sandia, Los Alamos, Brookhaven, other laboratories and industrial organizations who worked most effectively with IEAL and my staff in producing this handbook.

Harvey E. Lyon

Director

Safeguards and security 
The purpose of this handbook is to present to United States industrial organizations the Department of Energy's Safeguards Technology Program. The handbook may also be of interest to international organizations and energy development and regulatory units of U. S. and foreign governments.

Safeguards, as the term applies to the nuclear energy industry, refers to measures taken in response to a perceived threat of facility sabotage, material theft, or material diversion for an undesirable purpose. These measures are implemented as a result of two major areas of concern involving nuclear materials and facilities used in research, power generation, or in fuel cycle activities: diversion of material on a national level for use in nuclear weapons production, and diversion of material on a sub-national level or sabotage of facilities. International safeguards utilize methods to inspect and verify that nuclear material intended for peaceful use is not being diverted to non-peaceful use. Domestic safeguards utilize methods to prevent the unauthorized possession or use of significant quantities of nuclear materials through theft or diversion, and sabotage of nuclear facilities.

Within the U.S. government, the Nuclear Regulatory Commission (NRC), DOE, the Department of State and the Arms Control and Disarmament Agency (ACDA) have major safeguards functions. In addition, Congress, the General Accounting office (GAO), the 
General Services Administration (GSA), the Environmental Protection Agency (EPA), the Department of Health, Education and Welfare (HEW), the Department of Commerce, the National Security Council, the Department of Transportation (DOT), and the Department of Housing and Urban Development (HUD) have safeguards-related responsibilities. The lead agency in international safeguards is the International Atomic Energy Agency (IAEA), formed in 1957 under United Nations sponsorship. The U.S. nuclear industry has a history of strong management involvement in meeting nuclear power program objectives, such as health, safety, and environmental and quality assurance programs, and including safeguards. U. S. companies are now integrating nuclear safeguards into facility designs for plants:
(1) in operation,
(2) in construction,

and (3) in the planning and design stage. Principal industry guidance for safeguards planning comes from the still evolving Nuclear Regulatory Commission safeguards regulatory criteria.

The NRC is considering changes in regulation of safeguards activities. The major change proposed would be the use of performance objectives and criteria which safeguards programs and systems must meet as opposed to mandating systems technical specifications. Performance objectives would dictate the level of protection required for given amounts and kinds of nuclear material and for potential threat levels. The elements of the regulatory framework would be

- Objectives and performance criteria focusing on what the safeguards systems should accomplish, rather than the technical details of how. 
- The safeguards system designer being permitted greater flexibility to tailor his choice of systems and equipment to accommodate site-specific factors.

- The safeguards system implementer and user being permitted flexibility in utilizing new technology to satisfy regulatory requirements.

The purpose of the DOE safeguards technology program is to develop and transfer to users a set of safeguards technologies for nuclear reactor plants and fuel cycle facilities.* The principles guiding the DOE program include the following:

- Develop safeguards system design methods for the consideration of industrial designers, owners and operators, and evaluation by regulatory authorities.

- Examine alternative nuclear process designs with respect to safeguards.

- Develop equipment and procedure to meet the requirements of the safeguards system designs. Best use should be made of available commercial equipment.

- Demonstrate system designs, equipment and procedure by installation and performance at representative facilities.

- Transfer developed technology to industry, governments and appropriate international organizations by offering as major product types:

(1) design tools

(2) completed safeguards system designs for generic nuclear facilities to serve as a reference and as examples

(3) equipment, procedure and associated specifications.

DOE and NRC safeguards research programs, which are closely coordinated, fully exchange threat analysis and safeguards evaluation methodology. DOE safeguards technology products in the form of safeguards technology, system modules and integrated generic systems concepts are designed to satisfy both industry safeguards needs as established by NRC criteria as well as DOE facilities and IAEA safeguards requirements.

* The description of the DOE safeguards technology program which is presented here is intended for general information. It is the responsibility of each industrial safeguards program to ensure that the total facility safeguards system meets specific regulatory requirements. 
DOE safeguards design principles require that an effective safeguards system perform four basic functions:

- Detection of unauthorized activities and material balance discrepancies.

- Delay of unauthorized activities until appropriate response can be made.

- Response to unauthorized activities and discrepancies in an adequate and timely manner.

- Deterrence of potential adversary actions through public awareness of the general capability of safeguards.

The DOE design sequence involves the use of a threat analysis process and establishing minimum safeguards requirements. It provides identification of the weakest areas in the total safeguards system for a facility, and the development of the relative cost-effectiveness of design alternatives which satisfy the minimum protection requirements. The design sequence follows a normal industrial approach.

As a part of its design approach, DOE suggests roles, responsibilities and authorities of the facility safeguards organization and the facility process operations organization and defines the operational relationship between the two. In this regard, DOE consults with industrial organizations having experience in nuclear facility design and operations.

The DOE safeguards technology is being transferred to industry through handbooks, technical reports, consensus standards, journal papers, briefings, and training programs. Technology transfer aids include:

- design methods and models, 
- equipment specifications to support design, costing, procurement, testing and performance analysis,

- procedures for installation, testing and evaluation of systems and equipment, and

- standardized operating procedures, including inspection, operations, quality control and verification of ongoing systems operation against design criteria.

Feedback from industry facility safeguards design activities is an important element in DOE safeguards technology transfer. Information flowing from industry to DOE provides evaluation and corrective action signals to DOE for its products related to commercial, licensed facilities. This feedback applies to the performance of design tools, designs, equipment and procedure.

Technology transfer activities to date have been directed toward:

- Use of industry facility projects as design reference. DOE safeguards design efforts use industry projects where possible as a reference for process design, plant operations and management inputs.

- Use of available commercial equipment and systems. Commercially developed safeguards equipment and systems are evaluated to provide for their maximum use in safeguards systems.

- Providing equipment information to suppliers and users. DOE equipment improvement and design information and performance requirements are provided to potential commercial suppliers and facility owners, operators and designers.

- Operations support.

DOE provides operations support to industry and government projects in safeguards equipment installation, test, evaluation and operations. 
- International cooperation.

DOE provides safeguards technology to the International Atomic Energy Agency's safeguards system under a coordinated support program involving also the NRC, Department of state, and ACDA.

Additional information concerning the DOE safeguards program and product availability is available from DOE at the following address:

Director

Safeguards and Security

Department of Energy

Washington, D.C. 20545

Specific questions related to the projects of a specific DOE support laboratory may be directed to the appropriate addressee indicated in the last section of this handbook, Guide to Sources and Products. 


\subsection{The Safeguards Problem}

Safeguards, as the term applies to the nuclear energy industry, refers to measures to detect and deter material diversion for an unauthorized purpose, and (domestically) measures taken in response to a perceived threat of facility sabotage or material theft. These measures are implemented as a result of two major areas of concern involving nuclear materials and facilities used in research, power generation or fuel cycle activities: diversion of material on a national level for use in nuclear explosives production (international safeguards), and loss or theft of material on a sub-national level or sabotage of facilities (domestic safeguards). Safeguards concerns are separate from safety concerns. Although certain safeguards measures may complement safety measures (and vice versa), the focus of safeguards is purposeful malevolent acts. Safety measures, rather than safeguards measures, are designed to assure against losses of material because of operator error or other accidental means.

The safeguards issue has had a pervasive effect on the U.S. nuclear power industry and on U.S. nuclear export policy. Concern about safeguards has been a major factor in U.S. reconsideration of policy regarding reprocessing, plutonium recycling, and the breeder reactor. 
3.1 International Safeguards $1 /$

International safeguards utilize methods to verify that nuclear material intended for peaceful use is not being utilized for non-peaceful purposes. These methods comprise a system to ascertain that a particular government is not diverting nuclear materials/equipment from peaceful uses to development of a nuclear explosives capability or to other unauthorized uses. $2 /$ This is only one facet of the larger issue of nuclear weapons proliferation.

In the United States, the Nuclear Regulatory Commission (NRC), the Department of Energy (DOE), and several other federal agencies are actively involved in support of the development and implementation of international safeguards measures. U.S. agencies' functions in this connection are described in Chapter 4.

1) Much of the information about the International Atomic Energy Agency which is presented here is adapted from Role of the International Atomic Energy Agency in Safeguarding Nuclear Material, by the Comptroller General of the United states, Washington, D.C., July 3, 1975.

2/ Because international safeguards address material diversion on a national level, sub-national diversion (i.e., sabotage and terrorism) is not considered here; safeguards which address sabotage and terrorism would be a function of each country's domestic safeguards system, considered in sections 3.2 and 4.0 . 
The lead agency in international safeguards is the International Atomic Energy Agency (IAEA), formed in 1957 under

United Nations sponsorship. Its objective is to

seek to accelerate and enlarge the contribution of atomic energy to peace, health and prosperity throughout the world. It shall ensure, so far as it is able, that assistance provided by it or at its request or under its supervision or control is not used in such a way as to further any military purpose. 3 y

A key function of IAEA is

to establish and administer safeguards designed to ensure that special fissionable and other materials, services, equipment, facilities, and information made available by the Agency or at its request or under its supervision or control are not used in such a way as to further any military purpose; and to apply safeguards, at the request of the parties, to any bilateral or multilateral arrangement, or at the request of a state, to any of that State's gctivities in the field of atomic energy. 4 )

The aim of IAEA safeguards is to detect, and by the threat of detection to deter, any diversion of significant quantities of nuclear material from peaceful activities. Key elements in the IAEA safeguards system include IAEA examination of facility design information; existence of an effective national system of accounting for and control of nuclear material; maintenance of records by facility operators; submission of reports to the IAEA by national

3) From the Statute of the International Atomic Energy Agency, as amended as of 1 June 1973 .

4/ From the Statute of the International Atomic Energy Agency, as amended as of 1 June 1973. 
authorities on nuclear materials used, processed, or produced; and on-site inspection of facilities and facility records by IAEA personnel, to verify through observation and independent measurements the information submitted. In addition to its function of applying international safeguards, IAEA has developed guidelines for the use of member countries in developing their own domestic safeguards system.

Non-nuclear-weapon states party to the Treaty on Non-Proliferation of Nuclear Weapons (NPT), which entered into force in 1970, are committed to accepting IAEA safeguards on their entire peaceful nuclear programs. This Treaty has as its purpose the prevention of the spread of nuclear weapons to non-nuclear weapons states. $\underline{5}$ / (The Treaty defines a nuclear-weapon state as one which manufactured and exploded a nuclear weapon or other nuclear explosive devices prior to January 1, 1967.6/)

There is a difference of opinion regarding the adequacy of international safeguards, as they now exist. An area of concern is the unwillingness of some non-nuclear weapons states to become NPT parties or to accept safeguards on their entire nuclear

5/ Signatories to the NPT are not necessarily members of IAEA, and not all IAEA members have signed the NPT. The focus as well as the detail of the two safeguards systems which IAEA administers differ. The original IAEA system proscribes all military uses of nuclear material and does not specifically address peaceful explosives (although the no-military-use prohibition is regarded as precluding use for any nuclear explosive device). The NPT system proscribes manufacture of nuclear weapons or any nuclear explosives, but does not prohibit non-explosive military uses.

6/ The United States Soviet Union, United Kingdom, France, and the People's Republic of China 
programs. In spite of this concern, IAEA safeguards are widely accepted--almost all industrially-advanced non-nuclear weapons states have (or will soon have $7 /$ ) their entire peaceful nuclear programs under IAEA safeguards.

The problems attendant to international safeguards will command increasing attention in the next few years. It is clear that unusual international cooperation as well as safeguards technology development will be required to ensure an adequate international safeguards system in light of the increasing quantities of nuclear material and growing number and complexity of nuclear facilities.

\subsection{Domestic Safeguards}

Domestic safeguards address the unauthorized possession or use of significant quantities of nuclear materials through theft or diversion, and sabotage of nuclear facilities. $9 /$ Domestic safeguards measures have as their objective the deterrence, detection, and delay of unauthorized activities, as well as appropriate response to these activities should they occur. The responsibilities for domestic safeguards within the U.S. government are described in Chapter 4.

7/ IAEA is currently working on the implementation of its agreement to verify the findings of the EURATOM safeguards system in the seven non-nuclear-weapon EURATOM states. EURATOM consists of nine European countries whicti have their own multilateral safeguards system which has not previously been subject to IAEA verification. Negotiations are also under way, pursuant to Japan's ratification of the NPT, on the application of IAEA safeguards on all of Japan's peaceful nuclear activities. Similar negotiations are expected soon with respect to switzerland, which became an NPT party in March 1977.

8/ Energy Research and Development Administration, Final Environmental Statement on U.S. Nuclear Power Export Activities, Volume 1, April 1976. 
Both domestic and international safeguards systems utilize material accountability measures to verify that nuclear material has not been diverted or stolen. Domestic safeguards utilize two other types of measures in addition to material accountability. One category includes measures intended to prevent, detect, or respond to unauthorized access to the facility or to particular areas within the facility (referred to as physical security or personnel control). The other category includes measures to oversee handling of nuclear material in order to prevent, detect, or respond to unauthorized activities involving the material by those who have authorized access to it (referred to as material control).

3.3. Interrelationship Between International and Domestic Safeguards

Although domestic and international safeguards have evolved (and continue to evolve) in response to two separate concerns, similar public attitudes affect both. Public interest in the total safeguards problem is increasing for a number of reasons: 1) increase in the number of terrorist acts of all kinds in the U.S. and abroad, 2) public availability of technical information relating to nuclear explosive design, 3) realization that nuclear energy is a significant present and future power source, and 4) potential for increase in the supply and use of potential weapons materials in nuclear power generation, as in the recycle of plutonium in light water reactors and in breeder reactors. Many of the safeguards procedures and equipment now in 
use or in development have both international and domestic applicability. This is the case in material accountability, for example.

of related interest is the interaction between certain national policy decisions and international safeguards. For example, decisions on whether to export nuclear material or equipment, and if so, on what conditions, will influence international safeguards requirements. Conversely, the effectiveness of international safeguards will be an important factor in such national decisions.

An illustration of this interrelationship can be seen in the considerations which are taken into account when the U.S. enters into agreements to cooperate with other countries in the peaceful application of nuclear energy. Section 123 of the Atomic Energy Act of 1954, as amended, specifies that Agreements for Cooperation must include safeguards guarantees:

a) that security safeguards and standards as set forth in the agreement will be maintained (assurance of domestic safeguards);

b) that any material transferred pursuant to the agreement will not be used for atomic weapons or for any other military purpose (assurance of international safeguards); and

c) that any material transferred pursuant to the agreement will not be transferred to unauthorized persons 
or beyond the jurisdiction of the cooperating party except as specified in the agreement. 9 /

Agreements for Cooperation are entered into by the U.S. with individual nations or with international organizations. $10 /$ The duration of an agreement varies depending on scope and other factors. These agreements may cover either research or power applications or both, and may allow for the transfer of nuclear material and equipment and the provision of services (such as enrichment).

9/ Energy Research and Development Administration, Final Environmental Statement on U.S. Nuclear Power Export Activities, Volume I, April 1976.

10/ Agreements are signed on behalf of the U.S. by DOE and State which are the two U.S. agencies most actively involved in formulating the agreements. However, other interested agencies (such as the Department of Defense and Arms Control and Disarmament Agency) are consulted in this process. Each agreement is submitted to Congress, which may pass a resolution disapproving the agreement and thus prevent it from becoming effective. 
4.0. ROLES AND MISSIONS FOR SAFEGUARDS IN THE U.S. GOVERNMENT

The Nuclear Regulatory Commission (NRC) and the Department of Energy (DOE) are the major federal agencies with domestic safeguards functions. These are described in Sections 4.1 and 4.2. Other U.S. government offices (as well as the legislative branch) have safeguardsrelated responsibilities in the performance of their other duties and in cooperative interagency efforts; these are detailed in section 4.3. A chart representing these responsibilities is presented in section 4.3 .

4.1. Nuclear Regulatory Commission (NRC)

The Energy Reorganization Act of 1974, in addition to establishing the Energy Research and Development Administration (now a part of $\mathrm{DOE}$ ) and $\mathrm{NRC}$, outlined the specific responsibilities of these agencies for safeguards. DOE responsibilities are described in section 4.2. NRC offices have safeguards responsibilities as specified below:

Office of Nuclear Material Safety and Safeguards

- Overall development if NRC safeguards program

- Development of NRC safeguards policy options

- Identification of NRC safeguards policy or program weaknesses by field assessment teams

- Licensing of all private sector fuel cycle facilities except reactors

- Analysis of safeguaras-related information

- Coordination with DOE regarding safeguards

- Upgrading, testing and monitoring of nuclear material accounting systems

- Development of safeguards contingency plans for dealing with threats, thefts, and sabotage relating to licensed nuclear materials and facilities. 


\section{NUCLEAR REGULATORY COMMISSION}

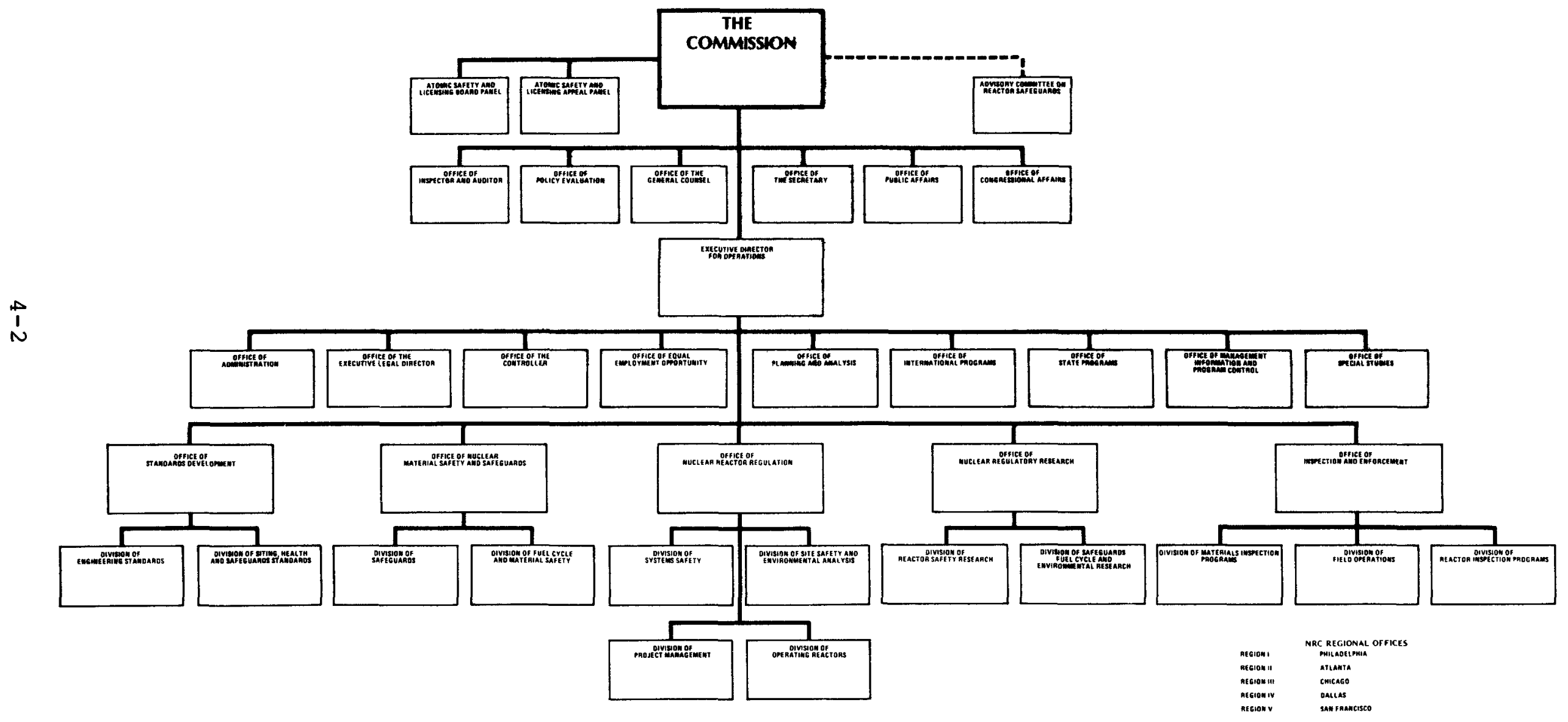




\section{Office of Standards Development}

- Development of regulation criteria, guidelines, standards and codes regarding safeguards aspects of

- location, design, construction and operation of licensed nuclear facilities

- management and uses of nuclear materials held by licensees

- Coordination with IAEA on standaxds development

Office of Nuclear Reactor Regulation

- Development of safeguards evaluation plans for review of reactor license applications

- Licensing of private sector reactors

\section{Office of Inspection and Enforcement}

- Development of detailed programs for inspection of 1 icensees

- Inspection of licensees and enforcement of requirements

- Development of recommendations for issuance, amendment, or denial of permits and licenses

- Investigation of abnormal occurrences at licensee facilities

\section{Office of Nuclear Regulatory Research}

- Determination (with other offices $1 /$ ) of NRC requirements for safeguards research

- Planning and implementation of NRC safeguards research programs

- Coordination of work and communication of results within NRC

- Coordination of NRC safeguards research with DOE and other government agencies

I/ Each office is also responsible for recommending research necessary to perform its function. 
NRC participates in international safeguards development through the work of its experts on IAEA panels, working groups and task forces. It regulates the export of nuclear facilities and materials through the issuance of licenses. Consideration of license applications includes input from the Executive Branch agencies through the state Department regarding the status of safeguards in the importing country as well as general U.S. $f$ eign policy. NRC has also been working with DOE, IAEA and 0 ers on implementation of the US/IAEA safeguards agreement prov_..ing for application of safeguards to U.S. civil nuclear facilities.

Although NRC and DOE have distinct safeguards responsibilities, there is cooperation where these responsibilities interface. Certain DOE facilities (new demonstration power reactors and nuclear waste disposal sites) are subject to NRC licensing. NRC and DOE have set up Iiaison committees (such as the Technical Advisory Committee) to establish and maintain contact between the two programs. NRC, DOE, and other agencies cooperate in areas broader than the responsibility of any single agency, such as in the areas of international safeguards and contingency planning.

The regulatory nature of its mission has resulted in NRC giving emphasis in its research program to the development of methods for evaluating the effectiveness of regulations and licensee implementation. The development of these methods is coordinated with DOE to permit their adaptation and application in the development of conceptual safeguards systems designs for 
the commercial nuclear industry. The coordination also permits NRC to take account of technological improvements and data developed in the DOE program.

\subsection{Department of Energy (DOE)}

\subsubsection{Overall DOE Program}

The DOE program is aimed at the development of integrated safeguards systems having three major elements:

1. Personnel control - including such measures as barriers and alarms, personnel identification, access controls, and response force action.

2. Material control - monitoring and controlling handling and processing operations in which personnel access to SNM is involved.

3. Material accountability - timely data-keeping and verification of inventory and location of SNM.

A system comprising a balance of these three elements aids in protecting facilities from sabotage, facilitates detection of theft or diversion of SNM, and, should it occur, provides information to determine where the system failed and to aid in SNM recovery.

Thus the goals of DOE's safeguards program are to develop a system which will provide a deterrence to adversary actions, attempt to detect and/or delay successful completion of adversary actions if they are initiated, and take measures to recover nuclear materials if they are misappropriated. Additional goals are cost-effectiveness and flexibility to meet evolving safeguards objectives. The implementation of this program involves 
threat assessment, effectiveness evaluation, cost-benefit optimization, and examination of a graded system based on material quantity and type.

DOE responsibilities and objectives for safeguards originate from the Atomic Energy Act of 1954, as amended. The Energy Reorganization Act of 1974 assigned safeguards functions to both NRC and ERDA by retaining much of the language of the original mandate to the AEC found in the Atomic Energy Act. The Energy Organization Act of 1977 created the Department of Energy by bringing together many fragmented energy programs and agencies, including ERDA.

From this base DOE has formulated three objectives for its integrated plan for safeguards and security:

1. Prevent successful malevolent acts involving nuclear materials or facilities, so as to protect the public against risk of death, injury, and property damage that could arise from such acts;

2. Protect classified information from unauthorized disclosure; and

3. Protect government property from theft or malevolence.

DOE is responsible for the application of safeguards to governmentowned and DOE contractor facilities which are not licensed by NRC. DOE is also responsible for the development and demonstration of effective safeguards systems for commercial facilities.

The responsibility within DOE for safeguards research, development, test, and evaluation has been assigned to Safeguards and Security (SS). SS is also charged with providing guidelines and criteria for the

2/ Master Plan, ERDA Division of Safeguards and Security, Washington, D.C., September 1976 
design of safeguards and security systems at DOE-owned nuclear facilities. In addition, ss develops policy, issues and enforces directives, and coordinates with other government agencies.

An important element of the DOE safeguards program is coordination among the various DOE components which have safeguards responsibilities.

One specific SS function, in coordination with the DOE International Security Affairs component, is the evaluation of physical protection systems in foreign countries for the purpose of providing information to the Department of state regarding a proposed U.S. nuclear export. Ss's international safeguards responsibilities involve coordination of its activities with the DOE Assistant Secretary for International Affairs, NRC, the Department of state, the Department of Commerce, ACDA, DOD, and IAEA.

When international security aspects must be evaluated by DOE (or national security aspects of exports or proliferation), this evaluation is performed by International Security Affairs. The DOE Military Applications (MA) component, as part of its responsibility for safeguarding weapons and special nuclear material (SNM) in the DOE weapons program, coordinates and monitors research and development programs for weapons and weapons nuclear material safeguards. Components under the Assistant Secretary for Energy Technology are responsible for the adequacy of safeguards at the DOE facilities for which they have programmatic responsibility, and to identify requirements for safeguards activities or developments which should be included in the SS R\&D program. 
In the event of a safeguards or other nuclear emergency, DOE's emergency response capability resides in its Emergency Action and Coordination Team (EACT) and Nuclear Emergency Search Team (NEST). EACT membership consists of the directors of Military Applications; Safety, Standards and Compliance, and Safeguards and Security, as well as the Chief of the Nuclear and National Security News Branch (Public Affairs). NEST is directed by MA, and SS provides development technology. EACT and NEST would coordinate with the FBI and other law enforcement authorities in recovering SNM.

Aside from exercising responsibilities with respect to domestic safeguards, DOE has been charged with applying safeguards on U.S. nuclear materials and reactors supplied to other countries under Agreements for Cooperation. Beginning in the early 1960's, however, U.S. rights to apply such safeguards have been progressively suspended in favor of IAEA safeguards, in accordance with trilateral agreements between the U.S., the IAEA and most cooperating countries outside the European Communities.

\subsubsection{Brief History of Safeguards and Security (SS)}

Prior to 1964 all special nuclear materials was owned, processed, and fabricated by the federal government. Domestic safeguards concerns from 1946, when the Atomic Energy Commission (AEC) was 
formed, until 1964 primarily related to military nuclear material. Protection related to the non-military uses of nuclear energy within the U.S. relied essentially on the monetary value of SNM and on existing criminal penalties.

Two events in 1964 altered this situation. First, the Atomic Energy Act of 1954, as amended, was amended to allow private ownership of SNM. Second, the AEC imposed safeguards on the civilian uses of nuclear materials in the form of material control requirements.

In 1967, the AEC created two high-level offices with specific responsibilities: the Office of Safeguards and Materials Management under the General Manager (to develop AEC safeguards policy and criteria), and the Division of Nuclear Materials Safeguards under the Director of Regulation (to administer safeguards on material held by AEC licensees). These offices continued work on safeguards development and application, including strengthening and improving requirements for physical protection and accounting.

The Energy Reorganization Act of 1974 divided the former AEC functions between two newly created agencies, ERDA and NRC. Non-regulatory functions of the AEC Division of Nuclear Materials Safeguards were combined with those of the AEC Divi- 
sion of Security to form the ERDA Division of Safeguards and Security (DSS), under the ERDA Assistant Administrator for National Security. DSS was assigned responsibility for applying safeguards to ERDA-owned nuclear-related property (including facilities, materials and ERDA classified information), and developing safeguards for this application as well as for private sector use. The Energy Organization Act of 1977 transferred the program activities of ERDA into the Department of Energy. The DSS responsibilities under ERDA have been assigned to the DOE Safeguards and Security (SS) component which is under the Assistant secretary for Defense Programs.

\subsubsection{Current DOE SS Program}

Within the overall DOE safeguards program, ss has the following objectives: 3/

1. To develop, assess, and assure the availability of cost-effective systems for safeguarding special nuclear materials at DOE facilities and for application to commercial facilities;

2. To assist the International Atomic Energy Agency (IAEA) in its safeguards role in guarding against the proliferation of nuclear explosive devices and defining effective safeguards internal control and physical protection systems in conjunction with efforts of foreign countries for guarding against domestic threats to nuclear materials and facilities; and

3. To develop, assess, and assure implementation of effective physical protection and information control systems for the protection of classified information and DOE property at DOE, selected other U.S. government, and privately owned facilities.

3/ Master Plan, Division of Safeguards and Security, Washington, D.C., September 1976. 
The ss program has identified nine tasks to achieve its program objectives:

$\underline{\text { Safeguards Design, Development and Testing }}$

Task I Characterize Threat

Task II Conceptual Design, Development, and Analysis

Task III Technology, Equipment, and Modular system Development/Test \& Evaluation

Task IV Integrated System Design (Plant Specific)/ Installation and Test \& Evaluation in Operating Environment

Safeguards Operations

Task V Assessment and Contingency Operations

Task VI Safeguards Analytical Laboratory

Task VII Nuclear Materials Management and Safeguards system (NMMSS)

Task VIII International Safeguards

Task IX Personnel Clearance Program

The ss design, development and testing tasks are efforts to improve safeguards systems and technology both for DOE facilities and for transfer to other government and private safeguards systems, thereby facilitating the use of nuclear energy for meeting a part of the nation's energy needs.

Task I - Characterize Threat. This task has three areas of concentration. First, the possible misuses of nuclear materials are examined as well as the potential consequences. From this examination, priorities for what is to be prevented can be established. Second, possible adversary actions (including an assessment of resource requirements) which could produce these undesirable events are studied against a back- 
ground of existing safeguards systems for the purpose of determining the adequacy of present systems. Third, actual adversary activities such as terrorism and bombing are analyzed and the resulting information used in determining what threats the safeguards system should guard against.

Task II - Conceptual Design, Development, and Analysis. This task focuses on developing generic safeguard system concept definitions and effectiveness evaluation methodologies. The methods developed are used to analyze physical protection and internal control systems to determine cost-effectiveness and to identify potential vulnerabilities or weaknesses. The analysis methods and assessment models include a diversion path analysis system developed at the National Bureau of Standards (NBS), fault tree analysis, graphic analysis and other techniques.

Task III - Technology, Equipment and Modular Systems Development/Test and Evaluation. This task is directed at evaluating a wide variety of equipment for application to identified requirements in the areas of

- physical protection--entry control, intrusion detection, information and item protection systems, barriers, guard equipment.

- material control and accountability--non-destructive assay technology, reliable analytical measurements and confirmatory assessments, quality and quantity assurance

- detection and recovery--mobile diagnostic equipment, high resolution detection assays 
Improvements, when tested and evaluated, can be applied to safeguards systems designs for existing or future facility types under the next task.

Task IV - Integrated System Design (Plant Specific)/ Installation and Test and Evaluation in Operating Environment. The equipment and technology development work done under the previous task is applied to systems and modules to be demonstrated in prototypical operating environments. Specific design features are selected on the basis of economic and operational constraints for the appropriate facility type, resulting in guidelines for implementation.

The facility classes and representative plants under study are :

- Research reactor-- Sandia Pulse Reactor

- Plutonium storage facility--Hanford 200-West

- Plutonium processing and recovery--LASI Plutonium Processing and Recovery Facility

As vilnerability to theft or sabotage differs from facility to facility, safeguards systems for each must be specifically structured. Also, conceptual designs for breeder reactor fuel cycle facilities are being developed. Facilities selected for this study are the High Performance Fuel Laboratory (HPFL), and Fast Flux Test Facility (FFTF).

SS safeguards operations tasks specifically address the objectives of the DOE integrated safeguards system (see p. 4-6) in protecting nuclear materials, facilities, information, and property. 
Task V - Assessments and Contingency Operations. DOE Headquarters and Field offices coordinate in the evaluation of DOE and DOE contractor facilities. This evaluation considers planning and performance, and provides information from an operating environment on the adequacy of existing safeguards requirements. These assessments serve as a basis for justification of budget requests, identification of research and development needs, and upgrading of DOE regulations.

Assessment methods include:

- identification and correction of system weaknesses

- computer simulation of detection and response capabilities

- SNM inventory verification, scheduled and unscheduled

- observation of system in operation

- physical simulation of threat

- variation in assessment schedule and procedure to avoid predictability

Task VI - Safeguards Analytical Laboratory. This function is performed by the New Brunswick Laboratory under the administration of the Chicago Operations office. Its services are utilized by DOE, NRC, and IAEA in support of their safeguards programs. These services include

- Developing and applying chemical analysis methods to satisfy criteria for material balance accounting and measurement uncertainty 
- Providing reliable independent measurements to be used in inventory verification (NBI also provides analysis and measurement services for non-safeguards purposes)

- Evaluating performance of laboratories and providing analytical standards

- Participating in efforts to upgrade measurement reliability at other laboratories by providing reference samples, evaluating data, issuing reports, and resolving measurement differences.

Task VII - Nuclear Material Management and Safeguards

System. Union Carbide Corporation operates this centralized automatic data processing system at oak Ridge, Tennessee. Safeguards-related information contained in the system is available to both DOE and NRC. A study group has been formed including representatives of Brookhaven National Laboratory, National Bureau of Standards, and Union Carbide Oak Ridge to identify system modifications that will better serve the DOE safeguards program.

Task VIII - International Activities. Current ss participation in international safeguards support involves separate topical areas of activities as part of an overall comprehensive program developed in cooperation with other U.S. government agencies and the IAEA. The resources of DOE contractor facilities are used to provide assistance to IAEA as part of this program. Specific activities of DOE laboratories and contractors include:

- Training of IAEA inspectors in non-destructive assay (NDA) techniques

- Conducting IAEA-requested studies on IAEA's accountability information system and on material balance statistical evaluation 
- Developing statistical and technical bases for IAEA inspections

- Manufacturing NDA instruments for IAEA use

- Analyzing IAEA inventory samples

In addition, $S S$ has cooperated in the negotiation of and preparation for the application of international safeguards to U.S. nuclear activities not related to national security. Task IX - Personnel Clearance Program. The FBI and Civil Service Commission conduct for DOE background investigations of persons who will have access to classified information or SNM. DOE employees in sensitive positions and contractor employees who occupy positions with a high degree of importance and sensitivity are reinvestigated every five years under the DOE selective reinvestigation program. All other individuals are required to furnish updated Personnel security Questionnaires every five years, at which time a decision is made as to whether a reinvestigation is required. DOE evaluates the investigation reports to determine the desirability of granting access privileges to a particular individual. The purpose of this activity is to assure that permitting such access will not endanger the common defense and security of the U.S.

4/ Other ss international activities which are not directly related to DOE facilities include providing representatives to IAEA working groups, informal assessment of the IAEA program through DOE/IAEA interface, and on-site inspection of facilities in foreign countries to determine adequate physical protection of exported U.S. nuclear materials. 
4.3. Complementary Responsibilities to Those of NRC and DOE The Department of State, as the primary agency involved in formulating U.S. foreign policy, is responsible for assessing the foreign policy implications of U.S. actions in the area of international safeguards. The Department of State (with the consultation of other interested government agencies) represents the U.S. in negotiating Agreements for Cooperation. State also assembles the views of federal agencies in formulating an Executive Branch position on a proposed export license. U.S. participation in international organizations is a responsibility of the state Department, which provides representatives to the IAEA.

The Arms Control and Disarmament Agency (ACDA) was created by Congress in 1961 as an independent federal agency responsible for advising the President, Secretary of state, other Executive Branch offices, and Congress on U.S. arms control policy. This agency has primary responsibility for research in the arms control and disarmament field. It has conducted research to improve television surveillance for international safeguards, spent fuel assays, remote monitoring of seals on sensitive equipment, techniques for verification of plutonium production of reactors, and portable measurement instrumentation which is nondestructive of the container in which the material is located. With the cooperation of the Canadian government, ACDA has worked on the development of tamper-resistant unattended safeguards surveillance 


\begin{tabular}{|c|} 
Congress \\
Legislation \\
Review of international \\
agreements \\
Appropriations \\
GAO \\
Evaluation of effec- \\
tiveness of programs \\
of other agencies
\end{tabular}

\begin{tabular}{|c|}
\hline State \\
International safeguards \\
coordination (re: \\
foreign policy) \\
U. S. representation in \\
international agree- \\
ments and organi- \\
zations \\
\hline
\end{tabular}

ACDA
Research
International safeguards
cooperation
Review of Agreements for
Cooperation and export
licenses

$\underset{\infty}{\stackrel{t}{L}}$

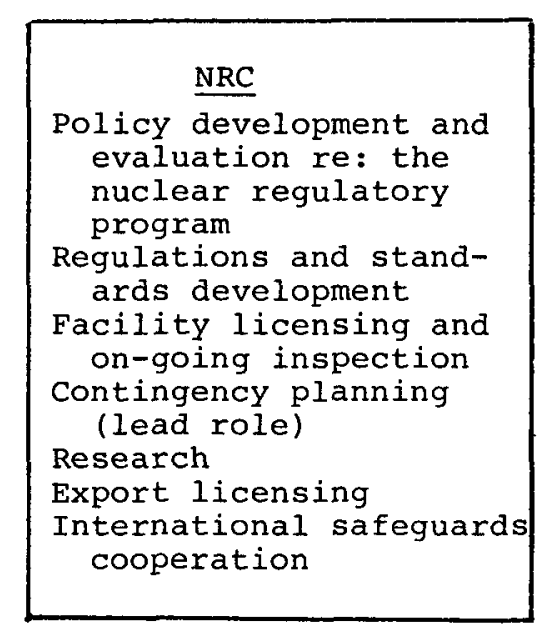

\section{Commerce}

Export review and/or approval

Research

Measurement services

\section{NSC}

Evaluation of system adequacy (re:

national security)

Interagency coordination on security

matters
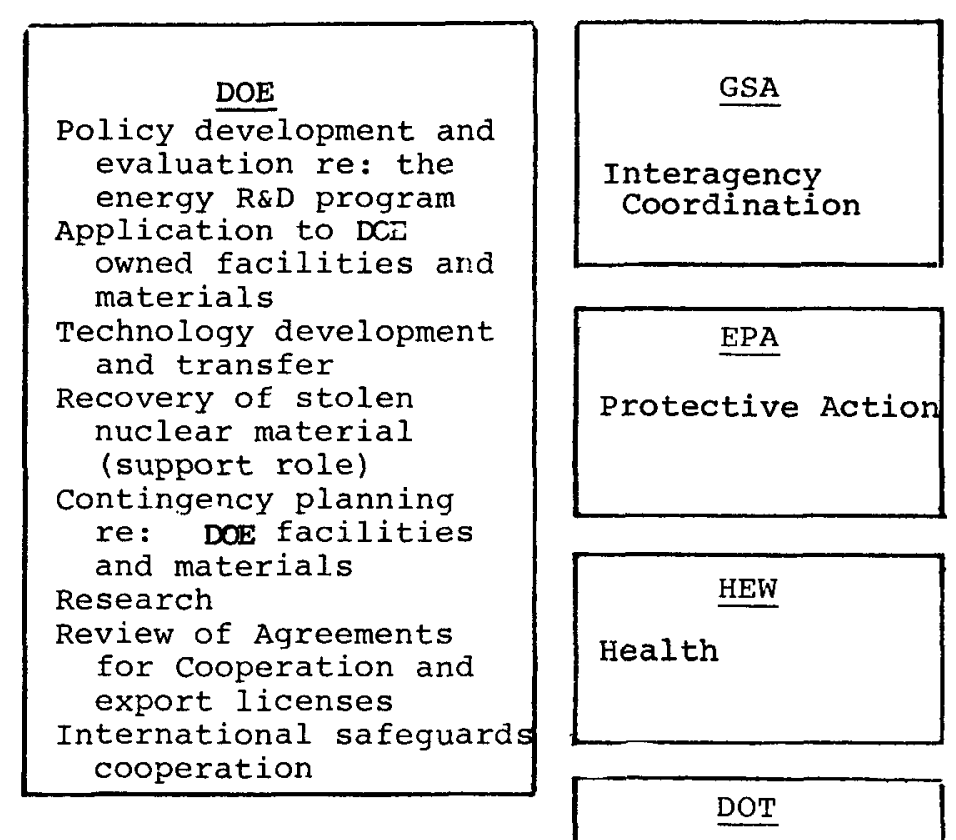

Transportation

\section{FBI}

Personnel clearances Recovery of stolen

nuclear material

(lead role)

\section{$\underline{\mathrm{CSC}}$}

Personnel clearances

FIGURE 4-2

Safeguards Responsibilities in the U.S. Government

\section{Disaster}

Preparedness 
instrumentation. ACDA provides technical support to IAEA for verification of plutonium quantities and minimizing measurement errors. ACDA is one of the agencies consulted by the Department of State in its consideration of proposed Agreements for Cooperation and export license applications.

The Department of Commerce issues licenses for export of nuclear and nuclear-related commodities and technology which are not issued by $\mathrm{NRC}$, such as certain nuclear reactor components. Commerce consults DOE regarding applications to export such items, and DOE proceeds to consult other agencies as appropriate. Commerce reviews applications for export licenses issued by NRC, and transmits its views to the Department of State for consideration in the formulation of an Executive Branch position on the applications. The National Bureau of Standards within Commerce performs safeguards research and provides services in the area of material accountability.

The National Security Council (NSC) is responsible for making recommendations to the President based on its consideration of matters related to the national security. In this role it performs certain safeguards-related functions regarding matters of an interagency nature. It receives, on behalf of the President, periodic reports on the status of domestic safeguards. NSC has provided the framework for interagency studies on particularly sensitive Agreements for cooperation. If the various federal agencies are unable to agree on an Executive Branch position on a proposed export license, the matter is referred to NSC. 
The Federal Bureau of Investigation (FBI), under the Department of Justice, and the Civil Service Commission (CSC) provide assistance in background investigations for personnel clearances granted by DOE and NRC. The FBI is responsible for investigating all incidents that involve suspected or actual violations of Federal laws, including the Atomic Energy Act. Thus, the FBI would have the primary jurisdiction and overall responsibility for direction of operations involving actual or suspected theft or unlawful possession of nuclear materials. The FBI would also play the primary role in the recovery of stolen nuclear materials.

The U.S. Congress is responsible for legislation in the nuclear safeguards area. Certain penalties included in criminal statutes passed by congress would apply should a domestic safeguards incident occur. The Atomic Energy Act of 1954, as amended, and the Atomic Weapons and Special Nuclear Materials Reward Act specifically address unlawful activities involving SNM. In the area of international safeguards, the Congress has held hearings (in the senate Government Operations Committee and the House Committee on Interior and Insular Affairs) on proposed changes in export regulations which could have an impact internationally regarding nuclear proliferation. Congress also reviews Agreements for Cooperation. An additional role of Congress is its impact on government agency safeguards activities through budget authorizations.

The General Accounting Office (GAO) is responsible to Congress, and examines and reports on how federal departments and agencies perform their responsibilities. It reviews and evaluates planning, implementation, and results of programs of other agencies, and develops information on the effectiveness and efficiency of these programs. Its recommendations

$$
4-20
$$


may lead to improved management practices and substantive changes in the programs it has studies. A recent focus of study resulted in a report entitled "An Assessment of U.S. and International Controls over the Peaceful Uses of Nuclear Energy," available from the General Accounting Office.

The General Services Administration (GSA) was created in 1949 and given a wide range of responsibilities. One of its divisions, the Federal Preparedness Agency (FPA), is charged with stimulating and coordinating planning at the federal, state, and local levels, for federal response to peacetime nuclear emergencies (which would include safeguards and safety incidents). The delineation of emergency responsibilities, publishea by FPA in December 1975, is as follows:

- The Nuclear Regulatory Commission (NRC) is the lead agency in radiological emergency response planning, training, and other assistance. It issues guidance to other federal agencies and to state and local governments in preparing the plans, reviews and concurs in these plans, determines the potential for a radiological incident at each licensed nuclear facility, and provides guidance for establishing effective systems of emergency radiation and detection measures.

- The Environmental Protection Agency (EPA) issues Protection Action Guides on projected radiation doses from incidents involving nuclear facilities or materials, recommends protective actions to lessen the consequences of an incident, and cooperates with NRC and other agencies in providing assistance in planning to state and local authorities and in developing detection and measurement guidelines.

- The Department of Energy (DOE) determines the potential for a radiological incident at non-licensed DOE nuclear facilities, provides assistance to state and local governments in their emergency planning in general and specifically. 
in regard to DOE facilities and materials, and also assists in developing effective systems of emergency radiation detection and measurement.

- The Department of Health, Education and Welfare (HEW) provides assistance to state health departments, hospital associations and other health services in their planning for radiological emergencies, issues guidance regarding possible contamination of food, and establishes guidelines for radiation detection and measurement systems for use by emergency health care personnel.

- The Department of Transportation (DOT) provides guidelines and assistance to state and local governments in their planning for transportation incidents.

- The Defense Civil Preparedness Agency (DCPA) of the Department of Defense issues guidance on the use of civil defense resources 'warning, communications, training, and radiological defense emergency response systems), and provides assistance to state and local governments in coordinating their emergency operations.

- The Federal Disaster Assistance Administration (FDAA) of the Department of Housing and Urban Development (HUD) provides guidance to state and local governments on disaster preparedness aspects of planning, and provides recommendations to NRC on their evaluation and review of the plans.

- The Federal Preparedness Agency (FPA) of GSA provides assistance in resolving interagency conflicts or federalstate problems in emergency planning, encourages states to produce emergency plans, aids both federal and state authorities in establishing priorities, and performs an overview function. 
5.0. APPLICATION OF THE DOE TECHNOLOGY PROGRAM TO INDUSTRY SAFEGUARDS PLANNING

5.1. The DOE Safeguards Technology Program

PROGRAM PRINCIPLES

The purpose of the DOE Safeguards Technology Program is to develop a comprehensive set of safeguards technologies for nuclear reactor plants and fuel cycle facilities, and to transfer the technologies to appropriate user organizations. The principles of this program include the following:

- The design methods developed by DOE should allow determination of cost-effectiveness by designers, owners and operators, and enable evaluation of performance by regulatory approval authorities.

- DOE should examine alternative nuclear process designs with respect to safeguards.

- DOE should develop equipment and procedure as needed, and not available commercially, to meet the requirements of the safeguards system design.

- The safeguards system designs and the associated equipment and procedure should be demonstrated by installation and performance at representative facilities.

- The DOE safeguards technology should be transferred to industry, governments, and appropriate international organizations by offering as major product types:

(1) design support for safeguards system design,

(2) engineered safeguards system designs for generic nuclear facilities, and

(3) equipment, procedures and associated specifications.

The above products are intended for use by nuclear facility designers, equipment suppliers, owners and operators, and nuclear safeguards regulatory authorities to support safeguards system planning, design, evaluation, manufacture, construction, testing, operations, and continuing performance verification. 


\section{SAFEGUARDS DESIGN PRINCIPLES}

DOF design methods are described in Section B.I. of the "Guide to Sources and Products." The design principles require that an effective safeguards system perform four basic functions:

- Detection of unauthorized activities and material balance discrepancies.

- Delay of unauthorized activities until appropriate response can be made.

- Response to unauthorized activities and discrepancies in an adequate and timely manner.

- Deterrence of potential adversary actions through public awareness of the general capability of safeguards.

The structure of a safeguards system contains three essential elements: physical protection, material control, and material accountability. From these elements are derived the engineered safeguards system design elements: personnel control, item operations control, and material measurement and accounting. The personnel control and item operations control elements are categorized under physical protection and are focused on special nuclear material (SNM) diversion and sabotage threats. The material measurement and accounting (MMA) element functions as an element of detection against short-term SNM diversion, and performs the inventory and accounting functions. The MMA also provides an independent assessment system against long-term diversion. The structure of the safeguards system design is described in more detail in section B.1. 
The physical protection element, through a combined use of detection, delay and response capabilities, functions by:

- exclusion of all unauthorized persons and contraband from the facility,

- exclusion of all but essential persons from sensitive areas within the facility,

- control of all significant activities to preclude unauthorized ones,

- prevention of unauthorized removal of special nuclear material.

The associated physical protection equipment is described in Section B-4, and is categorized as:

- integrated entry and exit-control, including contraband detection and personnel and credential identification,

- intrusion detection and assessment, and

- barriers

The material measurement and accounting (MMA) element provides an indication that nuclear materials are present and at their proper location within a facility. Material measurement equipment and procedure are described in section B-5 and include bulk and sample analytic chemistry techniques, weights, volumes, dimension, position, and the non-destructive assay techniques. Material measurement equipment provides: (1) "single-theft" material detection based on material balance calculations when made on a near-real time basis, and (2) "long-term" material diversion detection of amounts too small to be detected by a single material balance. The long-term material diversion detection is based on trends in successive 
material balances. Both single-theft and long-term material diversion detection are inputs to safeguards systems design.

Accounting systems are those which involve bookkeeping data on the location of SNM inventories and those procedures used to verify through measurements the physical inventory of special nuclear material as compared with the bookkeeping records. Accounting systems supply the final evidence that the safeguards system has provided protection against loss of material. They also provide data to facilitate tracking events and isolating the location of material loss problems, either real, hoax, or caused by facility equipment of procedure error.

In addition to safeguards functions, the MMA can make important contributions to process and product control, business accounting, and in areas such as criticality control.

\section{SAFEGUARDS DESIGN SEQUENCE}

The design sequence involves the rationalization of the threat analysis process by whirh minimum safeguards protection requirements are established. It requires identification of the weakest areas in the total safeguards system for a facility and the presentation of the relative cost-effectiveness of design alternatives to satisfy the minimum protection requirements. The design tools recognize the complementary use of physical protection and MMA elements, i.e., in a particular location, the capability of one design element may reduce the requirements upon the other. 
The design sequence follows a normal industrial approach and employs the DOE design tools. The design sequence includes the following tasks:

(1) Determination of the threat attributes to be used in comparing safeguards system options.

(2) Definition of an initial safeguards system concept.

(3) Generation of preliminary safeguards system designs.

(4) Generation of coordinated safeguards system options.

(5) Selection of an acceptable safeguards system option based on a comparison of performance against postulated threat and the associated incremental cost estimates.

(6) Production of a detailed facility layout, subsystem and component specifications, and response force requirements and procedures.

A brief description of the DOE safeguards design sequence is given here, and a more detailed description is presented in Section $B-1$.

- Determination of the Threat Attributes to be Used in Comparing System Options In order to make an informed selection among possible safeguards systems design options, it is necessary to determine the relative effectiveness of each option against a range of threats. By presenting effectiveness against a range of threats rather than a single threat, it is possible to show the sensitivity of design options to assumptions concerning threat attributes. The threat spectrum should be broad enough to allow the design analyses to present the incremental costs of various design options required to protect against incremental levels of threat.

- Definition of an Initial Safeguards system Concept This definition is in terms of a set of safeguards requirements specified for designated elements of a generalized facility layout. Requirements are given in the form of minimum detection probabilities and delay times.

- Generation of Preliminary Safeguards System Designs A set of preliminary safeguards system designs, based on the initial safeguards system concept, is developed, which presents alternative levels of protection. These designs are assessed against detection probabilities and delay times without considering guard response. 
- Generation of Coordinated Safeguards System Options The preliminary safeguards system designs were based on delay times related to assumed response force deployment times. Final design evaluations must be based on a more complete consideration of response force capabilities. This includes the measure of the probability of adversary sequence interruption. Interruption requires a confrontation between adversaries and response forces, since an unchallenged adversary can eventually penetrate any barrier or complete any path.

Guidelines for the selection of candidate options are based on the principles of: minimum operational impact, minimum reliance on guards, maximum isolation of personnel from. SNM and vital equipment, If centralized closed-loop control of significant activities, near-real time nuclear material accounting, and continuous verification of safeguards system performance.

- Selection of an Acceptable Safeguards System Option Based on a Comparison of Performance Against Postulated Threat and the Associated Incremental Cost Estimates Safeguards system performance measures (based on the basic detection, delay and response functions) are probability of detection of unauthorized activity, probability of detection of short-term and long-term diversion of material, remaining time to complete the adversary sequence, and probability of adversary interruption or defeat by the response forces after detection.

- Production of a Detailed Facility Layout, Subsystem and Component Specifications, and Response Force Procedures and Requirements Once a particular design option is selected, a detailed design phase would be undertaken. This would

I/ equipment, the failure, destruction, or release of which could directly or indirectly endanger the public health and safety by exposure to radiation. 
require an effort involving close cooperation among architectural engineering, safeguards engineering and facility operational personnel. The design output would include: detailed blueprints of the facility; safeguard system blueprints, component and subsystem specifications; computer software programs; procedures for activities such as management reporting and performance verification; and a comprehensive cost analysis.

\section{OPERATIONAL ROLES OF FACILITY SAFEGUARDS AND PROCESS OPERATIONS ORGANIZATIONS}

The DOE strategy presumes a facility safeguards organization unit separate from the facility process operations organization unit. In preparing its safeguards design approach, DOE consulted with industrial organizations having experience in nuclear fuel cycle facility design and operations in order to develop as a part of its design a proposed operational relationship between safeguards and process operations organizations within a facility.

The safeguards unit must provide approval and authorization for facility process operations to proceed, such approval and authorization passing to operations through facility management. The safeguards unit has no direct physical control of the process line. In those rare cases where the process line must be controlled to a secure position in response to a safeguards activity, the safeguards unit would request management to direct the process operations unit to initiate appropriate process line control measures.

The safeguards unit has specific direct physical control of certain non-process line facility operations. For example, 
the safeguards unit has control of area personnel access at all times, and the unit takes control of discrete item handling operations depending upon a hierarchy of responses evolving from discrepancy conditions and the level of a threat situation. An example of discrete item handling could be the operation of a material loading and stacking machine at the material receiving area. Assuming that the loading and stacking machine had an approved safeguards operational procedure, the safeguards unit could directly override safeguards operational discrepancies.

More serious safeguards conditions would require decisions by the safeguards unit in coordination with facility management. For the most serious threat conditions, on-site and off-site armed response would be activated.

SNM movement through the various locations of the facility is monitored by the material measurement and accounting (MMA) element. Inventory reports are issued to management and regulatory authorities as required. MMA outputs can be used by the process operations organization in process line operation and product quality control. MMA outputs are also used in facility waste management and business accounting.

\section{SAFEGUARDS PRODUCTS}

A description of DOE safeguards products, available or planned for industry use, is given in section B of the "Guide to Sources and Products." An outline of the product types follows here: 
- Design Tools

DOE Is developing and/or adapting NRC techniques for estimating the relative effectiveness of alternate safeguards designs (e.g., What is the change in effectiveness obtained by adding T.V. monitors to the storage access area?) These are being developed for both physical protection and material measurement and accounting systems. The techniques employ a range of modeling concepts and vary considerably in their complexity. Some can be performed manually; however, most require extensive computer programs. The current state of the art does not include a single comprehensive algorithm to be used for all systems against all threats. System design planning, therefore, requires a judicious selection of a mix of the models.

- Engineered Safeguards System Designs

DOE is in the process of developing Engineered Safeguards System (ESS) Designs for most of the generic nuclear facilities. The ESS Design is developed by introducing safeguards equipment and procedure into a baseline facility concept or design using the DOE safeguards system design sequence and design tools. A description of the baseline facility includes plant layout, process line operations and throughput, material locations, and personnel and material movements. The ESS Design is not intended to be site specific nor specific to a particular response capability (e.g., state police), but relates to the process concept or design of the baseline facility. The representative design of an LWR Mixed-oxide Fuel Fabrication Facility safeguards system is underway using the Westinghouse Electric Corporation proposed concept for an Anderson County, South Carolina facility as the baseline. Other design activities include a spent Fuel Reprocessing Facility including a spent Fuel storage Facility, Plutonium Product Conversion Facility, and a Waste Solidification Facility; a Plutonium storage Facility; and a liquid Metal Fast Breeder Reactor Facility.

The value of the representative safeguards system design to DOE is that it provides a reference, by type facility to be protected, for establishing specifications for prospective DOE-developed or commercially developed equipment and procedures, and for evaluation of the specifications of existing equipment and procedures. In addition, the 
representative design activities provide an exercise of the system design sequence and design

tools for various types of facilities.

- Equipment, Procedures, and Associated Specifications The DOE program operates to make best use of existing commercial physical protection equipment. Commercially developed equipment and systems are evaluated under controlled laboratory environments and in various field locations where the range of physical conditions and environments is typical of safeguards operational use. The cost and effectiveness of the equipment and procedure are identified in the ESS Design activity. Reports for industry are available or planned on physical protection equipment and procedure covering selection, procurement, installation, test, maintenance and evaluation. The "procedure" type of product treats the coordination of the physical protection and material measurement and accounting equipment in the operation of a safeguards system.

There is a commercial market, supply and use of material measurement equipment in areas such as weight, volume, dimension, position and analytic chemistry techniques. However, the possibility of near-real time material measurements in safeguards has required the development of non-destructive assay equipment and systems which have not been previously offered by commercial suppliers. In this area, DOE is a principal developer. Reports for industry are available and planned covering the specifications and intended use of this equipment.

\subsection{Application of DOE Safeguards Products to Industry Fac- ility planning}

\section{INDUSTRY ACTIVITIES IN PLANNING \\ A FACILITY SAFEGUARDS PROGRAM}

The U.S. nuclear industry has a history of strong management involvement in meeting major program objectives, such as sound and effective health and environmental safety and quality assurance programs, in support of nuclear power 
generating station design, construction and operations. A similar effort is required in the nuclear safeguards program for nuclear fuel cycle facilities, including nuclear generating stations. U.S. companies must now consider nuclear safeguards for relevant facility projects which are: in operation, (2) in construction, and (3) in the planning and design stage.

The principal guidance for safeguards planning comes from the Nuclear Regulatory Commission (NRC) safeguards regulatory criteria; however, industry is aware that such criteria are evolving and that prospective regulatory trends must be considered. As the safeguards regulatory criteria continue to develop and facility safeguards experience expands, companies will address a number of planning questions, including:

- Is it reasonable to proceed with a project considering the status of safeguards regulations?

- How much additional cost should be allowed for a project to provide for future safeguards regulations?

- What would be the effects on civil rights of such activities as employee background investigations, clearances or employee work surveillance?

- What is the relationship between the safeguards and process operations organizations during a safeguards alert?

- What is the possible corporate response to theft or diversion of SNM? Does it include armed intervention; does it involve public police forces; and what is the potential impact upon the community?

During safeguards design, a facility owner/operator would benefit from a presentation of design options compared with

$$
5-11
$$


regulatory criteria, giving cost increments and levels of safeguards protection. This presentation may indicate areas in which small increments of additional cost could provide significant protection above the minimum regulatory requirements, thereby providing some cushion against future regulatory changes. Ancillary contributions of the safeguards design should be considered, in such areas as process and product control, business accounting, and criticality control.

\section{INDUSTRIAL PROGRAM SUPPORT}

The application of DOE safeguards products to industry programs is represented in Figure 5.1, a flow chart representation of a "typical" industry program for facility safeguards planning. The main industry activities--Safeguards Planning, Facility Preliminary and Detailed Design, Procurement, Installation, Test and Evaluation, and Operations--are presented in the mid-section of Figure 5.1. The DOE products--design tools, engineered safeguards system designs, and equipment and procedures--access the industry process from the lower section of the Figure. The Nuclear Regulatory Commission safeguards regulatory criteria and licensing functions enter from the upper section.

NRC and DOE have separate mandates and research programs covering safeguards threat analysis and effectiveness evaluation methodology. There is technical exchange between the two programs to the extent that there exists a coordinated 
$G$
1
$\omega$

DOE SAFEGUARDS TECHIOLOGY PROGRAM IN SUPPORT OF INDUSTRY FACILITY SAFEGUARDS PLANNING AND IMPLEMENTATION

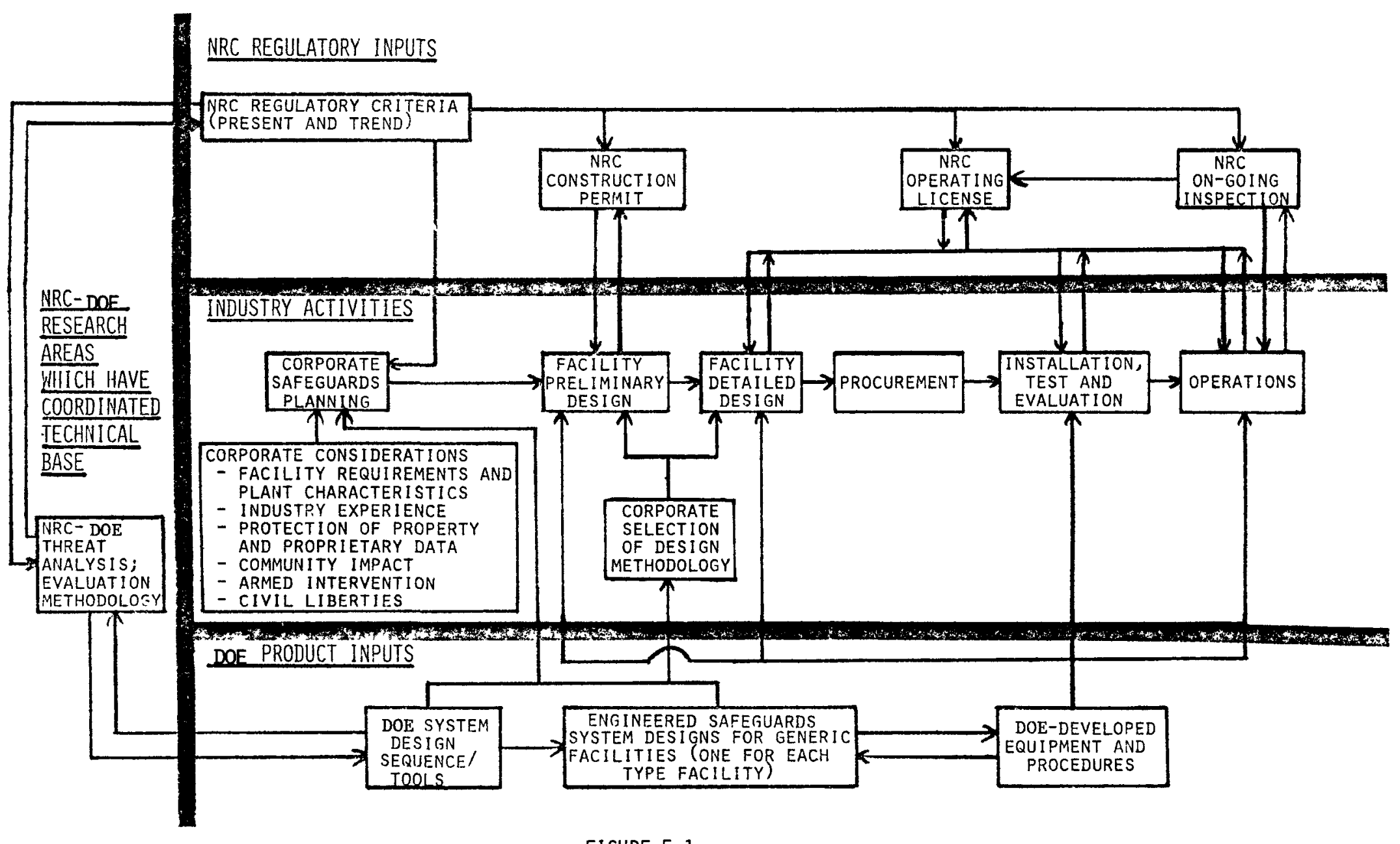

FIGURE 5.1 
technical base. DOE data and analysis are inputs to NRC research. The NRC safeguards research program is coordinated with the NRC regulatory staff to assure that it is consistent with policy and will result in useful products. NRC research results developed in effectiveness evaluation modeling are inputs to DOE's technical program. While the NRC research emphasis is upon evaluation of licensee safeguards to assure chat NRC requirements are met, the DOE research emphasis is upon facility design and associated equipment development. The importance of the NRC and DOE research program having a coordinated technical base is twofold:

(1) The DOE safeguards technology products are given an opportunity to assist in shaping the NRC safeguards program.

(2) The NRC regulatory criteria have a mechanism for entering the DOE research program.

This relationship does not inhibit the flexibility of the DOE program in developing safeguards products, but it does provide inputs to DOE research regarding the realism of regulatory criteria, present and trend.

DOE recognizes the importance of safeguards regulatory criteria and approval to the acceptance of a viable commercial project. NRC assessments to date have led it to believe that performance-oriented safeguards regulations could be superior to the systems oriented regulations which are now in force. Accordingly, NRC is considering changes in the present safeguards regulatory framework for fuel cycle facilities and other nuclear material activities. The major change would be utilization of performance requirements to help 
identify what safeguards systems should accomplish as opposed to mandating systems technical specifications. Performance requirements would bound the level of protection required for given amounts and kinds of nuclear material and for potential threat levels. The NRC believes the advantages of a performance requirement regulatory framework are:

- Objectives and performance criteria focus on what the safeguards systems should accomplish, rather that the technical details of how.

- The safeguards system designer is permitted greater flexibility to tailor his choice of systems and equipment to accommodate site-specific factors.

- The safeguards system implementer and user is permitted flexibility in utilizing the new technology to satisfy regulatory requirements.

- A rational regulatory base will be established which can be shown to be all-encompassing, effective, and consistent.

The position contemplated by the NRC to allow flexibility in developing options in safeguards designs is compatible with the DOE design sequence, as outlined in section 5.1 .

The application of DOE technology by industry starts at the planning stage. During facility safeguards planning, a company would gain a "first-order" reference of the range of cost and responsibilities involved through examination of the appropriate DOE Engineered Safeguards System Design. The ESS Design provides a rough assessment to a company considering a particular safeguards project of the range of capital and operating costs involved in using the DOE design sequence and appropriate equipment and procedure. It provides an indication of the possible operational mode between plant process operations and plant safeguards organizations. It provides an insight into the possible corporate actions 
required in the protection of the facility and proprietary data. It characterizes the possible response force activities required of the facility organization and the public police force, including possible impacts upon the surrounding community. At the planning stage, the company would be comparing the DOE representative safeguards system design with the NRC regulatory criteria (present and trend), and also with the experience of other industry and government facility safeguards projects.

All three DOE product categories are available as inputs to a company's preliminary and detailed design activities. If the company elects to use the DOE system design tools, using the Engineered Safeguards System Design as a guide, equipment and procedure specifications would be introduced through that mechanism. If the company elects to use a different design approach, the specifications of the DOE products and procedures are available for use in the approach developed or selected by the company. In making its decision on design approach, the company would consider at least three important elements: the NRC regulatory criteria (present and trend) including the NRC construction Permit, Operating License and ongoing inspection during operations; the experience of other facility safeguards projects; and the experience of DOE demonstration projects and products as well as the prospective products of the DOE safeguards technology program. 
As indicated in Section 5.1, the DOE design method allows the company a cost/performance examination of alternative safeguard system designs against a range of threat levels. The company may elect to design to minimum acceptable regulatory levels. Equally important to the company is the ability to assess the reserve safeguards capability of various design parameters on a cost increment basis. The company may find significant reserve safeguards capability at low incremental cost and may elect to build in this reserve capacity so as to be less sensitive to changes in regulations.

DOE recognizes that industry safeguards system procurement, installation, test and evaluation, and operations activities require careful execution and coordination, and that DOE products must, therefore, be responsive to industry requirements, including the following:

- Equipment procurement specifications must be appropriate for the equipment's role as dictated by the system design.

- Equipment performance to specifications must be demonstrated in a prototype or operational environment.

- Equipment installation and test procedures should evolve from prototype or operational experience.

- Ongoing safeguards system operations should be consistent and capable of periodic verification against design criteria.

\section{TECHNOLOGY TRANSFER}

The form and availability of DOE safeguards technology transfer products reflect the dynamics of the safeguards 
problem. DOE has developed SNM measurement instruments and installed the equipment in government and industry facilities. DOE has a background in physical security associated with the nuclear weapons program and DOE nuclear facilities. However, increasing concern regarding nuclear safeguards in recent years has caused DOE to increase its level of research in threat analysis, system design, and equipment and procedure development. The productivity of this recent program acceleration is being planned for demonstration in DOE facilities and selected industry facilities and design projects. The safeguards technology will be transferred to industry through DOE handbooks, technical reports, consensus standards, journal papers, briefings, and training programs. The technology transfer areas include:

- design methods and models,

- equipment specifications to support design, costing, procurement, testing and performance analysis,

- procedure for installation, testing and evaluation of systems and equipment, and

- standarized operating procedure, including inspection, operations, quality control and verification of ongoing systems operation against design criteria.

Most of the material is being developed by DOE support laboratories. Sandia Laboratories, Los Alamos Scientific Laboratory and Brookhaven National Laboratory are supporting DOE in the development and demons:ration of methods for designing integrated safeguards systems involving physical protection and material measurement and accounting elements. 
Physical protection product development is supported principally by Sandia Laboratories and Brookhaven National Laboratory. Material measurement and accounting product development is supported by Los Alamos Scientific Laboratory, Brookhaven National Laboratory, Lawrence Livermore Laboratory, the National Bureau of Standards (through its Department of Commerce budget), Idaho Chemical Processing Plant, Mound Laboratory, Pacific Northwest Laboratory, and the New Brunswick Laboratory. As products become available, DOE will direct the technology transfer activities of these support laboratories.

An important element in DOE safeguards technology transfer is the feedback from industry facility safeguards design activities. This information flow to DOE provides industry evaluation and corrective action signals to DOE for its products as they are applied to commercial, licensed facilities. The feedback applies to the performance of design tools, designs and specified equipment and procedure. In addition to being the proving ground for the DOE product line, industry should provide new concepts for DOE consideration.

5.3 Examples of DOE Safeguards Technology Transfer Activities

Technology transfer activities have been directed toward:

(1) Use of industry facility projects as design reference DOE design efforts use industry projects where possible as a reference for process design, plant operations and management. 
Best use of available commercial equipment and systems -

Commercially developed safeguards equipment and systems are evaluated to provide for their maximum use in safeguards systems.

(3) Providing equipment information to suppliers and users -

$\overline{\mathrm{DOE}}$ equipment design information and performance specifications are provided to potential commercial suppliers and facility owners, operators and designers.

(4) Operations support -

DOE provides operations support to industry and government projects in safeguards equipment installation, test, evaluation and operations.

(5) International cooperation -

DOE provides safeguards technology to the International Atomic Energy Agency's safeguards system through the International Safeguards Project Office at Brookhaven. This is a coordinated support program involving also the NRC, Department of state, and ACDA.

Examples of these activities and prospective opportunities for technology transfer are:

(1) Use of industry facility projects as design reference. - DOE representative safeguards design using Westinghouse Electric Corporation facility design of an LWR Mixed-Oxide Fuel Fabrication Facility (Anderson Plant) as design reference.

Sandia Laboratories and LASL have let contracts with Westinghouse to use the Anderson Plant design as a baseline for the conceptual design of an integrated safeguards system employing the DOE design methodology. Westinghouse experience in nuclear facility management, design, engineering, process operations and safeguards operations has been incorporated into the design activity.

- Design studies of the Allied-General Nuclear Services Spent Fuel Reprocessing Plant (AGNS).

Sandia Laboratories and LASL contracted with AGNS to use the AGNS facility as a baseline for design studies. Areas of application included material measurement and accounting elements associated with the separations Facility, and the conceptual design of operational control modules connected with the Plutonium Nitrate storage and Load-out facility. 
- General Electric Company evaluation of the DOE representative safeguards system design of an LWR Mixed-Oxide Fuel Fabrication Facility. General Electric Company, Nuclear Energy Division, under contract to Sandia Laboratories, evaluated the economic impact and operational feasibility of the DOE safeguards design on prospective operation of such a facility. The analysis included data requirements for OSHA and NRC reporting; evaluation of operation control modules and safeguards information systems; definition of alternative processes to provide additional planning flexibility, such as wet front end and liquid scrap recycle; and recommendations for further development and demonstration of the DOE concepts to insure technical validity and operational feasibility.

- Safeguards support to the Clinch River Breeder Reactor Project (CRBRP). Sandia Laboratories has supported the Project Management Corporation and the Tennessee Valley Authority safeguards activities of the CRBRP, including those to meet NRC regulations for safeguards licensing. Sandia has evaluated the safeguards system and suggested possible improvements, employing the DOE design sequence as outlined in section 5.1 .

(2) Best use of available commercial equipment and systems. As indicated in section 5.1, the employment of available commercial equipment and systems is particularly relevant to the physical protection area, in which there is a large commercial business in the U.S. today.

(3) Providing equipment information to suppliers and users. LASL has developed nondestructive assay instrumentation and provided information to industry to support technology transfer. Examples include the following:

- The Segmented Gamma Scanner (SGS) was designed to assay low density $235 \mathrm{U}$ or $239^{\mathrm{Pu}}$ waste products in 55 gallon drums. Segmented Gamma Scanner systems are available from Canberra Industries, Inc. and Eberline Instrument Corporation. 
- Fuel rod scanners measure both total fissile content (235u and $239 \mathrm{Pu}$ ) and the pellet-to-pellet fissile loading uniformity in PWR, BWR, and $\mathrm{Pu}$ recycle fuel rods. Fuel rod scanners are available from National Nuclear Corporation and Intelcom Radiation Technology, Inc.

- The Neutron Wel1 Coincidence Counter is used to assay $\mathrm{Pu}$ bulk fuel and scrap. The instrument is available from National Nuclear Corporation.

- Other LASL developed equipment which is available commercially include "random driver" units used to measure high density bulk fuel and scrap, $235 \mathrm{U}$ portable enrichment monitors, the "elephant gun" used to measure waste generated in LWR fuel fabrication facilities, and the portable shielded neutron assay probes used to measure $240 \mathrm{Pu}$ in plutonium oxide and metal configurations.

(4) Operations support

- Physical protection system performance verification (possible transfer capability).

Brookhaven National Laboratory (BNL) has developed a "Physical Protection Simulation Model" which is capable of transfer to industry for use in quick assessments of facility physical protection. DOE has used the system in conducting physical security evaluations of DOE nuclear facilities. The model employs a real-time computer program, and a facility physical protection assessment is developed during the program run.

Analytical chemistry quality control program longoing transfer program).

The Safeguards Analytical Laboratory Evaluation program (SALE), conducted by the New Brunswick Laboratory (NBL), has as its objective to improve the quality of analytical chemistry measurements of samples containing transuranium elements. The program is national and international in scope and includes both government and private organizations. NBL produces, measures, and distributes unmarked samples for measurement and evaluation by participating chemical assay laboratories. Through a post-analysis coding and reporting system, each participating laboratory knows the accuracy of its analysis against the NBL standard and can compare its results against the other unidentified participants. 
- Inspection and verification of material measurement and accounting systems (possible transfer capability). Pacific Northwest Laboratory is developing technical guides for inspectors to use in evaluation and substantiating operation of facility material measurement and accounting systems. At present, this activity is intended for use in DOE facilities. As the concepts are demonstrated and proven by DOE inspectors at DOE contractor nuclear facilities, DOE will evaluate the applicability of transfering this technology to industry for its use in ongoing verification of safeguards system operation.

Field support in material measurement and accounting equipment, procedure and systems.

A representative listing of field support activities in material measurement and accounting follows :

(a) Allied-General Nuclear Services (AGNS) plutonium measurement support Lawrence Livermore Laboratory (LIL) has developed a computer-based gamma spectrometer system which is being used for experiments to evaluate measurement of plutonium in $\mathrm{PuNO}_{3}$ handling and storage areas.

(b) Lawrence Livermore Laboratory (LLL) is developing an automated system for measuring uranium in solution. Specifications will be made available to industry.

(c) National Bureau of Standards (NBS) material measurement standards program. DOE coordinates with NBS in the conduct of the NBS nuclear material measurement program, which provides standards, standards data, reference measurement techniques, and technical assistance to industry.

(d) Pacific Northwest Laboratory (PNL) defined the role of statistics in safeguards. PNL identified the use of specific statistics in connection with inventory differences.

(e) Los Alamos Scientific Laboratory (LASL) field support activities

- Measurements and verification of plutonium holdup at Kerr McGee fuel fabrication facility.

- Random Driver was installed at Savannah River Plant in an evaluation of scrap and waste from the fabrication of $\mathrm{U}-\mathrm{Al}$ fuel. 
- Segmented Gamma Scanner was installed and evaluated at Atlantic Richfield Hanford Company and Nuclear Fuel Services, Inc.

- Segmented Gamma Scanner and Random Driver were installed and evaluated at General Atomic Company in connection with High Temperature Gas Reactor materials measurements.

- LASL tested fuel rods fabricated for SEFOR fast reactor using NDA methods and determined $\mathrm{Pu}$ variances.

- LASL demonstrated several first generation instruments, including neutron coincidence counters, a portable "hold-up" measurement device, and a segmented gamma scanner, in a mobile non-destructive assay laboratory (MONAL) . MONAL was demonstrated at Goodyear Atomic Corporation, Union Carbide Corporation, National Lead Company of Ohio, LASL Pu recovery facility, Rocky Flats Pu facility, NUMEC and General Electric Vallicitos. The demonstrations responded to interests in safeguards, process control and criticality control.

- A fuel rod scanner using Cf252 was developed to measure pellet-to-pellet uniformity during fuel fabrication, at a rate not to impede production. A commercial version operates at the General Electric Wilmington fuel fabrication facility. A LASL prototype was installed at the Hanford Engineering Development Laboratory (HEDL) to measure 20 percent $\mathrm{Pu}$ in fuel.

- The "elephant gun" was evaluated and installed for waste measurement at the General Electric wilmington facility.

- LASL prepares plutonium-containing materials for the Safeguards Analytical Laboratory Evaluation program.

- LASI prepared high-purity plutonium materials for issue by NBS or NBI as "reference and calibration test materials." 


\section{GUIDE TO SOURCES AND PRODUCTS}

Information provided in this guide is a description of the source or product as of the time of writing. Developments after April 30, 1977, have not been included. 
GUIDE TO SOURCES AND PRODUCTS

(information through April 30, 1977)

A. Guide to sources

A. 1 Sandia Laboratories....................... A-1

A. 2 Los Alamos Scientific Laboratory................ A-10

A. 3 Brookhaven National Laboratory................. A-25

A. 4 Lawrence Livermore Laboratory................. A-34

A. 5 National Bureau of Standards.................A-38

A. 6 Pacific Northwest Laboratory................... A-43

A. 7 New Brunswick Laboratory..................... A-49

A. 8 Idaho Chemical Processing Plant................ A-55

A. 9 Mound Laboratory.........................A-62

B. Guide to Products

B.1 Safeguards System Design Methodology.............. B-3

B.1.1 Threat Considerations................. B-9

B.1.2 Physical Protection System Design and

Evaluation........................... B-1

B.1.3 Materials Measurement and Accounting

System Design and Evaluation............ B-32

B. 2 Design Support........................... B-46

B.2.1 Evaluation Techniques and Models.......... B-46

B.2.2 Physical Protection Equipment Evaluation.... B-54

B. 3 Representative System and Subsystem Designs........ B-59

B. 4 Physical Protection Equipment Development......... B-63

B. 5 Mațerial Measurement and Accounting (MMA)......... B-68

B. $5.1 \quad \mathrm{NDA}$ Instrumentation...................... 69

B.5.2 Other Physical Techniques for Bulk and

Sample Measurement................... B-94 
B.5.3 Analytical Chemistry Techniques for Bulk

and Sample Measurement...................... B

B.5.4 storage Vaults and seals.................105

B. 6 Inter-Facility Transportation................. B-109

B. 7 Inspection, Assessment and Verification........... B-110 
The function of this guide is to provide information concerning resources available in the DOE program that are or could be of assistance in the industry safeguards planning process. The guide is presented in two sections.

- Guide to Sources (A.) The laboratories participating in the DOE safeguards program are described briefly. Areas of expertise are identified through descriptions of the safeguards projects at the various sites. When a laboratory has developed through work on other programs a capability which can have major relevance to solving safeguards problems (e.g., sandia's work on sensor detection and interpretation systems for the Air Force (see Section A.1.2.), such capabilities are also presented.

- Guide to Products (B.) The major end products of the various DOE safeguards projects (both current and prospective) are presented in summary form. When the product represents a methodology or design concept, the description is of sufficient detail to trace the essential ideas. Where products can be defined in very specific terms (e.g., a computer model, a measurement technique, an NDA instrument) the information is presented in the form of a summary data sheet. Introductory summary tables have been developed to denote the elements of the nuclear fuel cycle for which the products are most applicable.

The intent of this guide is to provide safeguards planners with enough information to make preliminary judgments between basic alternative safeguards approaches, to make some estimate of the feasibility of the chosen approach, and to provide quick access to the detailed technical information needed to complete the next step in the planning process.

Contact persons for organizations supporting the DOE/SS program are as follows: 
Mr. William C. Myre

Director, Nuclear Security Systems

Organization 1700

Sandia Laboratories

Kirtland Air Force Base-East

Albuquerque, NM 87115

505-264-4531

Dr. G. Robert Keepin

Nuclear Safeguards Program Director

Los Alamos Scientific Laboratory P. O. Box 1663

Los Alamos, NM

87544

505-667-4042

Dr. William A. Higinbotham

Senior Technical Support officer

Technical Support Organization

Brookhaven National Laboratory Upton, NY 11973

516-345-2908

Dr. John A. Miskel L-231

Radiochemistry Division

Lawrence Livermore Laboratory

University of California

P. O. Box 808

Livermore, CA 94550

415-457-8711

Dr. H. Thomas Yolken

Program Manager, Measurement

for Nuclear Materials

Safeguards

National Bureau of Standards

U.S. Dept. of Commerce

Washington, DC 20234

202-921-3747

Dr. Robert J. Sorenson

Nuclear Safeguards Systems

Pacific Northwest Laboratories

P. O. BOX 999

Richland, WA

99352

509-946-2372
Dr. Carleton D. Bingham

Director

New Brunswick Laboratory $\overline{\mathrm{D}-350}$

9800 South Cass Avenue

Argonne, Illinois 60439

312-739-5701

Dr. Glenn L. Booman

Supervisor, Measurement Systems section

Allied Chemical corporation CPP 637

550 Second street

Idaho Falls, ID 83401

208-526-0111 ×3322

Dr. Walter W. Strohm

Project Leader, Safeguards

Mound Laboratory

Monsanto Research Corp.

P. O. Box 32

Miamisburg, $\mathrm{OH}$

45342 


\section{A. 1 Sandia Laboratories}

Sandia Laboratories, a multiprogram national laboratory of the United States Department of Energy is located in Albuquerque, New Mexico, and Livermore, California. The laboratory is operated on a no-profit, no-fee basis by Western Electric. The principal task is to design and develop nuclear ordnance in conjunction with other national laboratories. Sandia also conducts energy-related research and development programs in the national interest.

\section{A.1.I Laboratory Description}

As an outgrowth of Sandia's extensive involvement in nuclear weapon systems, it has developed technical and management capabilities in systems engineering, system analysis andevaluation, component development, materials development and processing, instrumentation and testing, and quality assurance. Currently, sandia is conducting major programs in the following areas:

- Nuclear Ordnance

- Nuclear Reactor Safety

- Nuclear Materials Safety and Security

- Nuclear Waste Management

- Extraction of Energy from Coal and Magma

- Solar and Wind Energy Systems

- Combustion Research

- Electron Beam Fusion Research

- Atmospheric Research

- Laser Research 
Although DOE sponsors the majority of Sandia's projects, work is also done for other federal agencies. One example is the development of instrumentation for monitoring fissionable materials for the Arms Control and Disarmament Agency. Other sponsoring organizations include the Department of Defense, the Department of Transportation, the National Aeronautics and Space Administration, the National Science Foundation, the National Institute of Health, and the Nuclear Regulatory Commission. An important group of projects was initiated for the Defense Special Project Group in 1967 (intrusion sensors, information collection and display system), and in 1972 for the Air Force under the Base Installation security system Program (sensors, data links, and displays).

The average number of laboratory employees in FY 1976 was 6880 . of the 6880 employees, 1800 were technical staff members with degrees equally divided among Ph.D's, masters, and bachelors. The current and projected level of energy-related activities involves about 25 percent of the Làoratories' staff.*

\section{A.1.2. Sandia Safeguards Program Overview}

While the Atomic Energy Act of 1954 required arrangements for the security of nuclear material, the threat was then interpreted largely in terms of military and paramilitary action. Safety and physical custody of early nuclear weapons were quite simply handled because there were few weapons, they were kept on U.S. soil in

*The technical capabilities of sandia have been described in detail in a report "Technical Capabilities of Sandia Laboratories" (SAND74-0091) which is available from the Technical Information Center, DOE, Oak Ridge, Tennessee 
well-guarded areas, and nuclear materials were stored apart from the weapons themselves. However, as the world strategic balance changed, it became necessary to disperse weapons and eventually to put some of them in an alert posture. These changes in deployment required that additional safety features be incorporated in weapons. In late 1960, the Joint Committee on Atomic Energy, chaired by Congressman Holifield, toured the U.S. nuclear weapons storage locations in Europe and expressed concern about the provisions for custody and security. Three DOD committees (the Stern Committee, Defense Atomic Support Agency/Special Weapons Arming Council Committee, and Partridge Committee) studied nuclear weapon security and control procedures, communications, and the possibility of applying an additional mechanistic control system, which Sandia had developed, called permissive action link (PAL) to Europe-based weapons. More Joint Committee hearings were conducted and the federal government's concern culminated in National Security Action Memorandum 160. This Presidential directive in June, 1962, called for the installation of PAI systems in all nuclear weapons dispersed in NATO commands. Since that time Sandia has continued to develop and improve these command and control systems.

In the 1967-69 time frame a higher level of awareness on the part of Congress and the AEC of the threat from terrorists emerged. Consequently, in addition to providing increased security for nuclear weapons, Sandia became involved in developing 
safeguards for the transport of nuclear weapons, and for the protection of special nuclear material at government and commercial facilities. Briefly, the sequence of events which culminated in the current Sandia tasks include:

- 1969. The AEC-DOD Nuclear Safeguards Committee and the AEC established the requirements that the transport of weapons and of SNM be secure from terrorists.

- 1970. Sandia was requested by the Division of Military Applications (DMA) of the AEC to investigate the use of technology to reduce the reliance on people in the security of weapons transport.

- 1971. Sandia initiated the development of a truck/ trailer system to deter attempts to divert SNM in transit.

- 1973. The first Safe-Secure Trailer (SST) was delivered to DMA for shipment of weapons and weapons materials.

- 1973-74. DOD requested assistance of Sandia in the design of hardened entrances to weapon storage Igloos ( the emphasis was on hardening against overt attack).

- 1974. AEC-Division of Nuclear Materials Safeguards tasked Sandia to initiate the Fixed Facilities Protection Program in addition to continued support of the protection program for transportation of weapons and SNM that is funded by MA.

Sandia's current safeguards program for DOE/SS is described below. Sandia also is supporting the NRC in the development of evaluation methodology for assessing the adequacy of licensee safeguards plans and design for fuel cycle facilities and transportation systems. In addition, the vulnerability of the current commercial power reactors, shipping containers and transportation systems to accident situations and sabotage is being assessed. 
Sandia is also participating in a concurrent MA/SS program to assess the vulnerability of DOE facilities to sabotage or theft of SNM. Sandia is developing safeguards options which can be implemented to eliminate any identified vulnerabilities.

\section{A.1.3 Sandia's Safeguards Program for DOE/SS}

\section{A.1.3.1 Mission}

The objective of Sandia's Fixed Facilities physical Protection Program is to define, develop, evaluate, and demonstrate advanced systems for safeguarding nuclear materials at representative government and industrial facilities. Integrated systems to protect against theft, loss, and sabotage are structured around a three-element strategy: (1) detection (including assessment), (2) delay, and (3) response. Applications include special nuclear material facilities, weapon facilities, and fuel cycle facilities. These integrated safeguards systems must be effective against threats ranging from forcible attack by well-organized terrorist groups to internal diversion by stealth or collusion, and combinations thereof. A concommitant objective is to transfer to industry the safeguards technology which is developed.

\section{A.1.3.2 Summary of Projects for DoE/SS}

This section describes the major projects being conducted by Sandia Laboratories that are applicable to the LWR and LMFBR fuel cycles. The anticipated benefits to industry which result from Sandia's safeguards program are summarized in section $B$. From the standpoint of candidate technology for transfer to 
potential users, the activities can be grouped into four basic areas :

\section{(1) Threat Analysis.}

The major question this activity addresses is "What are the attributes and range of the threat?" This involves analysis of historical, sociological, psychological, and current intelligence data. The users of products of this activity are threefold:

1. NRC - to assist in establishing industrial regulations.

2. Design evaluation analysts - as criteria for determining system effectiveness.

3. DOE and industrial safeguards organizations - to update existing protection systems, based on current threat assessments. *

\section{(2) Design Methodology.}

The principal objective of this activity is to develop and improve methods and techniques for designing and evaluating safeguards systems. Currently the major use of these methods is in the development and evaluation of both conceptual engineered safeguards systems and subsystems for fuel cycle facilities and associated transport interfaces.

This design methodology will be used to develop representative engineered safeguards systems for fuel cycle facilities and will be made available to industrial facility designers. The current structure of the design methodolggy is presented in detail in B.I.

\footnotetext{
*It has been emphasized that probable threat levels and therefore appropriate levels of alertness are highly dependent upon changing world events.
}

$$
\text { A-6 }
$$


(3) Equipment Evaluation, Application, and Development.

This activity identifies equipment applicable to existing, programmed, and proposed facilities. The types of equipment include:

- Intrusion Detection and Assessment

- Entry Control

- Barriers

A new facet of this task is the development of a security seals system and a security locks system.

An important operating principle of this activity is the desirability of using existing or modified commercial equipment. New development projects are initiated only after determining that existing equipment cannot meet system requirements. For this reason a significant portion of the Sandia program is dedicated to the evalution of current technology. This activity will provide information to industry.

(4) Development of Representative Engineered Safeguards Systems for Fuel Cycle Facilities

This activity represents the application of the Sandia design methodology to safeguarding fuel cycle facilities. For existing facilities Sandia can be of assistance to the facility staff in the selection, installation, test, and evaluation of system components. In the case of programmed and proposed facilities the task is to develop and evaluate a representative engineered safeguards system for each type of fuel cycle facility. 
The relationship and interaction between these program activities is important to understand. The final product evolves clearly from the fourth activity (development of representative safeguards system designs); however, this is reached through an interactive process which involves cycling through each of the four activities. It should be emphasized that each phase produces products which may have independent value.

There are also interfaces with the NRC, the IAEA, and selected foreign countries. Bilateral discussions, sponsored by SS and International Security Affairs of DOE are conducted on a continuing basis with foreign countries to exchange information concerning the results of physical protection and safeguards. Sandia also provides technical assistance to the IAEA in the form of concept and equipment development. Finally, Sandia develops information which may be of value to the NRC in their development of regulations. The interaction of the elements of the Sandia program are represented diagrammatically in Figure A.1. 
Figure $A-1$. Information and Product Flows Within the Sandia Program

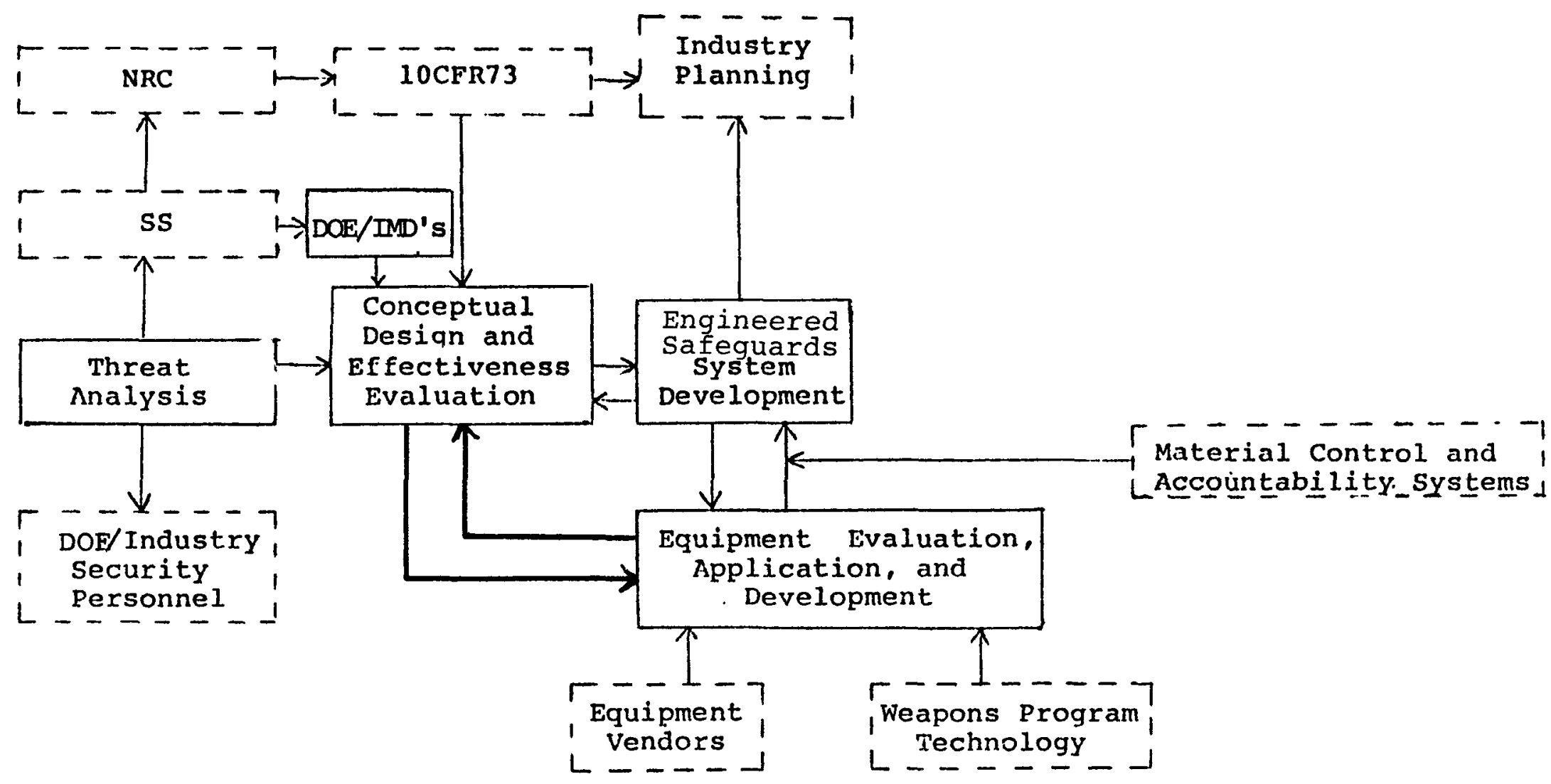

Key: Broken line represents external elements. Two-way arrows represent iterative loops.

Note: Links from individual program elements to industry planning are not shown. 


\section{A. 2 Los Alamos Scientific Laboratory (LASL)}

The Los Alamos Scientific Laboratory (originally, the Manhattan Project) was founded in 1943 at Los Alamos, New Mexico, and is operated by the University of California. Its original mission was the development of nuclear weapons. This mission now represents approximately $50 \%$ of the current effort, with the remaining $50 \%$ spanning a wide range of basic and applied scientific investigations.

\section{A.2.1 Lab Description}

The non-weapons-related activities at LASL include intensive basic and applied research in physics, mathematics, computer applications, chemistry, metallurgy, and materials. LASI also has significant programs in controlled thermonuclear research ("theta pinch"), laser fusion, laser isotope separation, mediumenergy nuclear physics, molecular biology, biomedical and environmental effects of radiation, waste management, pi-meson cancer therapy, reactor safety, geothermal (dry rock) and solar energy, and superconducting electrical transmission and storage. IASL operates an $800 \mathrm{MeV}$ proton accelerator (LAMPF), PHERMEX highintensity flash $\mathrm{x}$-ray machine, Scyllac controlled thermonuclear research facility, and a very large computer facility.* The majority of LASL's work is done for DOE. Some work is sponsored by other agencies (such as NRC, NASA, the military, and USDA) on a reimbursable basis.

ॠERDA 76-73, Capsule Summaries of Plants and Laboratories, FY 1975

$$
A-10
$$


LASL staff is comprised of over 5700 full-time employees, of which over $40 \%$ are technical staff members. Major areas of expertise are physics, chemistry, engineering (mechanical, electronic, and electrical), and mathematics. Laboratory technical areas cover 31 square miles.

LASL develops equipment as a part of its research program, but does not manufacture this equipment. All LASL-developed equipment is patented by DOE and made available on a non-exclusive basis for manufacture by private industry. Through this mechanism, a significant amount of LASL technology has reached the commercial market. Two recent examples are solar collectors, and a thermal drill to bore a hole through rock or other solid matter using heat rather than a drill bit.

\section{A.2.2. LASI Safeguards Program Overview}

While the need for control and accountability of special nuclear material has been recognized since the mid-40's, and emphasized in the charter of the International Atomic Energy Agency (IAEA), precise standards of measurement techniques and accuracy requirements had not been clearly established.

*Willrich, Mason and Theodore B. Taylor, Nuclear Theft, Risks and Safeguards, a Report to the Energy Policy Project of the Ford Foundation, 1974. 
In late 1966, LASL initiated a program to provide technical solutions to this problem through non-destructive measurement of nuclear materials. The highlights of this program trace the gradual expansion of the scope of the LASL activity from the development of particular pieces of hardware to a broader focus which encompasses the essential systems aspects associated with material measurement and control:

- 1969. LASL measured fuel rods fabricated for SEFOR fast reactor using NDA methods and determined $\mathrm{Pu}$ shortages of $12 \%-38 \%$ in some rods.

- 1970-73. Several first generation instruments, including neutron coincidence counters, a portable "hold-up" measurement device, and an early segmented gamma scanner were incorporated in a mobile non-destructive assay lab (MONAL). Requests for demonstration of this capability were received from Goodyear Atomic, Union Carbide (hold-up measurements in the K25 cascade), and National Lead of ohio (recovery at fabrication facility for low enriched uranium for $\mathrm{Pu}$ production reactors). These requests were motivated from combined safeguards, process control, and criticality interests. The MONAL also was demonstrated at the LASI Pu recovery facility, Rocky Flats Pu facility, NUMEC, ORNL Yl2, and GE Vallecitos.

- 1970-72. The need to measure the fissile content of all the fuel rods of a fabrication facility originated through the AEC regulatory branch. A fuel rod scanner using $252 \mathrm{Cf}$ with the turnaround capability of handling the entire plant throughput without production delay was developed. This was tested at GE Wilmington.

- 1971-73. Babcock and Wilcox, GE, and other vendors requested a refined fuel rod scanner with the capability of measuring pellet-to-pellet uniformity at a rate not to impede production. 
- 1972. A breeder fuel rod scanner was requested by HEDL for measurement of $20 \% \mathrm{Pu}$. This was developed and is currently operational.

- 1973. A training program on NDA techniques was established for AEC inspectors and IAEA staff (later opened to Iicensees).

- 1974. The "elephant gun" was developed for measurement of large $\left(4^{\prime} \times 4^{\prime} \times 3.5^{\prime}\right)$ pellets and transferred to vendor (National Nuclear Corporation).

- 1974-76. Inplant evaluations of Random Driver and Segmented Gamma Scanner at General Atomic Company.

- 1975. At the company's request, the holdup measurement technology was transferred to Kerr McGee.

- 1975. Absorption edge densitometer installed in Uranium Solution Assay System at the LASL high enrichment processing line.

- 1975. Test bed Segmented Gamma Scanners in operation at ARHCO, GA, and NFS.

- 1975. Canberra and Eberline markets commercial design Segmented Gamma Scanner.

- 1976. DYMAC installation at LASL/DP site initiated.

- 1976. The Random Driver was used at Savannah River in an evaluation of scrap and waste from the fabrication of U-Al fuel, and was sent to ERDA/ORO for evaluation of the DYMAC program.

\section{A.2.3. LASL's Safeguards Program for DOE/SS}

The LASL safeguards program sponsored by DOE/SS is currently focused on the development of the base technology and systematic methods (including both hardware and software packages) of material control and accountability for generic nuclear fuel cycle facilities. 
A.2.3.1. Mission.

The LASL mission may be defined on the basis of its major contributions and capability. These include:

- Develop systematic procedures incorporating NDA technology to insure material control and accountability to within established standards.

- Develop through field test and demonstration NDA technology for all elements of the nuclear fuel cycle.

- Improve analytical chemistry technology and prepare high accuracy reference materials for safeguards application.

- Contribute to physical security technology development in specific areas. Provide research and development support to nuclear emergency recovery programs.

- Insure rational integration of material control and accountability system into a comprehensive safeguards and security system (including physical security).

\section{A.2.3.2. Summary of Projects for DOE/SS}

The LASL program is focused on the solution of material control and accountability problems. The program strategy is to:

- Design material control and accountability systems for generic fuel cycle facilities.

- Develop a comprehensive software package to serve as the core of a material balance accounting system for a particular facility.

- Investigate, design, and test measurement techniques and hardware which will provide the essential data required for operation of the material control system.

Despite many significant advances in the state of the art of measurement techniques required by a safeguards program, some very basic problems in physics and mathematics still exist which seriously limit the ability to specify precise engineering and cost targets for given time frames. In the following projects, this limitation is addressed directly. 
(1) Performance Criteria: To Develop, Test, and Incorporate Performance Criteria (with Working Guides) for CostEffective, Integrated Safeguards Systems To Be Used in the Design of Future Industrial Fuel Cycle Facilities

The objective of this project is to determine the best combination of techniques and systems for material control and accounting, taking into consideration plant design, physical security, process control, and operational safety. The purpose is to provide performance criteria for the design of safeguards systems for specific facilities. This will be accomplished as follows:

For each element of the nuclear fuel cycle:

- Construct a model generic facility based on existing or projected facility design and material flows.

- Subdivide each facility into unit process, materials balance, and item control areas.

- Define performance (measurement, sampling, control, alarm, etc.) requirements for each sub-unit based on best available analytic techniques (in-house, other program office, or industry).

- Design in detail material control and accountability system for each facility. Estimate costs.

- Test and evaluate selected prototypical equipment and subsystems (developed under NDA Technology \& DYMAC programs).

- Assess compatibility of material control and accountability system with physical security, process control, and operational safety system.

- Determine best mix of techniques and systems through (relative) cost-effectiveness analysis. 
The last four items represent a loop which can be repeated several times before preparation of the final design specifications.

Long-range plans include engineering design and testing of prototypical systems. Current focus is on light water reactor fuel cycle facilities, with mixed oxide fuel fabrication assigned first priority.

The potential benefits of this project are expected on several levels.

- Reduce cost through multiple purpose use of control equipment.

- Focus integrated planning across divisional lines and thereby reduce delays and increased cost incurred as a result of late detection of failure to meet requirements in one or more functional areas.

- Provide analytic base for LASL (and other) program offices in determining specific requirements for technology development (i.e., what type equipment is needed, how accurate, upper limits on cost based on comparison with other alternatives).

(2) Material Control and Accountability System: To Develop and Demonstrate Dynamic Material Control (DYMAC)

The objective is to develop, implement, and demonstrate an automated in-plant material control system that can continuously pinpoint the quantity, form, and location of SNM throughout an operating nuclear facility. The DYMAC system consists of in-plant, nondestructive assay (NDA) instrumentation coupled with automatic data processing equipment. DYMAC systems provide a nuclear facility with the capability for essentially real-time accounting and control of SNM on a detailed unit process basis.

$$
\text { A-16 }
$$


The major project effort is focused on developing an operational system for the LASL TA-55 facility, a plutonium recovery and fabrication facility. Universal concepts and applications will then be abstracted from this working experience obtained in an operating plant environment. The potential benefits of a DYMAC type system have been identified as:

- Safeguards: The DYMAC/TA-55 will be a demonstration system for illustrating essentially real-time material control and accountability concepts and educating potential users. The resulting methodology is expected to be adaptable to other facilities.

- Production: A near real time material control and accountability system such as DYMAC can produce inherently or with minor modification several major production benefits. Several examples are cited below.

(A comprehensive comparison of system costs against a quantitative benefit assessment has not been undertaken.)

- Shutdown time for holdup measurements in the process line can be minimized through on-line measurement and automated inventory calculation.

- Plant efficiency (product out/feed in) can be constantly monitored and near-real time diagnostics provided (e.g., equipment malfunction, operator error, poor feed preparation, etc.).

- Accounting: The automatic system (including measuring devices reporting directly to the data base) can incorporate a wide range of edit and audit checks. Further, in non-real-time accounting systems, the potential exists for inversion of transaction records and large delays and problems in totaling the inventory. 
- Safety: The DYMAC type system can either supplement or supplant the current manual systems designed to preclude criticality accidents (current plans will retain the manual system). In either case, the probability of criticality accident is extremely small. Estimates (not reported here) on the safety benefit of the DYMAC can be made by calculating the cost of an alternative safety system designed to achieve the same level of assurance (if production time is lost, then that time should be added to the alternative system).

(3) NDA Instrumentation: To Develop, Test, and Evaluate NDA Instrumentation for $\mathrm{Pu}$ in use at DOE Facilities, Highly Enriched Uranium and Enrichment Facilities, and Spent Fuel Reprocessing Facilities

The objective is to develop measurement technology which will provide for the rapid detection and localization of losses of special nuclear material through the accurate determination of plutonium and uranium concentrations for the full range of solids and Iiquids found in the nuclear fuel cycle. This technology is required to enable:

- timely and continuous cognizance of the inventory of in-process nuclear materials,

- measurement of in-process and equipment holdup,

- assurance that the content of containers and data are as stated wi hout time-consuming, costly sampling and analyses,

- a means of control and measurement when conventional analysis would destroy or jeopardize a valuable finished product, and

- effective localization of attempted diversion by identifying specific areas, time, personnel, and materials.

The NDA technology developed will be transferred to the nuclear community through handbooks, technical reports, operations manuals, consensus standards, journal papers, consultations, briefings, and training programs in NDA technology. 
NDA is widely recognized as the desirable alternative where:

- Destructive (chemical or physical) techniques are not possible or feasible (e.g., fabricated fuel rods)

- Destructive techniques would produce economically unacceptable production delays (e.g., fuel fabrication process line)

- Destructive techniques cannot cope with the mass, form, or heterogeneity of material to be assayed (e.g., scrap and waste)

- Representative sampling is inadequate

The majority of the project activity is in NDA hardware development with an appropriate level of effort programmed for standards evaluation, calibration procedures, and for field tests, performance evaluation, and application analysis. The safeguards benefits of NDA are discussed in (2) above, as are the contributions of NDA to the production benefits of an MMA system. There are also some production benefits resulting from NDA technology that do not require the total system, such as:

- improved quality control (e.g., 1969-70 non-uniform fuel rod problem)

- elimination of requirement for recycling of low level waste containers and elimination of special handling requirement for containers with very low level contents

- elimination of throw-away samples

(4) NDA Field Support: Domestic Training and Field Operations Largely due to the diverse and wide-ranging nature of the task, this project has a minimum of structure. Requests are generated by industry as their needs arise. They are directed to LASL 
based on industry's assumptions and experience with LASL's capability. The current mechanisms through which LASL presents its capability are:

- Provision of teams and equipment to particular industry sites

- Technical advisory committee (meets three to four times/year and is attended by representatives of DOE, NRC, ACDA and contractors)

- Presentation of papers at IAEA symposia, INMM, ANS, IEEE, AIF and APS meetings, and special international conferences

- Formal training program for industry and government personnel

The Safeguards Technology Training Program is open to safeguards inspectors and qualified users (both domestic and international) of NDA equipment. Typical curricula (for oneweek courses) are: (1) basic passive gamma-ray and neutron assay, emphasizing the use of portable instrumentation, (2) an advanced course in high resolution gamma-ray assay, (3) an advanced course in in-plant NDA instrumentation and (4) a course in integrated safeguards systems. These DOE courses emphasize basic principles and practical skills through "hands on" experience with NDA instruments being adopted and used increasingly by safeguards inspectors as well as plant personnel. 
Field support activities facilitate technology transfer on three levels:

- Information given to potential end-users can contribute to the creation of a market.

- Feedback from potential end-users to LASL supports refinement of existing products and improved requirements definition for prospective products.

- Feedback from end-users to potential vendors provides essential input to the vendor venture-capital analysis and decision.

(5) Technology for Emergency Reaction, Detection, and Recovery

The emergency reaction, detection, and recovery program provides for DOE's response to a successful diversion. The action element is denoted the Nuclear Emergency Search Team (NEST). The program is directed by MA through the Nevada Operations office. The IASL project is one of two major contractor support efforts (EG\&G is the other). Sandia and LLL provide support on a limited basis.

(6) Radiation Detection and Surveillance Technology Development Radiation detection and surveillance techniques, as applied to perimeter access points at physical boundaries to SNM access areas, have been an integral part of the program of the LASL Nuclear Detection and Identification Research Group for several years. A related effort is the continued development, test, and evaluation of SNM portal monitors for use in domestic safeguards systems and the development of test methods and standards for DOE inspector verification of monitor installations. 
A substantial program has also been underway since mid-1974 to develop nuclear techniques for continuous inventory of SNM in storage vaults. For long-term storage of significant quantities such techniques may provide assurance in real time that no diversion has occurred, without the necessity of periodic physical inventory. The techniques rely on inherent nuclear signatures from the stored material as an alternative to providing tamperindicating containers and a high degree of physical security. The first small model of such a system was completed and tested in FY 1975 and the data used to establish design criteria for an improved version to be installed and tested at the LASL DP site in FY 1977. This vault will contain several hundred storage locations and will serve as a full scale demonstration model.

(7) Analytical Methods and Instrumentation for Fissionable Materials

Although NDA techniques are a valuable tool for analysis and measurement of nuclear materials, not all materials are amenable to NDA measurement. For these materials, destructive chemical analysis methods such as the ones being developed by this project are needed. Also, precise dissolution analysis techniques are needed for verification of NDA results.

This project has as its general objective to increase the accuracy and speed of analyses for plutonium and uranium through new methodology and automated instrument development. Specific tasks are: 
- Develop faster dissolution techniques than now are available for difficult-to-dissolve nuclear materials.

- Develop fast analytical methods for the determination of plutonium and uranium in various nuclear materials.

- Develop automated apparatus for the rapid determination of plutonium and uranium concentrations.

Major emphases are development of fast reliable dissolution techniques and equipment; uncomplicated assay methods for scrap materials; highly accurate and precise methods for pure product materials; and automated laboratory instruments for the assay methods. Analysis techniques are refined to improve reliability and speed, and to make the techniques adaptable to automation. Automatic instrumentation is designed and built to apply the developed analysis methods with greatest efficiency.

(8) Preparation of Reference Materials; Analysis of Fissionable Materials

This project has the general objectives of providing reference materials for analytical method calibration, providing analysis materials for safeguards, and generation of data necessary to improve accuracy in NDA measurements. Specific tasks are:

- Prepare, characterize, and package plutonium-containing materials for the SALE program

- Prepare, characterize, and package high-purity plutonium materials for issue by NBS or NBL as reference calibration test materials.

- Prepare, characterize, and assist in distribution of highly pure metals of enriched plutonium isotopes for an interlaboratory program to measure half-lives, and participate in the measurements.

- Chemically characterize unique and special lots of nuclear materials as requested by $5 S$. 


\section{(9) International Activities}

This project provides support for the IAEA in the form of training programs, technology development and transfer, documentation of instruments and standards, consulting, and other assistance. Specific goals include:

- development of a method for verifying complete LWR fuel assemblies in the field, including work on calibration, performance evaluation and operating procedures to enable prototype in-plant instrumentation.

- application of analytical techniques and computer codes to specific IAEA measurement problems in order to reduce the number of physical standards required.

LASL also supports other international cooperative efforts such as working groups, consultants' meetings and bilateral visits. LASL training programs are routinely attended by IAEA staff. Courses on NDA instrumentation may be conducted in other countries in coordination with DOE Standards development is assisted through review of the IAEA's Safeguards Technical Manual providing documentation for LASL-developed instrumentation, and providing physical standards for specific IAEA inspection requirements. NDA technology and instrumentation is developed in response to IAEA-defined needs. IASL participates in additional international working groups, meetings and visits as directed by DOE. 


\section{A.3. Brookhaven National Laboratory (BNL)}

The Brookhaven National Laboratory was established in 1946 at Upton, Long Island, New York, and is operated by Associated Universities, Inc. It has a multi-disciplinary scientific program with a strong emphasis in physics (high energy, nuclear, solid state), biology, chemistry, oceanography, meteorology, and medicine. BNL operates several accelerators and research reactors and maintains the National Neutron Cross Section Center and the National Center for Analysis of Energy Systems.

\section{A. 3.1. Lab Description}

BNL has programs in reactor safety, materials and molecular sciences, plant physiology, hematology, bubble chamber R\&D, bioenvironmental impact of offshore power-plant siting, and advanced use of computers. Non-nuclear energy work includes energy systems analysis and energy conservation (electrical power transmission and hydrogen storage).*

BNL employs about 2800 people. Of these, 500 are members of the scientific staff; about $90 \%$ have $\mathrm{Ph} . \mathrm{D}$. 's.

\section{A.3.2. BNL Safeguards Program Overview}

The BNL involvement in safeguards can be traced to a period of informal support of the IAEA for the AEC in 1967. In January 1968, the relationship with AEC was formalized and the BNL

*ERDA 76-73, Capsule Summaries of Plants and Laboratories, FY 1975. 
Technical Support Organization (TSO) established.* Some of

the major highlights of the subsequent period are:

- 1969. Provided first (of a series of 16) reports to AEC (regulatory division) on Materials and Plant Protection.

- 1970. Conceived, negotiated, and supervised installation of several types of NDA instrumentation in the facilities of four commercial nuclear fuel manufacturers.

- 1971. Developed for AEC an initial "conceptual design" for nuclear safeguards.

- 1971-72. Provided analysis for AEC in determining policy on IAEA inspection of enrichment facilities.

- 1973. Analyzed input of existing and proposed safeguards requirements on the nuclear fuel cycle for AEC (general manager).

- 1975. Provided technical assistance and equipment in the evaluation of plutonium holdup in the Kerr-McGee facility.

- 1975. Provided IAEA a paper on "States systems for Control of and Accounting for Nuclear Material," which was later adopted for recommendation to member states.

- 1975. Prepared NRC Special Safeguards Studies on Safeguards objectives, Impact of Safeguards Measurement, Spiking, and Records Access Limitations.

- 1975. Test and evaluation of the physical protection simulation model at the ARHCO site at Richland, and application of the model in safeguards assessment at the major ERDA sites.

\footnotetext{
*The initial TSO mission was stated as follows:

"Analyze data from systems studies of national and international, contractor and licensee fuel and material conversion and fabrication cycles, performed as a part of the safeguards research and development program; to provide technical advice to the AEC regarding possible changes in methods, techniques and procedures to reduce normal operational losses, materials unaccounted for, and scrap inventory. Provide technical assistance for AEC development of standards and criteria for safeguards systems."
} 
"The current BNL safeguards program for DOE and other sponsors involves studies in consequence assessment, physical protection, threat assessment, inspection support, material accountability, enrichment plant safeguards requirements, and equipment evaluation. DOE has established the International Safeguards Project Office at BNL to coordinate technical assistance to IAEA. In addition to DOE, the NRC, Department of state and ACDA are participants in this project. Contributing laboratories include BNL, LASL, Sandia, Argonne, PNL, and others. Technical support is provided to IAEA in the areas of measurement technology, training, system studies, information processing, surveillance and containment, and field operations.

\section{A.3.3. BNL's Safeguards Program for DOE/SG}

The Brookhaven program is designed to provide direct and immediate support to DOE/SS - As a result of the broad range of capabilities at the laboratory, the experience level of key personnel, and its geographic proximity to AEC (now DOE) headquarters, it was designated the Technical support organization (TSO)

In order to maintain the flexibility and responsiveness necessary to perform this function, BNL is not assigned prime responsibility for major long-term development projects (e.g., threat analysis, physical security devices, NDA instrumentation). When it has developed a particular capability, it has done so in a technical oversight role. Evaluation modeling is a good example. The TSo presentation of an early version of a physical protection model in mid-74 demonstrated the pos- 
sibility of using systematic analysis for physical security assessment and design. Development of additional, sometimes more sophisticated, models has been continued since then by Sandia, Science Applications, Inc., TRW, and others.*

\section{A.3.3.1. Mission}

The Technical Support Organization (TSO) acts as a dedicated advisory group to ss providing technical advice and assistance on a task basis as requested. It must maintain the flexibility to adjust priorities, plans, and activities on short notice. Its activities span a wide range of the total safeguards program, including:

- Policy. Assist ss in the development of inputs to policy decisions for IAEA, ACDA, foreign agencies, and other DOE offices.

- Program Evaluation. Assist SS in assessing weaknesses in the general safeguards program and in the particular programs at DOE facilities. Provide the capability to assist in physical security and material accountability evaluations and to provide independent measurements when required.

- Program Planning. Assist SS in identifying and ranking new initiatives necessary to correct program deficiencies. Provide studies and analyses for the development of short and long range plans. Provide technical review and assessment of RD\&D proposals.

- Program Support. Assist ss, as required, in the technical aspects of their day-to-day activities including preparation of plans, PADs, papers, reports, conferences, standards, informative publications, EIS, performance reviews, etc.

\section{A.3.3.2. Summary of Projects for DOE/SS}

BNL's projects for DOE/SS fall into seven major categories:

1) consequence assessment

2) threat analysis

3) modeling

*An assessment of current modeling techniques is being prepared by TSO and R\&D Associates for the NRC. 
4) IAEA-related studies

5) material balance studies

6) seal test, evaluation and application

7) other support activities.

\section{(1) Consequence Assessment}

The impact of successful acts of diversion, sabotage, or terrorism in terms of economic and social costs (including deaths, injuries, physical damage, etc.) are estimated. This work provides industry planners with specific assumptions being made in the regulation development process, and also assists them in assessing the seriousness of the safeguards problem.

\section{(2) Threat Analysis. *}

Adversary action sequences are identified and the economic, technical, and intelligence resource requirements to defeat these threats are estimated. The results of this project have a use analogous to similar results developed by Sandia (section A.1.3).

\section{(3) Modeling}

Physical Protection Simulation Model. The model was designed to simulate an overt attack upon a fixed site facility. The model is somewhat more general than the Sandia model and can be used in a complementary fashion. Results of the model include:

- Is attacker successful in penetrating to a building containing SNM?

* The current level of activity in consequence assessment and threat analysis is modest; however, BNL continues to monitor these fields and is prepared to update previous efforts. 
- Is attacker who has been successful in penetrating to a building containing SNM successful in entering the building and actually putting his hands on SNM?

- For a predetermined interception point or road block, is the attacker who is successful in gaining access also capable of removing material to a point beyond the interception point?

Material Accountability Model. This model provides a simulation capability for use by $\mathrm{SS}$ in assessment of the nuclear facility physical protection system, and in identification of the utility of proposed upgrading measures.

\section{(4) IAEA-Related studies}

The major effort under this heading is directed toward two areas of study--integrated safeguards and enrichment plant safeguards. In the first area, four facilities have been chosen (a power reactor, a low enriched uranium fuel fabrication plant, a reprocessing plant and a MOX fuel fabrication plant) as typical nuclear facilities to demonstrate the application and effectiveness of IAEA safeguards. With the participation of DOE, NRC, IAEA, and the facility, BNL conducts exercises in safeguards inspection and verification (e.g., examination of design information, outline of procedures for inventory verification, and testing of inspection procedures). The purpose is to provide assistance to IAEA in gaining experience in safeguards application. 
In the second major area of effort, BNL is working on the development and evaluation of international safeguards for enrichment plants, development of U.S. domestic enrichment plant safeguards, and assessment of "hidden inventory" (hold up) and how to account for it.

other tasks under this heading are:

--Technical support to SS, as required, concerning the application of IAEA safeguards to U.S. facilities under the President's offer

--Assistance to $S S$ in assessing the status of the IAEA safeguards information system, and suggesting possible U.S. assistance as well as qualified personnel for IAEA positions.

--Miscellaneous support to IAEA to upgrade safeguard effectiveness.

(5) Material Balance Studies

BNL assembles data on inventory differences (ID) from contractors and field offices for the purpose of determining the circumstances associated with the ID values.

In another project BNL is developing and directing a statistical effort to provide the basis for a program of data analysis and nuclear material accounting. 
(6) Seal Test, Evaluation and Application

The objective of this project was to determine what seals can be defeated (at what level of effort) and what improvements are possible (at what cost). Brookhaven involvement in seal evaluation was initiated in 1969 upon receipt of a request from IAEA to test the Type E security seal. BNL's task was to open the seals without leaving discernible evidence of the act. BNL improved the Type $\mathrm{E}$ seal and developed a complete sealing system (including field use manuals) that has been tested by a number of DCE facilities. Subsequently, BNL examined a large variety of seals to assess their vulnerability and suitability for safeguards applications.

BNL has made significant contributions to the theory of defeating these devices. Based on this experience, BNL has been instrumental in the development of new concepts and methods of seal preparation including:

- Photographic verification of (unique) seal identification marks

- Use of pressure sensitive tapes

- Optical comparison techniques

BNL's seals project is now complete; however, subsequent seals work is being continued at Sandia.

(7) Other Support Activities

- CRBR Hearings. Assistance in demonstrating to the Hearing Board that CRBR safeguards will be adequate.

- Technical Advisory Committee (TAC). Preparation for attendance of, and reporting on TAC meetings with the objective of assessing the progress in design of safeguards for new nuclear facilities. 
- NMMSS Support. Assistance in upgrading NMMSS and related information systems. Also involves assisting NMMSS in meeting IAEA's requirements for data on U.S. facilities.

- New fuel Cycles. Analysis of information on thorium fuel cycles (alternatives to $\mathrm{Pu}$ recycle) to determine impact on international and domestic safeguards.

- Support to SS Reps. Provision of equipment services Trequirements assessment, purchase and delivery arrangements, training) to DOE field offices.

- Assessment of Foreign Chemical Reprocessing Plants. Acquisition of information to evaluate safeguards at foreign plants receiving fuel from the U.S.

- Research and Development Review. Technical assistance to assess progress of projects funded by ss and proposed new projects.

- Miscellaneous. Short-term support to SS on specific unforeseeable safeguards issues. 
A.4. Lawrence Livermore Laboratory (LLL)

The Lawrence Livermore Laboratory was established in 1952 and has been operated since that time by the University of California at Livermore. It is a mission-oriented research and development laboratory with an historical emphasis in the weapons program. Of its staff of over 6000 , over 2000 are scientists--mainly physicists, chemists, and engineers.

\section{A.4.1. Lab Description}

LLL designed the warheads for Minuteman III and Spartan antiballistic missiles and missiles carried on Polaris and Poseidon submarines, and continues to be a major designer of nuclear weapons. In addition to weapons projects, LLL has programs in laser fusion, magnetic mirror confinement fusion, and laser isotope separation. ILL has large staffs in theoretical physics, cytogenetics, bioinstrumentation, terrestrial and aquatic ecology, atmospheric modeling, accelerator physics, and chemistry. It has the largest research computer complex in the world. iNon-nuclear research includes in situ gasification of coal, in situ liquefaction of shale, a solar pond method for generating hot water for industrial processing, and energy/resources studies. *

A technology utilization group at LLL is charged specifically with transferring products developed at LLL to the private sector. LLI-developed lasex components are now available

\footnotetext{
*ERDA 76-73. Capsule Summaries of Plants and Laboratories, FY 1975 .
}

$$
A-34^{\prime}
$$


commercially, as is LLL methodology for micro-computers. A current effort is to assemble a package of information for industry on equipment and methodology for automated uranium analysis systems.

\section{A.4.2. LLL Safeguards Program Overview.}

Much of LLI's early work on safeguards (beginning in the early 1960's) was required by the weapons program. The basis for LLL's involvement in the non-military safeguards program was its resident expertise in high resolution gamma-ray spectroscopy developed for weapon diagnostics. In 1971 AEC/TSO requested that LIL provide technical oversight of gamma-ray work initiated at GE. Since that time LIL has maintained a relatively small but independent program for the development of NDA techniques.

The LLL safeguards role was expanded in response to a request to assist NRC with problems associated with their Special Safeguards study and security Agency study. Current safeguards work (for DOE and other sponsors) involves development of material measurement and material control techniques, as well as integrating this work with physical and transportation security studies done elsewhere. The material control effort is a systems-oriented study to establish methods and tools to develop performance-based regulations and to be able to assess licensee submittals. 


\section{A.4.3. LLL's Safeguards Program for DOE/SS}

The LLL safeguards program for DOE/SS centers about the

- Expansion of gamma- and $x$-ray techniques to high throughput operation requiring high accuracy.

- Development of a fully automated system for the determination of uranium in solution with an accuracy of $\approx 0.1 \%$ for a sample size of $10-150 \mathrm{mg}$.

The NDA project has focused on two techniques which have an extremely high payoff potential if development proves successful, namely, high-resolution gamma-ray spectrometry and $x-r a y$ fluorescence. In addition, LLL is developing improved analytical chemistry methods for uranium measurement.

The gamma-ray effort has resulted in the installation and testing of a prototype system at the Savannah River Plant (SRP), and a laboratory test at AGNS. An x-ray fluorescence system has been sent to Savannah River for preliminary evaluation.

(1) Application of Gamma- and X-Ray Techniques to High Throughput Operation Requiring High Accuracy

One of the critical unanswered technical problems in designing a total safeguards system for reprocessing facilities is the in-line measurement in the hot process section. This project attempts to provide a technical solution to that problem.

The gamma-ray spectrograph activity includes measurement of the total plutonium and isotopic ratios contained in product process and load out streams and in storage areas. A major effort is the measurement of total $\mathrm{Pu}$ through the use of 
differential gamma-ray absorption on either side of the $\mathrm{K}$ absorption edge.

The $x$-ray fluorescence includes both uranium and plutonium measurements. The current technique is applicable to batchtype measurements and requires freeze-drying the sample. Achievement of $100 \%$ throughput measurements of the hot dissolver solution is being sought by application of wave length dispersion techniques developed in West Germany by A.H.E. Von Beckman. Desired accuracy of $0.5 \%$ at $95 \%$ confidence level is a stated objective. Both SRP and AGNS have supported the laboratory test and evaluation of both the gamma- and $x$-ray systems.

\section{(2) Automated Titration System for Determination of Uranium} The objective of this project is the development of a fully automated system for the determination of uranium in solution. The desired accuracy and precision is $\approx 0.1 \%$ with a sample of 10-150 mg. This effort has been carried out under a contract from NBL for the development of this system. Cooperation between LLL and NBL will be maintained to investigate possible system improvements.

The system uses a digital equipment computer, a sample changing unit, a control unit, and a programmable constant current source. The basic operations of subsample and solution aliquot weighing and titration have been integrated so that all data gathering, storage and calculations can be performed by the computer. 


\section{A.5. National Bureau of Standards}

The National Bureau of Standards (NBS) was established in 1901, and is currently within the Department of Commerce, with main offices at Gaithersburg, Maryland, and Boulder, Colorado. Major responsibilities under the Enabling Act as amended are*:

- The custody, maintenance, and development of national standards of measurement

- The determination of physical constants and properties of materials

- The development of methods for testing materials, mechanisms, and structures

- Invention and development of devices to serve special needs of government

- Investigation of radiation, radioactive substances, and $x$-rays, and their usual means of protection of persons from harmful effects

\section{A.5.1. Lab Description}

In the fulfillment of its statutory responsibilities, NBS has developed numerous technical procedures and devices that have been adopted by the commercial sector. They span a wide range from neon tubes to radio direction finders to electrodeless plating of nickel to dental drills. NBS staff includes 3100 full-time employees (2600 at Gaithersburg). Over 1000 of these are professional staff (physicists, chemists, and engineers) of which more than 408 have doctorates. **

\footnotetext{
*NBS FY75 Annual Report. **About NBS, April 1976.
} 
As a part of the Department of Commerce, NBS has long had a working relationship with private industry. In addition to providing services to industry, such as measurement calibration and verification, materials research, and product testing, NBS has also worked directly with industry to achieve specific research goals.

NBS has a strong basic research capability in a variety of disciplines. These are distributed among four program divisions:

- The Institute for Basic Standards maintains a system of physical measurements for the U.S., as well as coordinating that system with other countries. Research areas include cryogenics, electromagnetic measurements, time and frequency standards, and quantum electronics.

- The Institute for Materials Research performs research and develops methods and standards to quantify the properties of materials.

- The Institute for Applied Technology develops and puts into practice, in a form useful to government, industry, and the public, technology in such areas as building, fire, electronics, and consumer product performance and safety.

- The Institute for Computer Sciences and Technology provides standards and guidance to the U.S. government for use of computers and automation technology.

\section{A.5.2. NBS Safeguards Program Overview}

NBS has a long history of providing measurement calibration services. NBS has produced and sold Standard Reference Materials (SRMs) since 1906. New SRMs are still being developed; over 900 (approximately 30 are $\mathrm{Pu}$ and $\mathrm{U}$ ).

NBS work in the area of radiation research has also had safeguards benefits: 
- In the late '40's, NBS was asked by the AEC to organize a laboratory to analyze nuclear fuels. This lab is now the New Brunswick Laboratory.

- Beginning in the late '50's, NBS was requested to develop a reference method to measure the isotopic content of uranium and plutonium. NBS developed mass spectrometric and associated procedures. The instrument design was published and mass spectrometers are now manufactured by many companies in the U.S. and overseas. Work to improve mass spectrometry is still continuing at NBS.

- NBS cooperated in an interlaboratory effort to measure large masses of nuclear material, such as that encased in shipping containers.

Current NBS safeguards work involves development of facility information flow systems, diversion path analysis, and performance evaluation, in addition to continuing to provide services for improving measurement accuracy. A proposed NBS safeguards project includes improving nuclear material measurement techniques, developing new SRM's, and assisting industry in quality assurance of nuclear materials measurement.

NBS is also working with industry to improve plant-specific safeguards measurements. A cooperative effort with the AGNSBarnwell facility, for example, examined input tank accountability measurements to determine the best method of measurement calibration and standardization. General Electric's Wilmington facility has requested that NBS work with them to determine a methodology for waste stream flow measurement. 
A.5.3. NBS's Safeguards Program for DOE/SS

\section{A.5.3.1. Mission}

The focus of the NBS safeguards effort in support of DOE/SS is systems analysis. This incorporates a range of activity including the examination of vulnerability from a control systems perspective, and the development of structural information flows needed to operate the control systems.

The NBS safeguards work for DOE/SS is structured around three general categories:

Safeguards Information systems

Diversion Path Analyses

Evaluation Measures

A.5.3.2. Summary of Projects for DOE/SS

(1) Safeguards Information System (SIS)

NBS is developing a mechanism for communication of information which is required to determine safeguards status for a particular facility. The two main questions being addressed are what type of information is needed and who should have that information. The bulk of the system structure will be at the plant level where assessments of potential diversion are made. But the scope of the information system is also at the DOE Field Offices and Headquarters level, for verification of safeguards system function or for determination of the appropriate level of response to a probable diversion. 
NBS is utilizing system studies to define a generic information structure which can then be adapted for use at specific facilities.

\section{(2) Diversion Path Analysis (DPA)}

DPA is an important component of SIS as it provides information required for safeguards decisions. DPA systematically evaluates safeguards controls (either in place or proposed) to determine points in the control system which may be vulnerable to material diversion. The DPA procedure which has been developed and is utilized at NBS focuses on internal diversion, but the results are also useful for assessing the external threat. Methods of diversion are analyzed from the standpoint of attractiveness to the adversary, complexity, and sensitivity of the system to detect the diversion attempt. Corrective measures to the safeguards system can often be identified.

\section{(3) Evaluation Measures}

NBS develops evaluation measures for DOE/SS to assure independently that safeguards measures address the perceived threat. While a total safeguards system is difficult to evaluate, effectiveness can be determined on a subsystem basis. Existing evaluation techniques will be examined and revision suggested where required, as well as development of new techniques. This is a continual process because the perceived threat, performance criteria for safeguards mechanisms, and the mechanisms themselves are changing. 


\section{A.6. Pacific Northwest Laboratory (PNL)}

The Pacific Northwest Laboratory (PNL) was established in Richland, Washington. Its operation has been the responsibility of Battelle Memorial Institute since 1965. PNL maintains an interest and expertise in a broad range of energy, life sciences, social, environmental, and other technical disciplines. It conducts major studies in the evaluation and development of all energy systems.

\section{A.6.1. Lab Description}

Approximately 40 percent of PNL's work is sponsored by DOE, about 40 percent by NRC, about 20 percent by the Arms Control and Disarmament Agency ( $A C D A)$, and a lesser amount for other Federal agencies as well as private industry. Examples of the type of work done directly for industry include work related to DOE programs plus food processing technology development, energy conservation analysis, nuclear fuel cycle studies, and assessment of potential industrial plant sites.

The lab employs about 2000 people, approximately 1200 of whom are professional staff working in PNL's nine research departments: Atmospheric Sciences, Biology, Chemical Technology, Ecosystems, Energy Systems, Engineering Physics, Materials Research, Radiological Sciences, and Water and Land Resources. 
The basic focus of the PNL safeguards program is the assessment of effectiveness of overall safeguards systems. Recent emphasis is on after-the-fact inspection and feedback, i.e., did the system perform as expected and if not, why not?

PNL has been involved in the development of assessment techniques for both the design and the evaluation of safeguards systems since the late 1950s. Some of the key personnel were associated with safeguards at the inception of such concepts as inspection and control and the efforts to apply statistical techniques effectively in nuclear materials control and accounting. In addition, PNL was the principal U.S. contributor to the conceptual bases for the IAEA system.

Significant activity was underway at PNL by the late 1950s in the development of sophisticated approaches to material balance accountability (see also Brookhaven National Lab, B.3) .* Milestone accomplishments include:

- 1959 Report on control and inspection systems for plutonium production (HW-62119).

- 1960-61 Four TID documents on materials accounting at fuel fabrication plant, test reactor, reprocessing plant, and power reactor (TID-12099, 12100,12101 , and 12102).

* See, for example, K. B. Stewart, "B-PID and Inventory Estimates with Minimum Variance," HW-56536. 
- 1966 Report on the application of safeguards to nuclear fuel processing plants.

- 1967 Statistical portion of the special three-month safeguards course at Argonne National Laboratory.

- 1967-69 Resident inspection report on adequacy of safeguards course at Argonne National Laboratory.

- 1968-70 Concept of statistics used in safeguards for inventory differences (see Stewart and Jaech, 1970).

- 1972 Developed the "crossover plan" to guard against any combination of gross defects resulting in large removals of material.

- 1972 Application of aspects of game theory to evaluate sampling plans.

- 1973 Application of inspection strategies at the Hanford complex.

- 1974 Developed verification sampling and assessment plans for the IAEA inspections that are designed to guard against both individual and mixed diversion strategies. The plans are designed to detect the loss of a goal quantity of material at a preassigned assurance level.

- 1974 Application of plans for prompt materials assessment.

- 1974 Utilization of NDA equipment with automated data handling capability for inspector application.

- 1975 Application of societal risk concept to safeguards designs.

- 1975 Application and experience with isotopic correlations summarized.

- 1975 Prepared NRC special safeguards studies on Improved Material Accounting for Plutonium Processing Facilities and a 235 U-HTGR Fuel Fabrication Facility.

- 1976 Recognition of interacting assessment roles of facility operator, federal agency, and IAEA.

- 1976 Tested and evaluated diversion path analysis methodology as applied to an R\&D facility. 
The principal elements of the PNL program are summarized below. Many of PNL's technical projects are complementary in that they are related, for instance, to materials accounting, statistical evaluation, and assessment of the overall safeguards system.

1. Technical bases for safeguards assessment and assurance (DOE) .

2. Development of regulatory guidelines (NRC).

3. Technical assistance to IAEA (DOE.).

4. Inspection procedures for materials control and accounting (NRC).

5. Application of isotopic safeguards techniques to chemical reprocessing plants (ACDA).

6. Safeguards methodologies related to verification, data evaluation, and technical applications - IAEA $(A C D A)$

\section{A.6.3. PNL's Safeguards Program for DOE/SS}

\section{A.6.3.1. Mission}

PNL has the lead responsibility or is a principal contributor in:

- statistical interpretation of safeguards concepts.

- Material balance inspection and verification techniques including verification of source data and evaluation of mass balance data.

- IAEA inspector sampling plans for U.S. facilities (see also Section B.3). 


\section{A.6.3.2. Summary of Projects for DOE/SS}

The projects currently supported by DOE/SS are:

- Safeguards assessment and assurance.

- Technical support to IAEA.

- Special systems analyses.

\section{(1) Safeguards Assessment and Assurance}

The safeguards assurance and assessment project brings together a large number of related activities with a common focus, namely, the effective and accurate inspection of nuclear facilities. These activities include:

- Preparing technical guides for inspectors to use in evaluating and substantiating materials accounting.

- Preparing an overview report on the assessment process with a focus on the roles of the facility, the regional operations office, and headquarters in providing assurance and feedback.

- Continued development of assessment technology designed to integrate all elements of safeguards including physical protection.*

- Presentation of courses and seminars for inspectors.

- Proper development, as appropriate, of technical solutions to problems identified in the course of inspection.**

The safeguards assurance and assessment project contributes to the industry planning cycle by developing both guidelines for and a detailed statement of the inspection requirements that must be

\footnotetext{
* The PNL focus has traditionally been on material balance accounting, combined with physical protection.

**See, for example, the work on pressure sensitive seals, design requirements for verification equipment, etc.
} 
met by a facility. While this project addresses only the DOE evaluation of $D O E$ facilities, the relationship with analogous NRC-sponsored projects is sufficiently close to ensure more general applicability.

\section{(2) Technical Support to IAEA}

The objective of this project is to provide technical assistance to IAEA in order to ensure that U.S. views and requirements are inc rrporated in the development of effective IAEA safeguards. Th project activity is of a staff-support and consulting nature.

The contribution of PNL through their involvement in this activity is twofold:

- The definition of the IAEA safeguards systems including both technical criteria and verification practices (these should be incorporated into a separate analysis of the IAEA program).

- An understanding and possible forecast of subsequent definitions of the IAEA requirements for inspection and how these may be incorporated responsibly into industry planning. 
A.7. New Brunswick Laboratory (NBL)

The New Brunswick Laboratory, which is operated by DOE, was founded in 1949 at New Brunswick, New Jersey, and is now located in Argonne, Illinois. The original purpose of the lab was to be the official government assay point for imported uranium. NBL's staff level is currently at 65 , including 47 technical staff. The main area of expertise is inorganic analytical chemistry.

\section{A.7.1. Lab Description}

NBL's experience in uranium analytical chemistry provided the expertise for developing reference materials and analyzing samples of material used in various portions of the nuclear fuel cycle by contractor and commercial laboratories. Inter-laboratory measurement programs have been designed and administered by NBL to evaluate measurement technology and to determine where methods development/improvement is required. NBL has undertaken methods development activities for materials involved in the U.S. nuclear energy programs.

NBL contributes to the analytical chemistry requirements of the nuclear industry by providing improved measurement technology and by providing suitable and appropriate reference calibration and test materials. NBL provides the measurement service to industry only when that service is not available from the private sector. This effort is a small fraction of NBL's total technical effort. These "services" are charged at fullcost-recovery rates approved by DOF . NBL's equipment is 
not predicated on its "service" requirements, but rather on the needs of its primary mission programs, viz, methods development, inventory verification, evaluation programs, and standards and reference materials.

\section{A.7.2. NBL Safeguards Program Overview}

The emphasis of the total NBL program continues to be the achievement of high-level competence in the analytical chemistry of nuclear materials. In the 1969-71 time frame, the utilization of this capability shifted from general fuel cycle support to safeguards support by NBL analytical chemistry accomplishments. Some highlights have been:

- 1950-53 Initial preparation and characterization of $\mathrm{U}_{3} \mathrm{O}_{8}$ standard (SRM 950)

- 1968-69 Characterization of uranium metal standard (SRM 960)

- 1971-73 Modification of Davies-Gray assay method for uranium resulting in reduction of process time by approximately a factor of 5 (depending on the sample type) and an improvement in precision by a factor of $2-3$.

The program currently provides the prime analytical chemistry support to the DOE and NRC Nuclear Materials Safeguards Program, including assay of samples taken by DOE and NRC inspectors.

$$
\text { A }-50
$$




\section{A.7.3. NBL's Safeguards Program for DOE/SS}

\section{A.7.3.1. Mission}

The role of NBL in the safeguards program has been defined by its unique capabilities in analytical chemistry. Specific areas include

- Develop and improve chemical and physical methods for the measurement of fissile, fertile and control materials of interest to DOE nuclear programs.

- Responsible for analytical chemistry support for DOE safeguards programs.

- Conduct interlaboratory measurement evaluation programs.

- Prepare, characterize and distribute reference calibration test materials.

- Assess DOE contractor safeguards measurements.

\section{A.7.3.2. Summary of Projects for DOE/SS}

\section{(1) Methods Development}

This project involves the cost-effective development or improvement of measurement technology for nuclear materials. Project scope includes methods for major constituent assay, minor constituent or impurity concentration measurement, measurement of isotopic abundance distribution, and measurement by application non-destructive measurement technology.

The purpose of the project is to provide more timely or more precise measurement technology for the nuclear community. The objective is to develop methods which permit improved precision at no increased operating costs or which permit current levels of precision to be maintained with decreases in operating costs. Methods which have been developed or 
improved are investigated in depth to document their sensitivity to the presence of other elements, to variations in the practice of a published method, etc. This information becomes NBL's "product" for transfer to the industry which is made available through annual reports of the laboratory, through open-literature publication in technical journals, through publication of compilations of measurement methods, through symposia and workshops sponsored by industry or professional societies and through extensive personal contacts between the NBL staff and the worldwide nuclear community.

\section{(2) Inventory Verification}

This project provides a service to DOE, NRC and (in the near future) IAEA safeguards inspection activities. NBL performs routine measurements of nuclear materials taken in the field by safeguards inspectors. The purpose of this project is to provide an independent, measured assessment of the quantity of nuclear material in a contractor's or licensee's stated inventory. These measurements indicate whether a facility is in compliance with safeguards regulations. As-received samples are totally dissolved, where possible, to avoid introducing additional sampling errors. Aliquots are taken by weight, assayed for uranium and/or plutonium, scanned by emission spectrometry to assure the absence of interfering elements, and measured by thermal-emission mass spectrometry to 
determine isotopic abundance distribution. Because samples are taken from facilities working with many different materials and from different parts of the fuel cycle, NBL is asked to analyze a greater variation of material types than almost any laboratory in the world.

As a result of improved sample preparation and analyses methodology, the time between sample receipt and assay reporting is being reduced. Uranium measurements are being routinely reported with uncertainties of less than 0.1 percent (relative). Recently completed improvements in the analysis of plutonium-containing materials will result in shorter turn-around times and improved precision.

\section{(3) Laboratory and Methods Evaluation}

This project involves critical evaluation of the performance of laboratories making measurements on nuclear materials and of the methods developed for and applied to the measurement of nuclear materials. The purpose of this project is to provide to field inspectors and laboratory operators a basis for assessing the capability of laboratories and the methods which are being used to measure nuclear materials. By means of reports of results of interlaboratory comparisons, laboratories are able to assess their individual performance relative to other participants and institute remedial measures where necessary. Inspectors are able to compare actual performance with that stated in the nuclear materials control program plan. 


\section{(4) Standards and Reference Materials}

This project involves the preparation, characterization and making available to the nuclear community materials of elemental and/or isotopic composition whose values are traced to the national measurement system. The effort at NBL complements the efforts of the US NBS which cannot provide all of the industry's needs. NBL provides, in response to needs identified by the nuclear community, materials which NBS does not supply (secondary standards). At present, NBL makes available over 20 reference materials containing uranium, plutonium, thorium, or beryllium. Additional materials are being made available under the auspices of the SALE Program. 
A. 8 Idaho Chemical Processing Plant (ICPP)

The Idaho Chemical Processing Plant is located at the Idaho National Engineering Laboratory (INEL) site near Idaho Falls, Idaho. It was established in 1951 and has been operated by the Allied Chemical Corporation since 1971. The ICPP was designed to reprocess a wide variety of irradiated nuclear fuels and to recover unused enriched uranium.

\section{A.8.1 Lab Description}

The primary mission of the ICPP is the reprocessing of nuclear fuel (which may contain hiqhly enriched uranium) from defense and research reactors, and the solidification and interim storage of the resulting nuclear wastes. The ICPP also has a significant background in fuel cycle research involving reprocessing and waste management. Research at the ICPP is coordinated with the other contractors at the INEL, whose missions include the design and testing of nuclear reactors, including the LMFBR. Extensive programs in reactor safety research are also in progress. The ICPP currently employs 677 people and is actively expanding. The INEL as a whole employs over 7400 people.

Researchers at ICPP are investigating new processes for advanced reactor fuels and graphite fuel recovery. The ICPP pioneered the fluidized-bed calcination of high level liquid wastes, and is continuing to expand and improve this process. Other waste management projects in progress include systems for removal and storage of volatile and semi-volatile fission products and methods of encapsulating calcined waste for permanent storage.

$$
\text { A }-55
$$


Since 1951 the ICPP has processed nuclear fuels of widely varying types

for the AEC, ERDA, DOE and other nations. Several new processing techniques have been developed and are in use. As a result of this work for the technical programs mentioned above, there is a wide range of experience pertinent to safeguards programs. There are broad and general capabilities in the fields of safeguards accountancy, unit operations, separations technology, decontamination, direct maintenance, waste handling, waste disposal techniques, and high-precision uranium-plutonium analysis. The SALE program, a worldwide inter-laboratory sample analysis comparison program initiated at the INEL for ERDA/DSS, has been very important to the nuclear material safeguards effort.

The facilities and staff at the ICPP are backed by a wide range of immediately available skills and equipment at the Idaho National Engineering Laboratory. The extensive $D O E$ programs in reactor safety carried on for the past 15 years have produced an outstanding expertise in the fields of systems analysis, instrumentation, hydrodynamics, heat transfer, neutron physics, and mathematical modeling. The INEL has extensive computer facilities including complete digital and hybrid computer simulation equipment. The INEL has maintained an extensive program in gamma spectrometry, and has been responsible for basic measurements and technology in this field. The INEL has placed considerable emphasis on training programs. They currently train reactor operators for a very high flux test reactor complex using a reactor simulation facility. Training of chemical and reactor plant operators to meet stringent qualifications is a routine function. 


\section{A.8.2 ICPP Safeguards Program Overview}

The ICPP has developed material control techniques and equipment for its own use since 1955. While the principal purpose of this activity has been the measurement, safeguards, and material accountability needs of the Idaho facility, the results have found more general application:

- 1971. Experimental load cell installation on ICPP input tanks and tests of precision level transducers.

- 1973. The loadout area monitoring equipment with flow meters (for volume determination) and gamma absorptimeters (for heavy metal mass determination) were installed in the GE fuels reprocessing plant.

- 1976. The loadout area monitoring equipment was shipped to the Eurex Plant at Saluggia, Italy, for tests under the cognizance of IAEA and ACDA.

The ICPP staff has participated in several safeguards studies, including an evaluation of safeguards in the highly enriched uranium fuel cycle for the GESMO prepared by NRC. A comprehensive review of the ICPP safeguards system was recently completed and a long range program has been initiated to implement improvements recommended in the study. A similar study was carried out for a proposed HTGR fuel reprocessing plant. The ICPP is also participating in an NRC study to evaluate the effectiveness of the material control program at a highly enriched uranium fuel fabrication plant. 
A.8.3. ICPP's Safeguards Program for DOE/SS

The ICPP mission for DOE/SS is the development of concepts and components for integrated safeguards systems for test and evaluation in DOE chemical processing plants. The focus of the ICPP program is the development of an integrated SNM control system for a chemical reprocessing facility and for the development of components for such a system. The control system is planned to integrate present physical security and accountability elements and to add the concept of computer-run on-line diversion detection.

The ICPP program is intended to provide the best safeguards control subject to operational realities and state-of-the-art limitations in equipment development. The program has concentrated on those problems characteristic of chemical processing where the backlog of experience at ICPP is pertinent. The intent is to provide a safeguards system that can be shown to be effective as well as meeting the specific requirements and the full intent of DOE regulations.

The program approach taken is the isolation of specific problems and the development and testing of practical solutions. For example, since vessel samplers are essential to plants but provide a probable diversion path, program effort has developed a sampler concept that enables on-line detection of improper operation. 
The proposed SNM control system will consist of a computer with associated in-plant sensors that will allow the computer to monitor tank levels, stream flow, uranium concentrations, valve positions, time sequences of configurational changes, and compare them with approved standard operating Procedures. When the computer's information indicates non-standard or illicit procedures it will initiate the appropriate response.

A proposal has been made to expand ICPP's safeguards activity into two related areas to assist DOE in timely installation of safeguards facilities.

- Test and evaluation of new plant safeguard instruments and devices to ensure reliable operation in a hot operating environment and effective performance in unit process monitoring systems.

- Design, engineering, and coordination support to DOE facilities for upgrading their safeguard systems.

Summary of Projects for DOE/SS

(1) Development of Models of SNM Flow in Chemical Processing Plants This project models the SNM flow for use in designing a realtime accountability system for ICPP. The system incorporates control features and is intended to provide an alarm both in the case of either an unexplained material imbalance or a deviation in plant procedures which could be interpreted as a diversion attempt. 
Computer models of plant theft detection systems are being produced to identify optimum "theft detection" atrategies. The models are oriented towards small computers, and manuals will be available to explain their use.

(2) Development of Instruments and Methods for Measurements of Isotopic Ratios

The purpose of this activity is to determine the best techniques available for on-line isotopic measurement. Current plans call for a relative evaluation of small quadrupole instruments against a magnetic mass spectrometer. supporting work in the development of rapid sample separation will also be conducted.

The selection of instruments and methods is being made for rapid, convenient measurement of uranium and plutonium isotopic ratios in reprocessing plant samples. The instruments will provide inspecting groups and plant control staff with isotope ratio instruments adapted to their needs.

(3) Development of In-Line Sensors for Measurement of Uranium or Plutonium Concentrations

In-line uranium or plutonium concentration sensors are being developed for use by an integrated Safeguards Accountability 
System for a chemical reprocessing plant. Sensors to be developed include an improved plant gamma absorptimeter and a solution alpha sensor.

(4) Development of In-Line Sensors Indicating status, Composition, or Control of Plant Equipment

Computer readable sensors are tested, and where necessary

developed for use with a plant Safeguards Accountability System.

These sensors indicate the status, composition, or content of

plant equipment. Current work includes:

1) In-line sensors that detect the presence of liquid or liquid flow in plant lines

2) Samplers with integral instrumentation that will detect improper use

3) Pressure transducers for very accurate level and density measurements

(5) Development of Load-Out Area Monitor

The objective is a plant test of a system capable of independent measurements of the weight of SNM passing through a load-out area. Project effort will include a test of an SNM load-out monitor at the ICPP. The system tested will have application for plutonium load-out monitoring systems at commercial plants. 


\section{A. 9 Mound Laboratory}

Monsanto Research Corporation, a subsidiary of Monsanto Company, operates Mound Laboratory, Miamisburg, Ohio, for the

\section{U. S. Department of Energy. Mound Laboratory}

performs research, development and production activities in support of both DOE weapon and non-weapon programs, with emphasis on explosives and nuclear technology. Fields of concentration are chemistry (physical, inorganic and analytical), engineering (nuclear, chemical and metallurgical) and physics. The staff numbers 1600. Mound's concern for the security problems associated with nuclear material began with the participation of the Monsanto Company personnel in the Manhattan Project during World War II, and has continued with the Monsanto Research Corporation since the initial operation of Mound Laboratory in 1948 .

\section{A.9.1 Lab Description}

Mound supports activities of several DOE components in addition to its work for SS. Weapons work includes process development, production engineering, manufacturing and surveillance of detonators, explosive timers, explosive actuated transducers, firing sets, explosive pellets, nuclear components, and specific testing equipment. Non-weapon activites include research in radioisotope-fueled heat sources and in the production of stable gas isotopes. 


\section{A.9.2 Mound Safeguards Program Overview}

As part of its continuing program in support of the DOE weapons and non-weapons programs, Mound Laboratory has developed capabilities in several areas which have been utilized in the safeguards R\&D program. Their capabilities include:

- Calorimetry

- Data Processing for Nuclear Materials Control

- Statistical Analysis

- Gamma-ray spectroscopy

- Automated Processing

- Physical security

- SNM Storage

In 1971, the Albuquerque Operations Office (to which Mound is assigned) was considering alternatives available to meet safeguards requirements for verification of plutonium inventories at contractor facilities. The major problem was analysis of scrap and residue where chemical assay could not be used. Based on tests at Mound, it was demonstrated that calorimetric assay techniques could meet the safeguards requirements. The first sample selection from a contractor facility was shipped to Mound for a calorimetric assay in 1972 . 
In addition to calorimetry, Mound utilizes several other methods for the analytical measurement of nuclear material. These include mass spectrometry, pressure-volume temperature (PVT) gamma scanning, beta-counting, chemical assay and direct weighing .

Mound's total safeguards R\&D program (for DOE/SS and other sponsors) has five major areas:

1) Assay Standards and Traceability

2) NDA Assessment

3) Measurement System Development

4) Calorimeter Development

5) Guides and Regulations

\section{A.9.3 Mound's Safeguards Program for DOE/SS}

The major effort for DOE/SS is in the development of instrumentation for calorimetric assay. In addition, a significant level of activity is taking place in the investigation of related NDA techniques:

- Gamma-Ray Measurements of Isotopic Concentrations

- Watts-Balance Accounting

- X-Ray Fluorescence,

and in the development of the basic tools in order to conduct accurate NDA activity, such as

- Physical standards (characterized plutonium and standard heat sources) 
- Plutonium Half-Lifes*

- Weighing of Radioactive Material

- Plutonium Sample Exchange Programs

The Mound NDA philosophy asserts that an intimate relationship exists between various facets of NDA activities.

(1) Development of Calorimetric Assay Instrumentation

Calorimetric assay has proved to be a practical technique for the quantitative assessment of plutonium. The combination of the total heat measurement from a calorimeter and isotopic analyses from a gamma-ray spectrometer provides an accurate nondestructive analysis of the quantity of plutonium present in a sample. Calorimetry has been used extensively for the assay of radioisotopic material throughout the DOE complex; and most of the calorimeters have been supplied by Mound Laboratory.

Instrumentation development work is being conducted to demonstrate the applicability of calorimetric assay to meet the needs of the high throughput plutonium processing facilities. An information base is being prepared which will allow potential users of calorimetric assay to make knowledgable judgments concerning calorimeters, sample containers and operating techniques.

* Cooperative program of six laboratories (ANL, LLL, LASL, Mound, Rocky Flats and NBS). 
Mound Laboratory is developing the Automated Plutonium Assay System (APAS I) to demonstrate the applicability of automated calorimetric assay to meet safeguards assay problems. This system is designed to provide rapid and accurate assay of discrete containers of mixed oxide fuel in a glovebox line. A process control computer will control the movement of all samples, perform data acquisition and analysis, and help provide material control and accountability. This system will rely on calorimetry and gamma-ray isotopic measurements to determine plutonium values.

The calorimeters used in APAS I were designed and constructed around one size sample container and for a particular set of specifications. The concept of an automated system is demonstrated, both in terms of computer control and "hands off" material handling. Also demonstrated are the capabilities of calorimetry and gamma-ray spectroscopy. However, further calorimeter develop-nent work is required to provide the design and operating information necessary for defining the parameters and capabilities of new calorimeters measuring different size samples.

The calorimeter development program is concerned with providing design analysis, test information, and prototype instrumentation for two different types of assay systems: discrete container and continuous flow. The development of discrete container assay calorimeters is directed toward reducing the time required 
per assay without sacrificing the measurement accuracy. Areas of investigation include the servo-control electronics package interfaced to the calorimeter, the relationship between assay time and the sample container size and shape, and a technique for predicting a final value in advance of actually achieving a thermal equilibrium condition. Prototype calorimeter systems will be fabricated and tested allowing for the definition of the expected assay times and accuracies of a calorimeter given any sample size and configuration. The criteria for selecting sample size, calorimeter design and operating techniques for a given set of specifications will be established.

This project also involves developing calorimeters for the assay of in-process plutonium continued within a closed piping network. Continuous stream assay will eliminate the need for special handling and containerization of the material for assay purposes and will, therefore, improve the safeguards control and accountability of the system. The flow of material through the process lines will be interrupted for assay but will not be diverted from the process Iine. Calorimetry will be an integral part of any flow interrupt stream assay system. In addition to investigating the feasibility of adapting a standard twin-bridge calorimeter to the stream assay application, new types of calorimeters and instrumentation will be considered. 


\section{(2) APAS I Automation}

The three dimensional $(\mathrm{X}, \mathrm{Y}, \mathrm{Z})$ transport system has been assembled and is undergoing testing in a test frame that simulates the glovebox line.. The open design of this test frame allows evaluation and modification of the components which cannot be easily viewed or accessed when the system is installed in the gloveboxes. The test program, presently run on a PDP-8 computer, features an initialization routine to direct the return of all three axes to exact reference points, and an open-ended cycling program that will allow indefinite cycling of the system through up to 20 different positions to determine life cycle of components and to check for accumulative positioning errors. 
(3) Plutonium Isotopic Measurements By Gamma-Ray Spectroscopy

Several NDA techniques, e.g., calorimetry and spontaneous fission detection, require a knowledge of the plutonium isotopic concentrations to convert the instrument response to quantity of plutonium present in the sample. Normally, the isotopic concentration information is obtained by opening the container to take a sample for chemical analysis. An alternate technique is being used and further developed at Mound Laboratory to obtain the necessary isotopic information. Gamma-ray spectra are being measured with high resolution $\mathrm{Ge}(\mathrm{Li})$ detectors. Minicomputers are used to extract the gamma-ray intensities from complex overlapping peaks by simulating the detector's response.

When a gamma-ray is related uniquely to its parent isotopes, the gamma-ray intensity can be converted to the number of parent atoms present through the nuclear decay constants. This technique is used routinely for determining the isotopic concentrations used in calorimetric assay. The uncertainties associated with the gamma-ray technique dominate the overall uncertainty of the assay. Methods to reduce the uncertainties in the isotopic concentrations determined using gamma-ray spectroscopy are being studied.

Gamma-ray spectroscopy has the following advantages: (1) isotopic determinations are obtained on bulk containers thus minimizing the sampling errors and eliminating the hazards of opening the containers; and (2) the results can be more timely than chemical techniques. 
(4) Watts-Balance Experiment at Battelle-Columbus

Precise and accurate measurements of the heat (watts) produced by the nuclear decay of plutonium have been demonstrated by many laboratories. On the other hand, the technology for determining the conversion factor for watts to grams of plutonium, known as the effective specific power, has not been developed to the same high degree. The purpose of the watts-balance experiment is to make maximum use of the high precision and accuracy of calorimetry while minimizing the dependence on the effective specific power determination.

The experiment consists primarily of a calorimetric assay of all additions and almost all subtractions to the plutonium inventory at the Battelle-Columbus facility. Since the specific power increases slowly with time, about $3 \% / y e a r$ due to americium ingrowth, the watts out will have to be adjusted for this increase.

One of the principal strengths of this test is that it will be done in an operating plutonium-fuels processing plant. This initial test is limited to batch-type processes. If signfficant reductions in inventory difference can be achieved, further refinements will be necessary before the watts-balance concept can be applied to continuous processes. 


\section{(5) X-Ray Fluorescence Analysis}

The measurement of uranium and plutonium by $x-r a y$ fluorescence analysis has been studied for some time but has gained only limited use for accountability of SNM. Sampling errors and sensitivity are limiting factors for $x$-ray fluorescence.

Mound Laboratory has proposed a dispersive x-ray fluorescence system featuring: (1) a rotating anode $x-r a y$ tube; (2) a graphite monochromator; and (3) a stirred slurry sample cell. The stirred slurry sample cell can be operated in-line to provide a larger sample to reduce sampling error. In the extreme, total sampling is possible. The monochromatic exciting radiation will increase signal to noise by a factor of three over the use of white radiation.

Mound Laboratory is currently preparing a feasibility study for the use of the proposed system to assay plutonium in the dissolver tank of a reprocessing plant. 
The DOE/SS program is developing products which contribute

to safeguards system planning on several levels.

- Safeguards System Design Methodology. This is a sequence of design steps which can be used to structure the industry safeguards planning process. Inherent in the sequence is a guide to the utilization of the many supporting products being developed in the DOE program, including evaluation techniques and models; evaluation of and procurement specifications for physical protection equipment; representative engineered safeguards system designs; subsystem designs; physical protection equipment; and material measurement and accounting instruments and procedures. (Section B. I).

- Design Support. The two major areas of effort have been in the development of evaluation techniques and models for direct use in the design sequence and in the conduct of product evaluations and procurement specifications for the class of products being developed in the commercial sector whose assured performance is essential to the design of a satisfactory safeguards system (B. 2 ).

- Representative System and Subsystem Designs. The DOE program is developing Representative Engineered Safeguards systems through the process of applying its design methodology to selected nuclear fuel cycle facilities. This assures that industry feedback is incorporated not olly in these designs but in the entire design methodology (B.3).

- Physical protection Equipment. The majority of the equipment for physical protection is developed in the private sector. For this reason the main focus of the DOE program is determination of performance capability and system compatibility of commercially available equipment (B.2). This section presents devices which are being developed by the DOE program for specialized safeguards reolirements (B.4).

Material Measurement and Accounting. Procedures and instruments for material measurement and accounting have a market potential well below the threshold criteria of private industry. Extensive RD\&D is therefore conducted within the DOE program. These products 
are categorized into NDA instrumentation, other physical techniques, and analytical chemistry techniques (B. 5).

- Inter-Facility Transportation. A concept definition is nearing completion for a commercially operated vehicle for transporting plutonium oxide between dispersed facilities (B.6).

- Inspection, Assessment, and Verification. The experience gained in the conduct of inspection, assessment, and verification of particular facilities has been synthesized with anticipated future development to provide an indication of the requirements that safeguards systems may have to meet (B.7). 


\section{B.1 Safeguards System Design Methodology}

An orderly and comprehensive method is necessary to design effective safeguards systems to protect facilities containing special nuclear material (SNM) from adversary activities that could endanger public health or safety. An integrated safeguards system consists of two interactive systems, one used for physical protection, the other used for material measurement and accounting. Each system must meet separate regulatory requirements. The design method presented in this report is a summary of the results of the DOE safeguards design program at the time of writing. This program is making rapid advances as the level of sophistication of the basic design concepts, analytic techniques, and supporting models are increased. A comprehensive report, including a detailed discussion of all elements of the design method including the software under development, is expected in late 1977 .

Threat considerations to be used in the design analysis are given in B.1.1. The design method presented in B.1.2 applies primarily to the physical protection system and to the interface between physical protection and material measurement and accounting systems that is required for safeguards integration. The Los Alamos Scientific Laboratory is developing the material measurement and accounting system (B.1.3).

Physical protection system design is an iterative process that has been divided into the following five phases: 
- Preliminary Safeguards Concept Rhase;

- Engineered Safeguards System (ESS) Concept Definition Phase;

- Preliminary ESS Design Phase;

- Coordinated ESS Design Phase; and

- Representative ESS Design Phase.

Each phase includes the following activities:

- Baseline facility description,

- Theft and sabotage target analysis,

- Target zone definition,

- Safeguards concerns identification,

- Safeguards component, element, and module selection,

- Operational impact analysis,

- Adversary sequence diagram and fault-tree construction,

- Critical path analysis, and

- Cost and effectiveness analysis.

The only differences between similar activities in any two phases are ones of degree. In the conceptual phases, facility details are limited, systems are simple, analyses are shallow, and cost and effectiveness estimates are crude. As more facility details are considered in the design phases, system definition become more detailed, analyses can be conducted in depth, and cost and effectiveness estimates can be more precise. By proceeding in phases of increasing complexity, many options can be examined in limited detail in a short time and the less attractive options discarded before moving to the next more detailed and time consuming phase. 
Each of the activities is described following a general discussion of safeguards system concepts and threat considerations. Application of each activity is illustrated, where possible, with simplified examples drawn from the Mixed-oxide Fuel Fabrication Facility Safeguards Program (Ref. 1, 2, 3) and other programs now underway. A brief description of the concept and design phases, as they are now conceived, is provided in the final section.

\section{GENERAL DISCUSSION}

A safeguards system performs four basic functions:

- Deterrence of potential adversary actions,

- Detection of unauthorized activities and discrepancies,

- Delay of unauthorized activities until appropriate response can be made, and

- Response to unauthorized activities and discrepancies in an adequate and timely manner.

Deterrence, which results from adversary perception of system effectiveness, will not be discussed here.

Two major independent, but interrelated, systems are required to perform the three remaining functions: a physical protection system and a materials measurement and accounting system. Physical protection controls people, material, and operations. Materials measurement and accounting provides information on the locations and quantities of SNM in a facility. The physical protection system is divided into access and operations control. Access control enables and monitors authorized movement of people 
and material across barriers, and prevents unauthorized movement of people, SNM, and contraband. Operations control, which is concerned with the operational interfaces among people, vital equipment, and SNM, enables and monitors authorized plant activities and prevents unauthorized actions that could result in theft or sabotage. These safeguards systems must be coordinated with normal plant operational systems to obtain a safeguards design that is effective, is not too costly, and has an acceptable operational impact.

\section{Safeguards System Overview}

Safeguards and operations functions are coordinated using the authorization, information, and control channels shown in Figure B-l. Plant management delegates safeguards responsibility to safeguards coordination just as operational responsibility is delegated to plant operations coordination. Safeguards coordination supervises access control, operations control, and materials measurement and accounting. It also coordinates safeguards information flow among these elements, management, and plant operations. The three primary functions of safeguards coordination are: data collection and processing; safeguards condition assessment; and response determination. Whenever possible, safeguards coordination relies on automatic decision and control. However, human assessment, decision, and response initiation are required to supplement the safeguards hardware.

Although primary responsibility for safeguards assessment lies with safeguards coordination, it must not be the keystone of the safeguards system. Direct paths from detection to response 


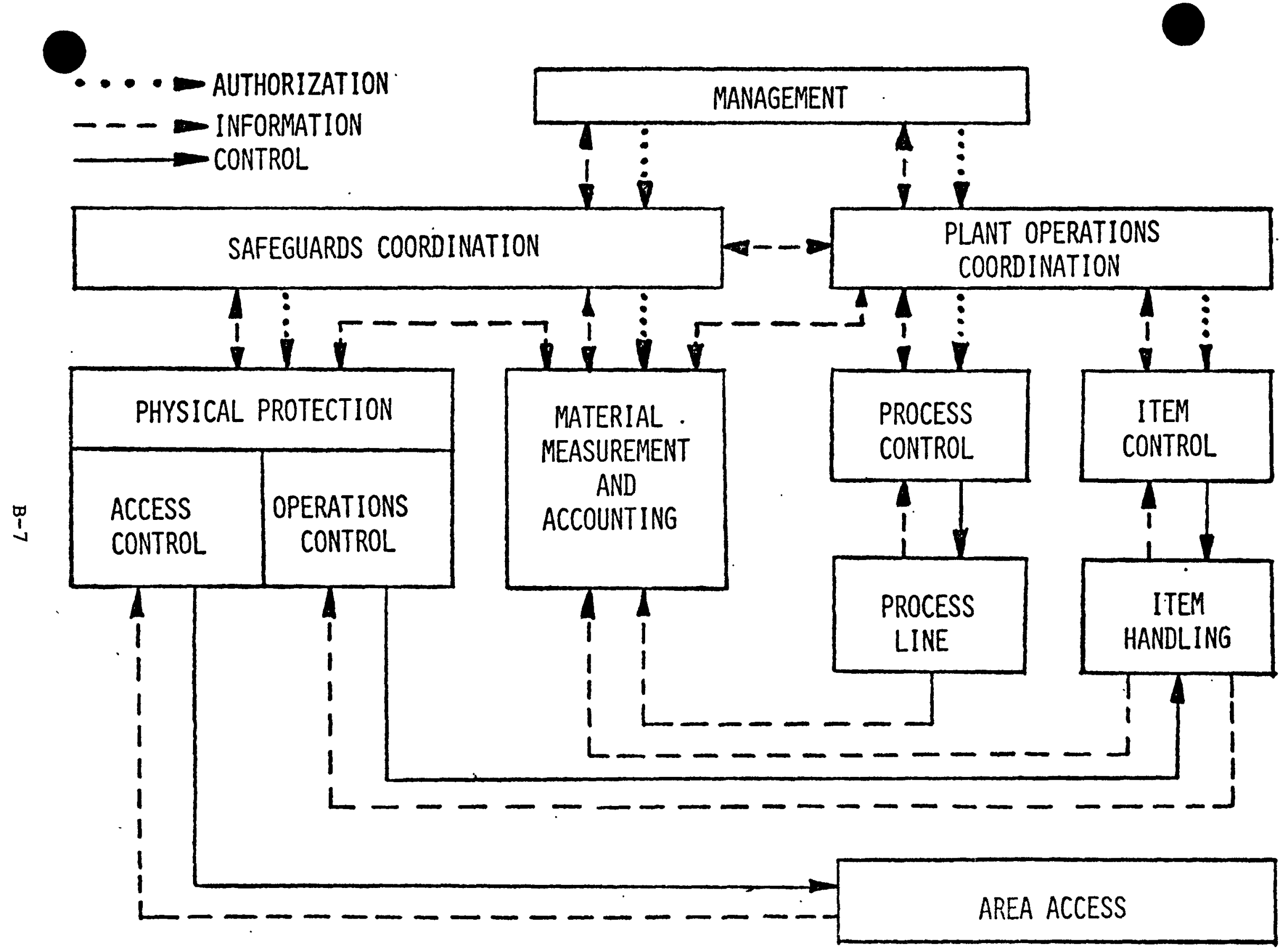

FIGURE B-1. SAFEGUARDS SYSTEM OVERVIEN 
elements must exist to avoid single point vulnerability and to reduce response times to rapidly developing threats. Direct control of area access and item handling is assigned to access control and operations control elements. These elements, working together, serve to exclude all unauthorized persons and contraband from the facility, exclude all but essential persons from selected areas, and preclude unauthorized activities involving SrM and vital equipment.

Direct control of area access and of item handing involves a hierarchy of responses depending on the discrepancy detected between the action authorized and the action performed. The response must be commensurate with the severity of the threat. For minor discrepancies, control can be automated at the access and operations control level. Short delays that might be required to insure safeguards in an area access or item handling sequence should not have unacceptable operational impact. Serious discrepancies calling for security force responses and/or plant shutdown would require coordination between safeguards and plant operations. Some plant processes must operate with continuous flow so that direct interruption of the process line by the safeguards system may not be possible. When process control is necessary for safeguards response, safeguards coordination would initiate appropriate control measures through management or plant operations. The materials measurement and accounting system (B.1.3) is used to obtain information on the quantity and location of SNM within the facility. This information is used to produce periodic inventory reports required by management and regulatory agencies, 
and it can also be used by plant operations for production control and quality assurance. Furthermore, the materials measurement and accounting system can provide useful detection information to the physical protection system related to both long-term diversion and theft. Long-term diversion (also called skimming and pilferage) is repeated thefts of small amounts of nuclear material, each too small to be detected by a single measurement because of measurement uncertainties. Long-term diversion is detected by searching for trends among successive balances and the detection threshold is determined by instrument capabilities. When long-term diversion is discovered, the physical protection system is informed and response action taken. This action can include a sweep of the facility to locate cached material or a temporary increase in personnel search and vehicle monitoring.

If the materials measurement and accounting system has a near-real-time measurement capability, it is possible to detect theft of large amounts of SNM (large enough to be detected in a single material balance) in sufficient time for adequate response by the physical protection system. Detection of loss at the point where the theft actually occurs can make identification of the suspects easier and permits the longest time for response action.

\section{B.1.1 Threat Considerations}

To make an informed choice among possible safeguards options, it is necessary to evaluate the relative effectiveness of each option against a spectrum of threats. By investigating effectiveness against a range of threats rather than one single threat, 
it is possible to show the sensitivity of conclusions to assumptions concerning threat attributes. Furthermore, if the threat spectrum is broad enough, the analyses will show the threats for which each option provides adequate protection and how the system degrades with increasing threat levels. This approach is particularly relevant considering the presently evolving perception of the threat.

Due to the lack of applicable nuclear related incidents, non-nuclear incidents such as terrorist assaults, robberies, burglaries and bombings have been investigated to establish a data base from which to estimate the range of credible threats to nuclear facilities (Ref. 4-12). Additional investigations, such as those by RAND for Sandia Laboratories, are in progress at this time. Based on these studies, it appears that the following threat objectives should be considered in a complete analysis: long-term diversion, theft (including robbery and burglary), and sabotage either by gaining plant access or by standoff weapons used against the facility. These objectives could be accomplished by outsiders with no authorized facility access, employees with appropriate facility access, or outsiders in collusion with employees.

Sensitivity of safeguards designs to variations in the following adversary attributes should be considered:

- Plant access,

- Number of people,

- Mode of transportation (foot, all-terrain vehicles, helicopters), 
- Weapons,

- Explosives,

- Special equipment (self-contained breathing apparatus, etc.),

- Technical and military skills,

- Knowledge of plant operations and layout,

- Knowledge of safeguards systems, and

- Dedication (willingness to risk death or capture).

\section{B.1.2 Physical Protection System Design and Evaluation}

\section{Facility Description}

The first step in the development of safeguards system concepts or designs is a description of the facility. Information is obtained from license application dockets, safety analysis reports, and nuclear design personnel. Facility layouts are required included:

- Site plans showing the site boundary, access points, and building locations, and

- Plan and evaluation views of all significant buildings. Details of the operations taking place within the facility are also required including:

- Material inputs, flow rates, and product and waste stream outputs;

- Description of unit processes, item handling, and storage operations;

- Block diagrams and flow charts for critical processes and operations; 
- Personnel staffing levels, work-shift patterns, personnel movements and access requirements; and

- Normal, maintenance, and emergency control procedures. The above material, together with information on material accounting and management procedures, is the baseline facility description.

Theft and Sabotage Target Analysis

Potential adversary objectives and the baseline facility description are reviewed to identify events or combinations of events that could result in loss of SNM or dangerous release of radioactive material. Event-tree methodology is employed to ensure that the analysis is comprehensive. Examples of events and event combinations that can occur at a Mixed-oxide Fuel Fabrication Facility are: theft of a $\mathrm{PuO}_{2}$ cannister; theft of a Pu-containing fuel bundle; or breach of a building, breach of a process canyon, and detonation of high explosives to disperse $\mathrm{PuO}_{2}$. Target analyses can be complex where sabotage is a primary concern, as with reactors, (Ref. 13) or it can be simple where theft is the main consideration.

Target Zones Definition

Physical locations that must be protected are identified using data from the facility description and the target analysis. Each event of the target analysis could result from an adversary action associated with one or more :ocations in the facility. All these locations must be identified. The locations that must be physically protected to prevent theft and sabotage are identified and designated as target areas. Locations containing

$$
\mathrm{B}-12
$$


special nuclear material (SNM) are called material access areas, while those that contain essential equipment but no SNM are called vital areas. Target zones are defined by combining contiguous areas with common protection requirements. For example, in the Mixed-Oxide Fuel Fabrication Facility the receiving, identification, assay, venting, and storage areas are combined. In all these areas, SNM is available in large quantities and is contained within pressure vessels. Areas containing emergency power and switching equipment are combined into another target zone in which no SNM is present. Other areas are similarly combined. Safeguards Concerns Identification

Consideration of threat objectives and significant operational activity within each target zone will reveal safeguards concerns such as the following:

- Unauthorized persons may try to enter a target zone to commit theft or sabotage;

- Authorized visitors may try to bring contraband (explosives, weapons, etc.) into a target zone to commit theft or sabotage;

- Employees may try to falsify records in a computer to facilitate theft or diversion; and - Handling equipment may be used to facilitate theft. Safeguards Component, Elements, and Module Selection Specific safeguards components are selected to counter each concern. Individual components and groups of components are added to the baseline facility as shown in Figure B-2. 


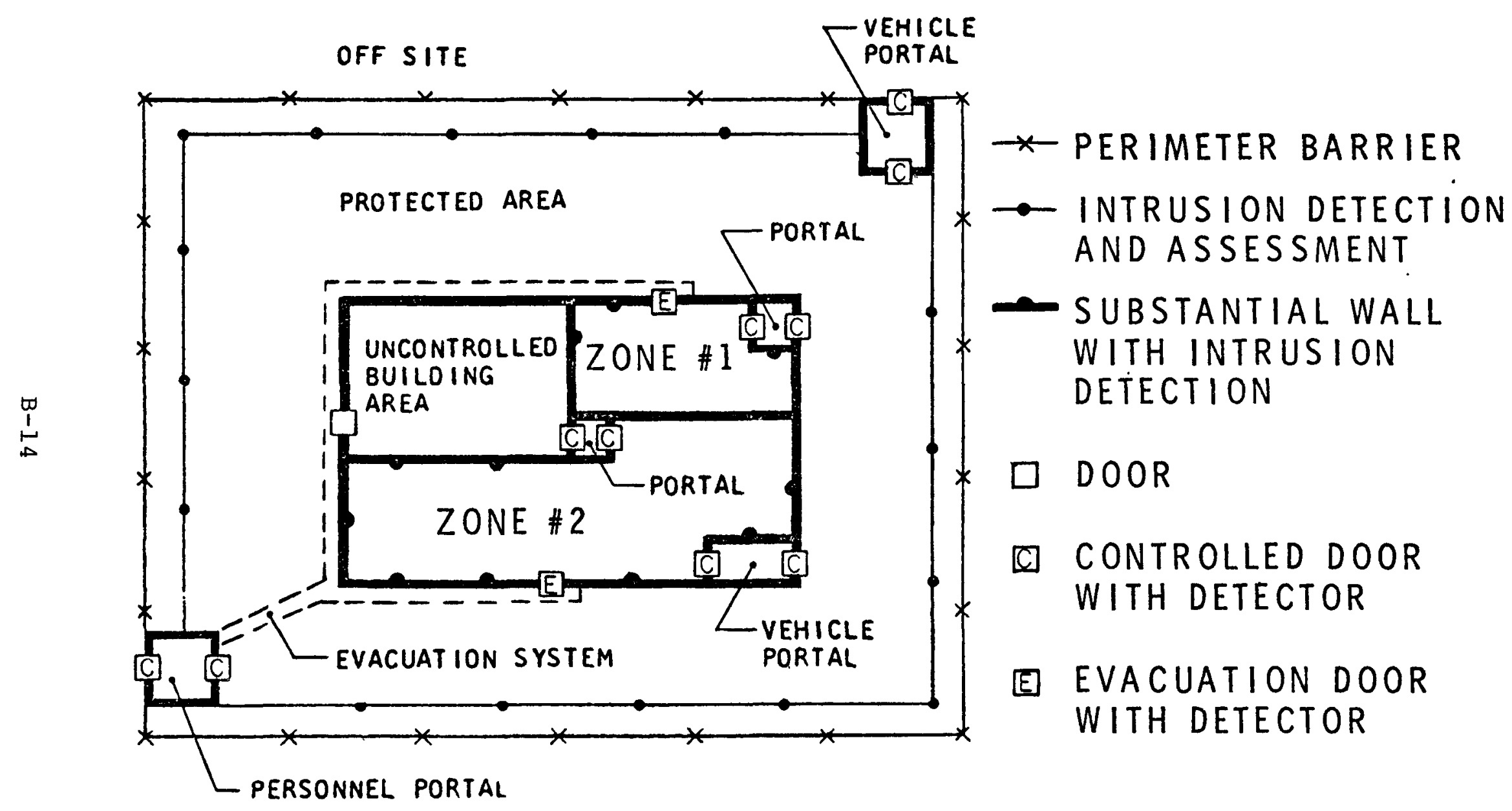

FIGURE B-2. ILLUSTRATIVE FACILITY WITH SAFEGUARDS COMPONENTS 
Safeguards components should isolate SNM and vital equipment from all unauthorized people with a minimum of operational impact. Protection in depth should be provided so that it is necessary to pass through several barriers with associated detectors to reach SNM or vital equipment. Controls of all authorized activity should be maintained to detect or stop employee actions that could pose a threat. Assurance that control is maintained requires guard and off-site response forces since any barrier or delay mechanism can be overcome in time. Components can be considered in groups called elements and modules. Components are discrete system parts such as sensors, barriers, computers, and security personnel.

Elements are groups of components combined to perform specific access control or operations control tasks. Elementrelated components may be located in different areas of a facility. Access control elements provide centralized closed-loop control of material and personnel passage through portals or controlled doors in target zones. Operations control elements provide centralized closed-loop control for plant operations involving handling of nuclear material and vital equipment. Both types of closed-loop control elements utilize monitor, control, and computer components as shown in Figure B-3. Monitor components measure appropriate events occurring in a given access or operational sequence. Monitored information is compared with a stored, authorized event sequence. If no discrepancy occurs, the sequence is allowed to continue in a normal manner. If a discrepancy is detected, a decision is made 


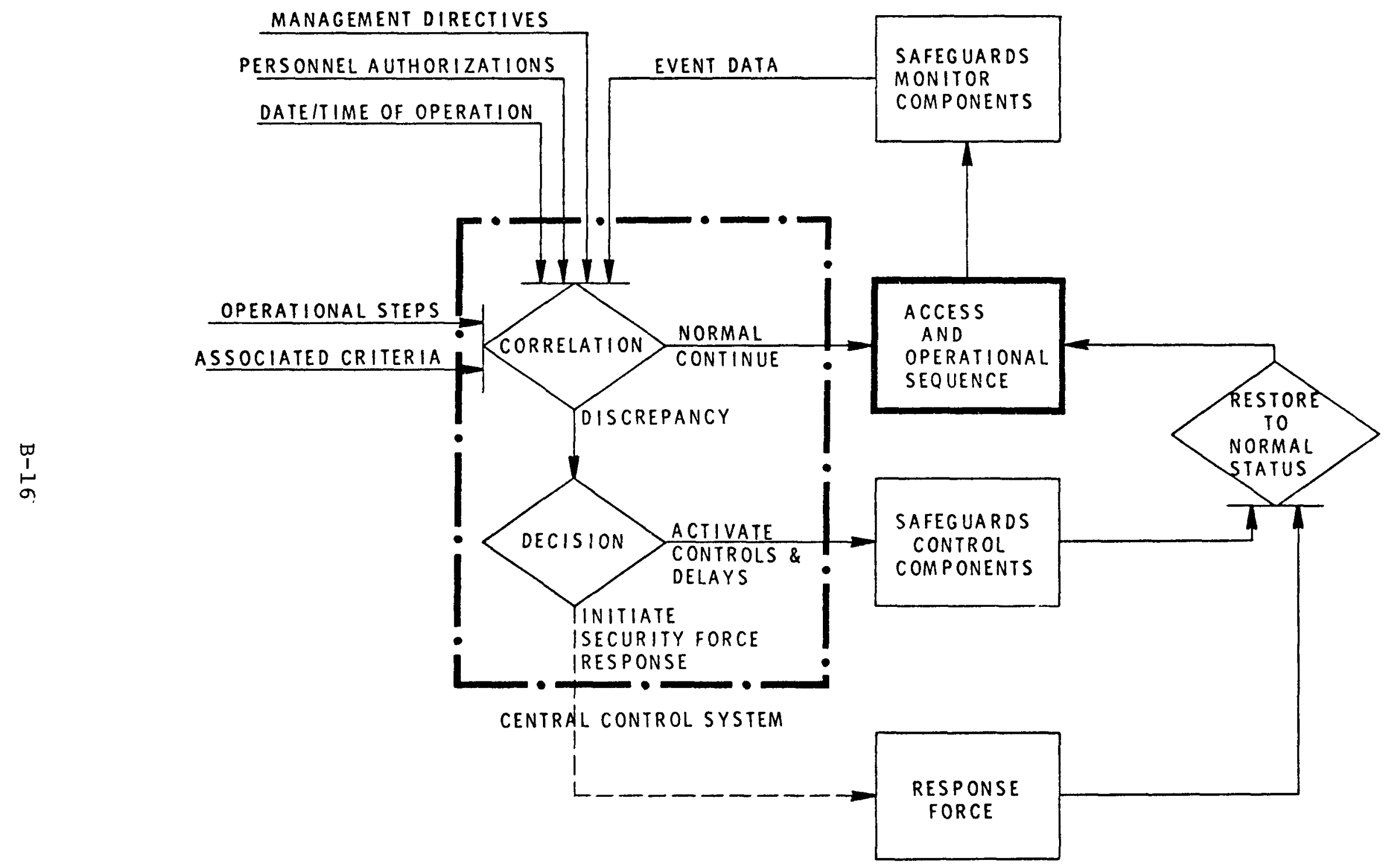

FIGURE B-3, SAFEgUARDS CLOSED - LOOP CONTROL 
to initiate a response action that is related to the severity of the discrepancy. Safeguards-related problems range in severity from trivial procedural errors to serious emergency alarms. The former can be handled by automatically informing an employee of the problem and halting further action until correction occurs. On the other extreme, fire or criticality alarms require immediate, wide-ranging actions by plant personnel while still maintaining protection of SNM. Response to as many situations as possible should be automatic; however, no automatic system can be comprehensive to monitor and assess complex, special situations and to request special action from management and plant operations.

An example of a closed-loop access control element is a guard who checks an entrant's badge, recognizes that it is counterfeit, and prevents passage of the bearer. However, this control function could be handled more effectively by an automatic, centralized identification and portal door control system. Components in a portal, in a central control station, and in a management center, together with communication lines, would make up this element. Thus, elements usually have components located in several areas. Operational Impact Analysis

The operational impact of safeguards components, elements, and modules is next reviewed to assure compatibility with process line controls and flow rates, item handing operations, health and safety, maintenance procedures, and material and

$$
\text { B-17 }
$$


personnel flow rates. The relationship between material

information required for quality assurance, management reporting, materials measurement and accounting, and physical protection is also studied to avoid duplication. Alternatives are pursued until all requirements, including those connected with safeguards, can be met. Adversary Sequence Diagram and Fault Tree Construction

Adversary sequence diagrams show all the potential paths that could be traversed by adversaries in penetrating the safeguards system to reach target zones to accomplish theft or sabotage. Figure $B-4$ is an adversary sequence diagram for the facility shown in Figure B-2. It is constructed of three parts: lines, triangles, and rectangles. Lines represent paths from one area to another through barriers (fences, doors, walls, etc.) and associated detection systems. Triangles are used as transfer symbols to simplify the diagrams. Paths flow from transferout symbols to transfer-in symbols as if there were lines between similarly numbered symbols. Rectangles represent areas. Areas may have internal divisions so that movement within them involves passage through barriers and detectors. In the case of target zones, rectangles also represent the location of operations that require control. When detailed design is required, the entire adversary sequence diagram can be constructed with lines representing individual barriers and their associated detectors, and rectangles representing simple areas with no internal fixed barriers. 


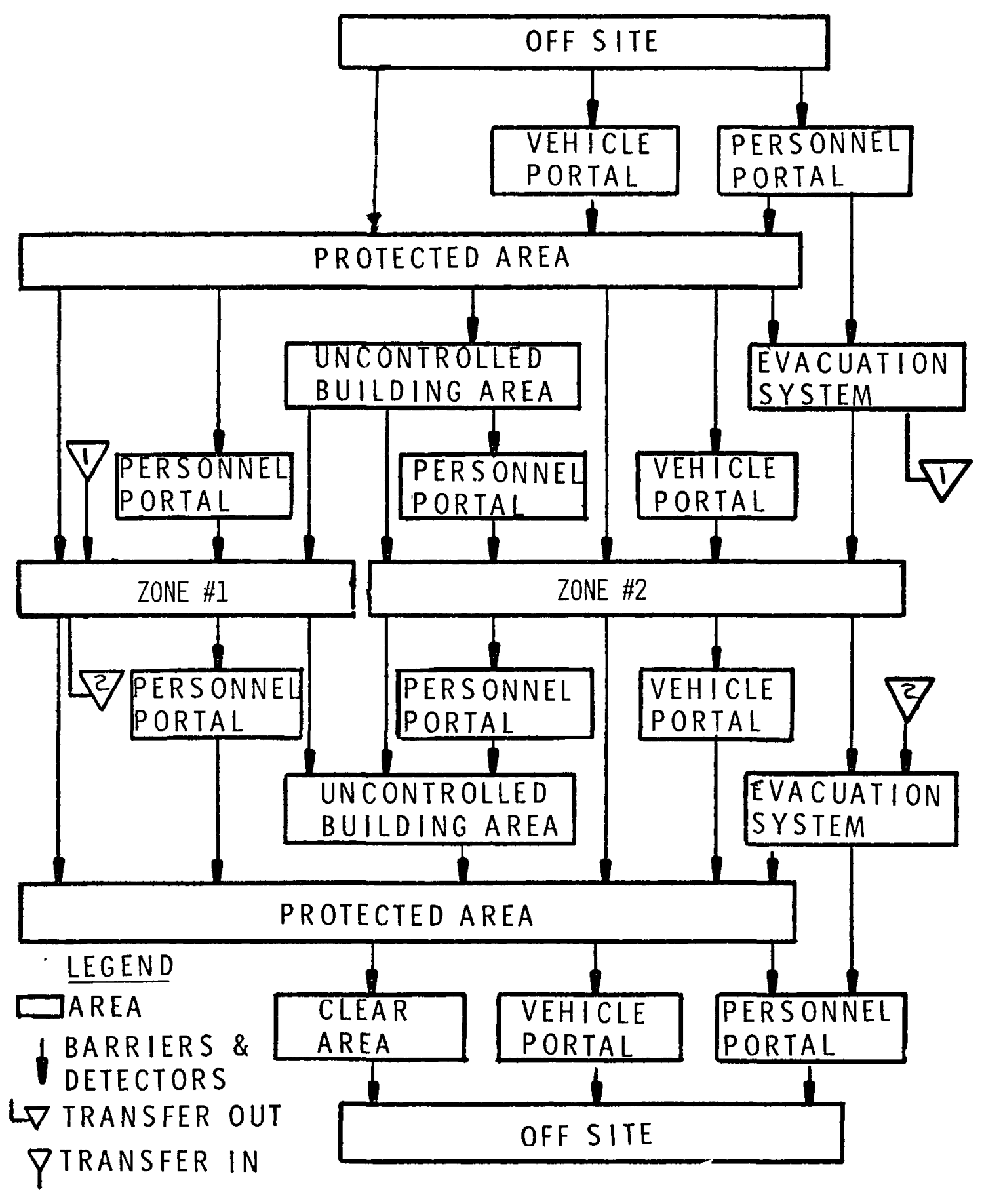

FIGURE B-4, ILLUSTRATIVE ADVERSARY SEQUENCE DIAGRAM B-19 
Fault trees are used to identify each method of system defeat and to facilitate estimation of detection probabilities and delay times. Figure $\mathrm{B}-5$ is a partial fault tree for the line on Figure B-4 representing the barrier between off-site and the protected area, showing several forms of forcible attack. In this particular fault tree, some details of the safeguards design have been developed. For example, the perimeter barrier is a double fence with an intervening detection zone. Fault trees would reflect the design detail of the particular phase in question. In the Preliminary Safeguards Concept Phase, only the top event might be considered. In the Preliminary ESS Design Phase, details of the detection system would be shown.

Fault trees similar to Figure B-5 are developed for each part of the adversary sequence diagram, and detection probabilities and delay times are estimated for each primary event. Where possible, estimates would be based on test data. From these values, detection and delay times for each part of the adversary sequence diagram can be found for each attack method or set of adversary attributes.

Critical Path Analysis

Detection probabilities and delay times for one path through the adversary sequence diagram are shown symbolically in the example of Figure B-6. It should be noted that specific values for these times and probabilities would be uniquely applicable to one adversary attack method. It is desirable at this point to investigate system vulnerability to several attack methods to establish a reasonable confidence that a system has 


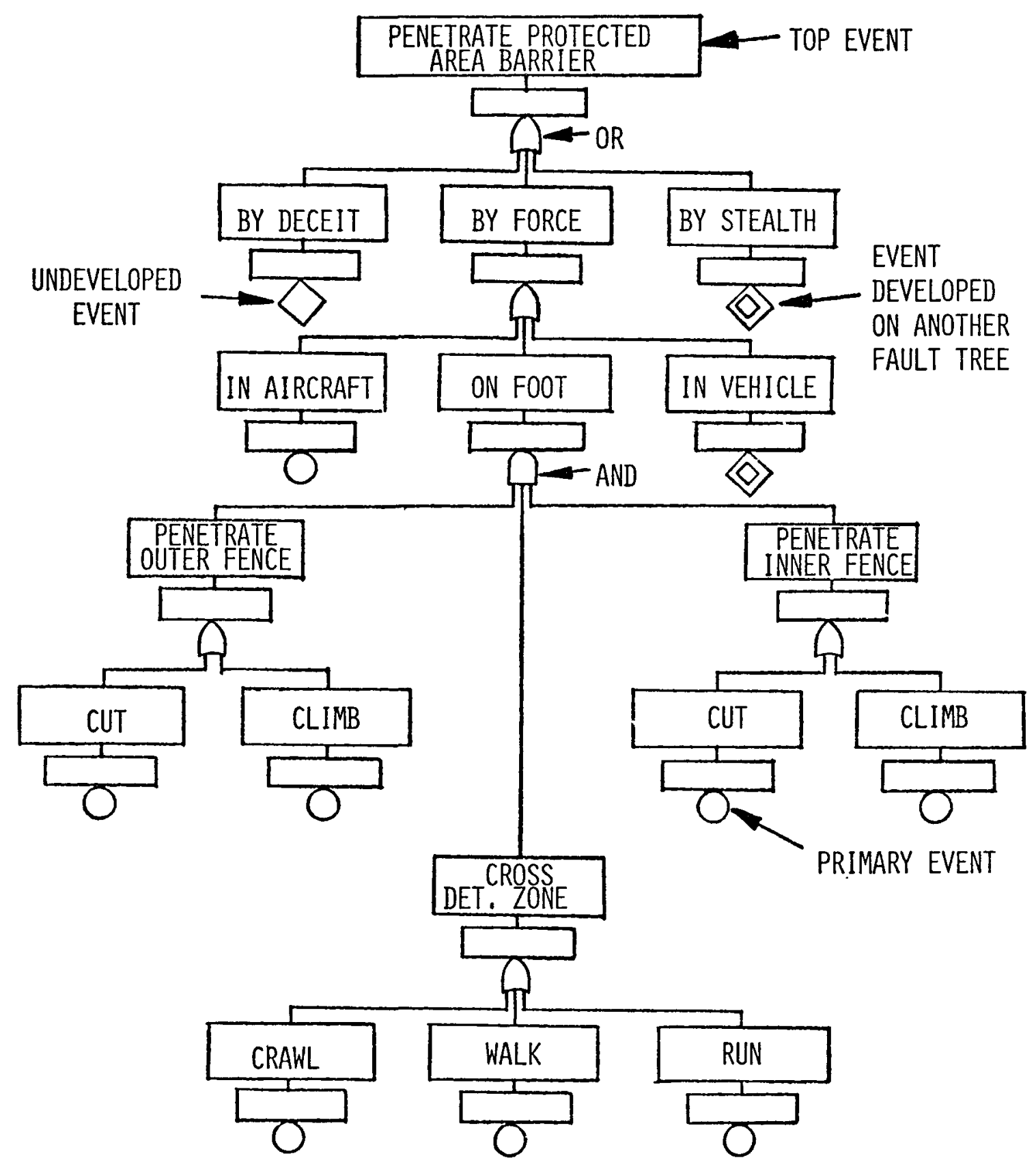

FIGURE B-5. SAMPLE FAULT TREE. 


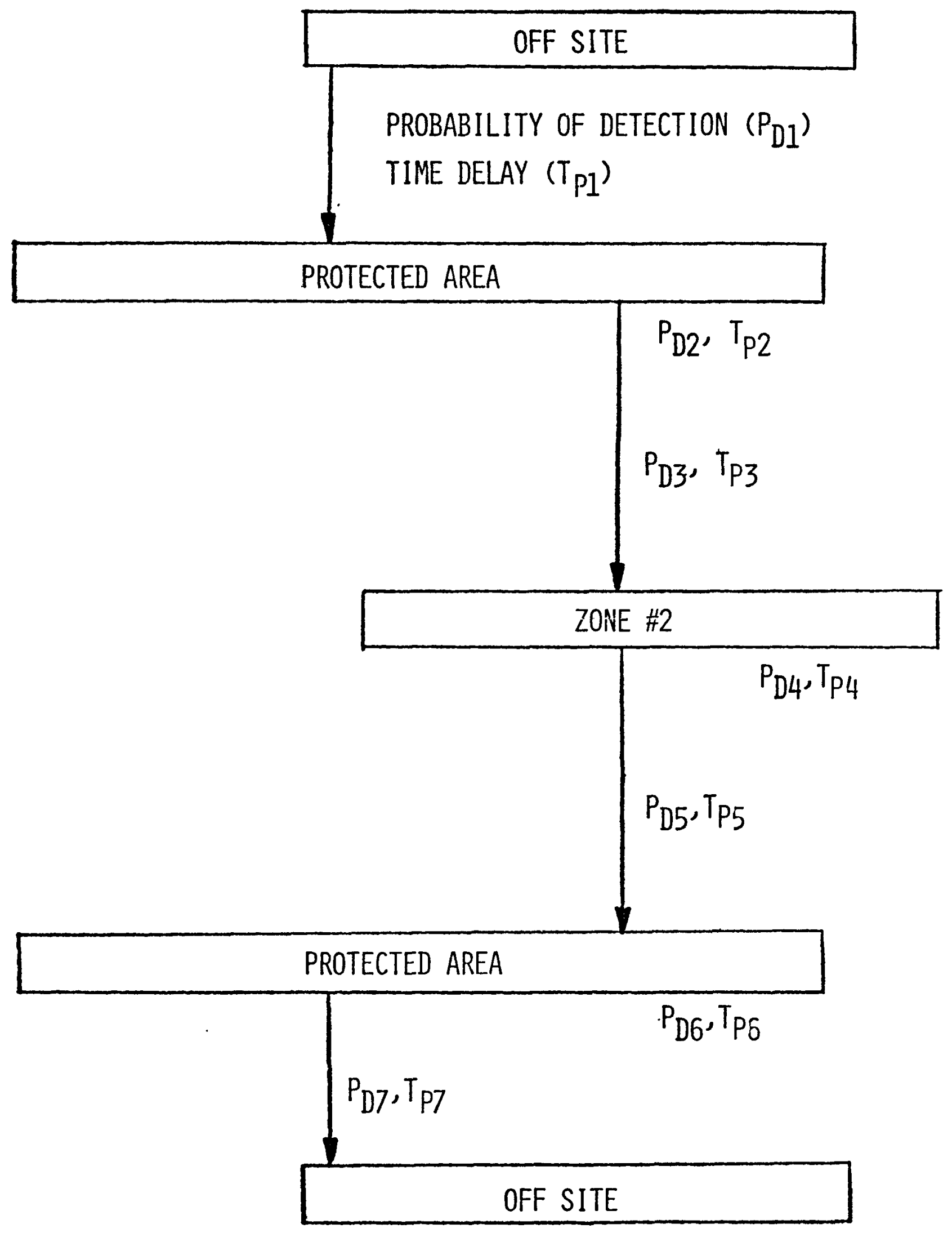

FIGURE B-6. ILLUSTRATIVF ADVFRSARY PATH 
been obtained with adequate values of delay time and detection probability for all paths for all credible threats. At a minimum, it is necessary to determine two attack methods, one requiring the least time and one having the lowest probability of being detected. Through the use of the Set Equation Transformation System (SETS) computer program, (Ref. 15,16) critical paths (those with adversary detection probabilities and delay times lower than specified values) can be determined.

The SETS program is used to determine critical paths for each concept or design. Figure $B-7$ illustrates that there are several discrete times during traversal of a path through the facility at which an adversary may be detected by emplaced devices. The earlier the adversary is detected, the greater is the time remaining for him to be intercepted before he completes the path. Also, the probability of detection increases as he proceeds along the path. Figure B-8 shows two paths with the time reference made equal to zero at path completion. A design goal is the adjustment of detection probability and delay time for each path so that the cumulative detection probability will reach an acceptable level (minimum $P_{D}$ (cum)) while the time for the adversary to complete the path is still in excess of some minimum value (minimum $T_{R}$ ) that is necessary for response force arrival. In Figure B-8, one path is acceptable, but the other path is unacceptable, since it does not meet the design goal.

Changes in the safeguards components and elements of each critical path are made to improve protection so that the design results in which no critical path remains, that is, all paths 


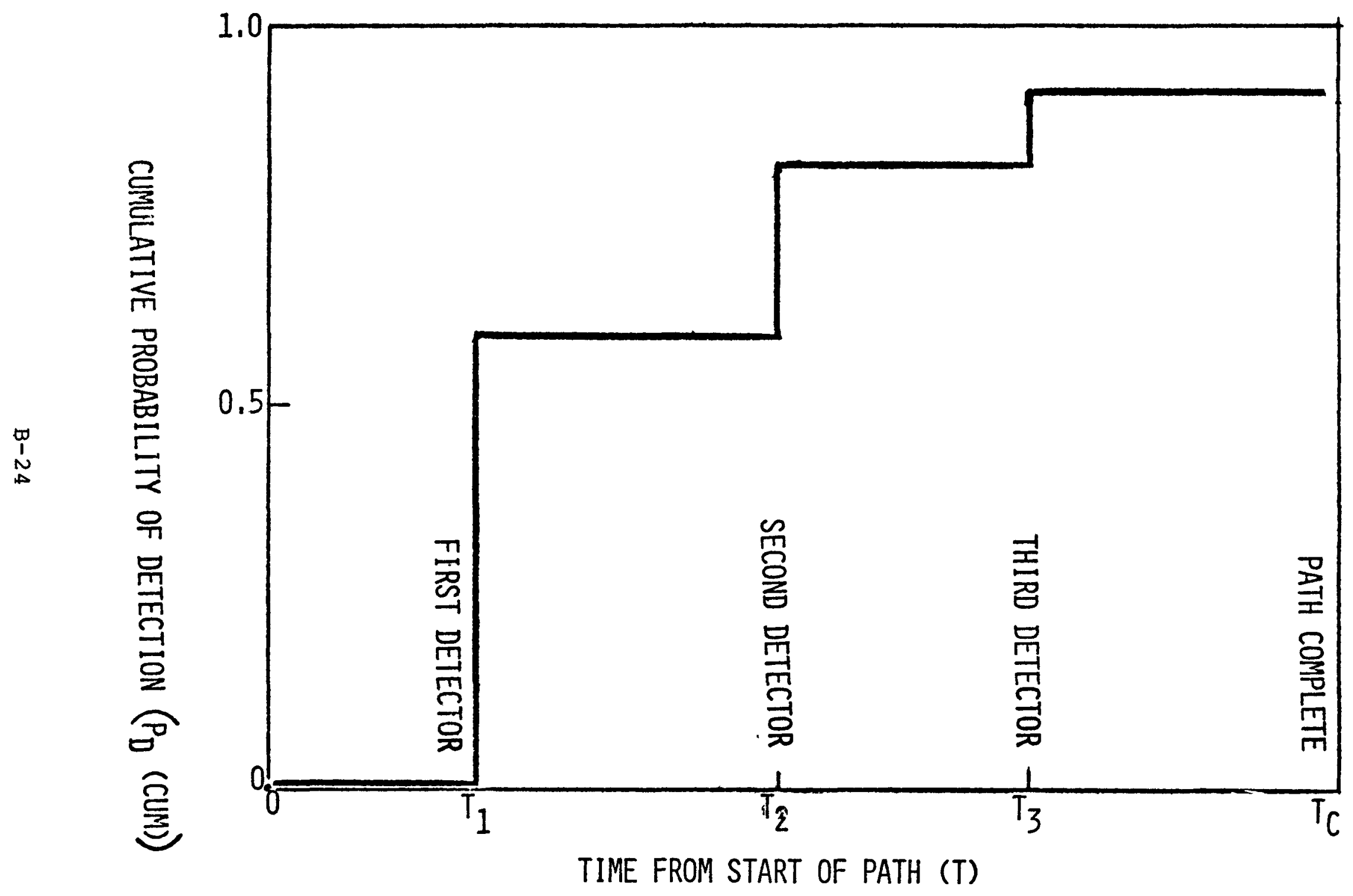

FIGURE B-T, DETECTION DISTRIBUTION FOR AN ADVERSARY PATH 


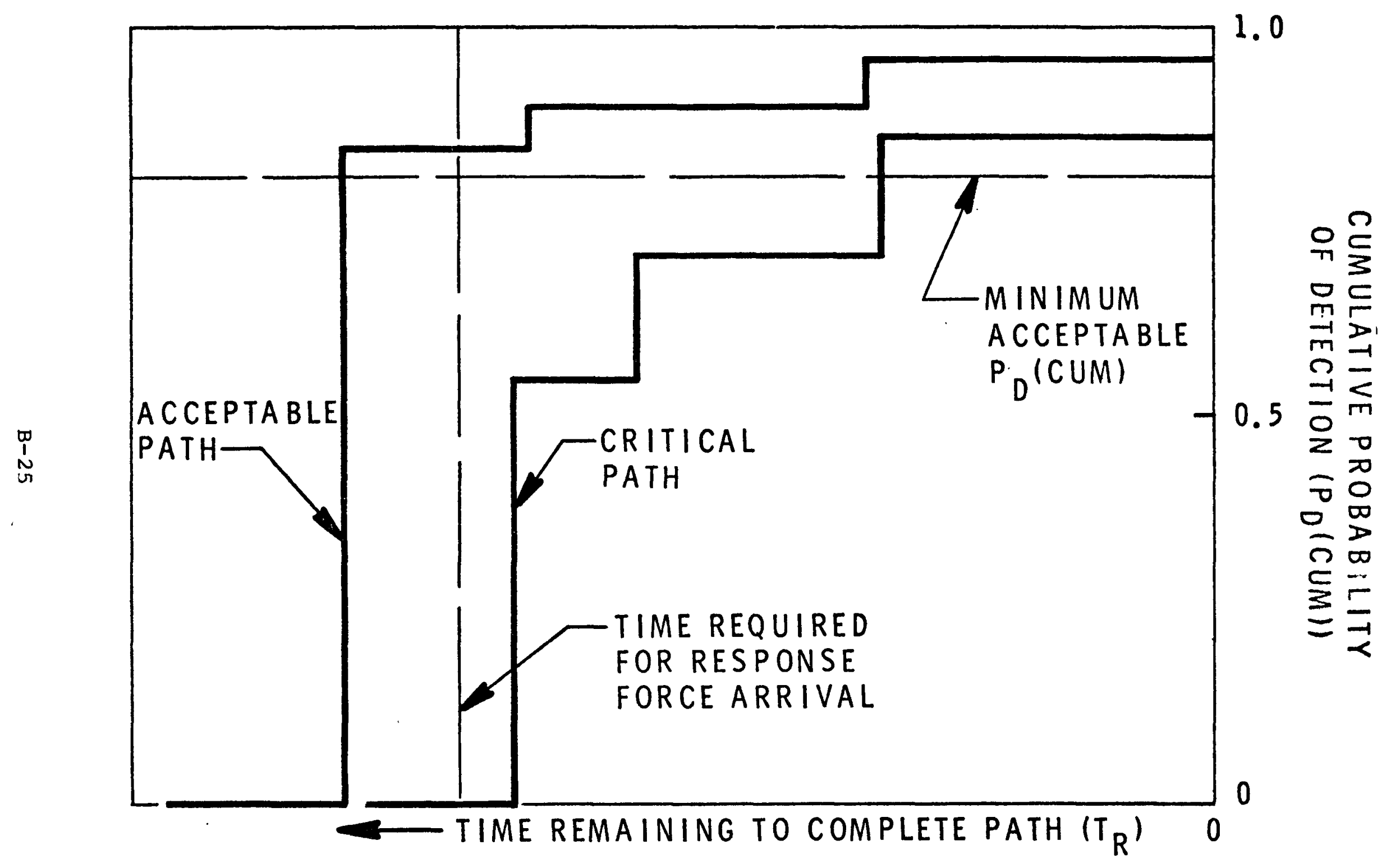

F.IGURE B-8, CRITICAL PATH EVALUATION 
will have an acceptably high probability of detecting initial adversary actions and will delay subsequent actions long enough to permit response force arrival. A few of the remaining paths are selected for the following effectiveness analysis. Cost and Effectiveness Analysis

The measure of system effectiveness used for evaluating concept and design options is the probability of adversary sequence interruption. Interruption requires a confrontation between adversary and response forces because an unchallenged adversary can eventually penetrate any barrier.

Two computer models are available to evaluate relative safeguards effectiveness. These are the Forcible Entry Safeguards Effectiveness Model (FESEM) (Ref. 17) and the Insider Safeguards Effectiveness Model (ISEM) (Ref. 18). Both FESEM and ISEM select probabilities of detection and delay times from predetermined statistical distributions. Then, by using a confrontation model (Ref. 19) that randomizes adversary and response interactions, they compute the probability of adversary success. The relative effectiveness of the response forces in defeating the postulated threats is evaluated by obtaining the results of numerous runs for each type of adversary attack. The measure of system effectiveness is the probability of adversary interruption given that an attack occurs. The complement of this value is generally plotted.

When effective systems have been identified, cost estimates can be made. Figure B-9 illustrates the types of effectiveness and cost information that can be used to compare various systems configurations. These curves are for a theft scenario and show 


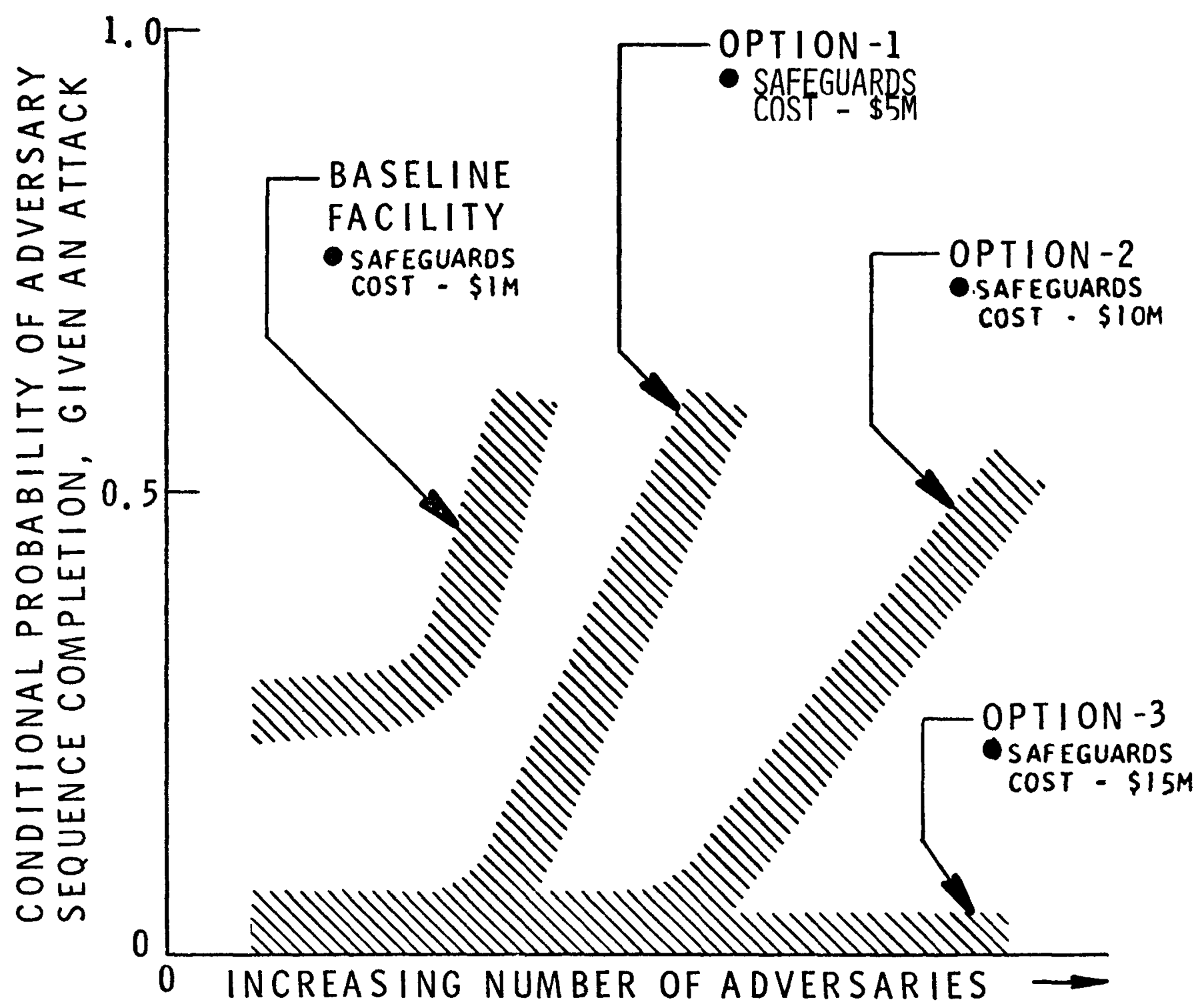

FIGURE B-9, EFFECTIVENESS ANALYSIS 
how effectiveness would vary with the number of adversaries attacking on foot. Other sets of curves would result for other scenarios and would show sensitivity to adversary trasnportation mode, level of plant access, and other attributes. Effectiveness analyses provide relative results. Absolute numbers are only as accurate as the input data and reflect the limitations of the model. However, the results can be used to make a decision to pursue a particular design based on available funds and relative performance. For example, if defense against large numbers of adversaries were required, it would be desirable to pursue option 3 in Figure B-9 at an estimated safeguards system cost of $\$ 14$ million. If defense against fewer adversaries were required, options 1 or 2 might be sufficient since they are less costly than option 3 .

\section{CONCEPT AND DESIGN DEFINITION}

Development programs, which will proceed through the conceptual and design phases, are being established for each type of nuclear fuel cycle facility. The tools and techniques discussed in the section on design activities will be used to produce outputs in each phase. These phases are in the process of being defined, but preliminary descriptions are given below. Preliminary Safeguards Concept Phase

Preliminary safeguards concepts would be generated to provide early, rough estimates of relative safeguards effectiveness for several protection options. 
The principal activities leading to preliminary safeguards concepts are:

- Description of a typical facility with identification of major plant systems and procedures;

- Determination of plant systems that must be protected;

- Initial theft and sabotage target analyses;

- Identification of safeguards concerns, both national and international;

- Identification of initial safeguards elements;

- Construction of an initial adversary sequence diagram, limited to general plant areas, and identification of critical paths; and

- Evaluation of resulting safeguards options. These activities provide initial facility site plans and layouts showing the location of major protection elements, initial performance requirements for these elements, initial response force requirements, and preliminary cost considerations. ESS Concept Definition Phase

Following completion of the Preliminary Safeguards concept Phase, activities are focused on a more detailed analysis. The objective of the ESS Concept Definition Phase is to define system options which provide protection against external, internal, and combined threats. These definitions provide a detailed base for facility design efforts and establish, in many cases, early direction for pursuit of development activities related to specific safeguards elements, principally closed-loop controls for plant operations. 
The principal activities leading to ESS concept definitions

are:

- Detailed description of the baseline facility;

- Detailed theft and sabotage target analysis;

- Definition of target zones, safeguard concerns, and safeguards elements;

- Construction of a general adversary sequence diagram for the entire facility, showing all material access and vital zones; and

- Evaluation of alternative safeguards options using critical path analysis and dynamic simulation models. These activities provide facility layouts showing the location of safeguards elements, performance requirements for the elements, response force requirements, and general cost estimates for selected options.

Preliminary ESS Design Phase

In this phase a set of preliminary designs that provide alternative levels of protection are defined. Each design includes element requirements for obtaining the specified level of protection. The principal objective of the preliminary ESS Design Phase is to provide sufficient detail of the safeguards system to enable selection of the most effective designs for consideration in the Coordinated ESS Design Phase.

The major activities leading to the preliminary ESS designs are:

- Identification of safeguards components, closed-loop control elements, and modules;

- Construction of detailed adversary sequence diagrams 
and fault-trees for closed-loop control elements;

- Comprehensive critical path and dynamic simulation analyses covering the range of adversary threats; and

- Analyses of all safeguards-related activities within each protection zone.

These activities provide facility layout drawings showing the location of safeguards components and elements, descriptions of the major safeguards modules, performance requirements for components and closed-loop control elements, response force requirements based on consideration of confrontation dynamics, and operational impact and cost estimates for each design. In general, the techniques used in this phase are quite similar to those used in the conceptual design phase, except that the analytical efforts are finely focused as additional safeguards details become available.

\section{Coordinated ESS Design Phase}

Liaison with appropriate industrial firms and government agencies is established in the conceptual phases and maintained throughout all design phases. Once preliminary ESS designs are completed, sufficient details become available to allow a comprehensive evaluation of operational factors. In conjunction with industrial firms and government agencies, the operational impact, costs, and general application factors related to each of the preliminary designs will be analyzed. As these analyses are performed, modifications to the preliminary designs may be necessary. Analytical methodology will again be utilized, as in the 
Preliminary ESS Design Phase, to evaluate system effectiveness of each design modification. This effort will enable the selection of an ESS design for a typical fuel cycle facility which will be pursued in the Representative ESS Design Phase.

\section{Representative ESS Design Phase}

Based on the particular design selected in the coordinated ESS Design Phase, detailed drawings, specifications, and procedures will be prepared for all parts of the system. To the extent required, confirmatory effectiveness analysis efforts will be pursued. Coordination with industry and government will be maintained throughout this phase. Representative designs will define an operationally compatible, cost-effective ESS for each type of nuclear fuel cycle facility. These designs will be in sufficient detail to evaluate practicality, determine development needs, and provide cost estimates for evaluation.

\section{B.1.3. Materials Measurement and Accounting System Design and Evaluation}

The materials measurement and accounting (MMA) system performs two safeguards functions:

- "Single theft" detection where material balance calculations are made on a near-real-time basis. This capability will be incorporated into the probability of detection $\left(P_{D}\right)$ values used in the physical protection system design discussed in B.1.2.

- "Long-term diversion" detection based on trends in the material balances. 
The minimum quantities of SNM that can be detected for a single-theft and for repeated long-term diversion attempts are calculated in each unit process area for a specified probability of detection and false alarm rate. An adequate detection probability of long-term diversion is related to the acceptable loss levels for SNM. If diversion of a cumuLative amount of SNM that is considerably less than the allowable loss level can be detected with a high probability, then timely action can be taken to discover the source of the diversion before the loss reaches the unacceptable level.

An adequate detection probability for the single-theft case must be determined by considering its relationship to other elements in the physical protection system, such as intrusion detectors, doorway monitors, etc.

In adaition, the MMAS can make important contributions to several non-safeguards functions if those requirements are integrated into the MMAS design sequence (for example, preparation of inventory reports, monitoring process streams for improved process control, warning of potential criticality, etc.).

The MMAS design sequence is analogous to that developed for the physical protection system. An essential difference is the need to incorporate whatever zon-safeguards requirements have been specified. This is most logically done as the first 
phase of step b (preliminary system design). As the system is varied in the subsequent evolution, the variations can be tested against the list of new safeguards requirements.

(a) Initial Process Definition

(i) Selection and review of baseline facility design and characterization of equipment, process and material flows

The result of this phase is a document that will serve as the principal data base for all plant-specific information during the subsequent phases. In addition, it provides a vehicle for management review of the assumptions being used by the safeguards design group. A suggested structure for this document is given as follows:

- Fuel Characterization

Isotopic Compositions and Ranges Radiation Fields Burnup Chemical Composition cladding

- Process Information

Flowsheets Material Balances Process Control Philosophy Operational Procedures

- Sampling Program

- Waste stream Characterization

- MBA/ICA structure

- Plant Management Structure

Hierarchy Information system 
- Structural Design

Equipment Placement

Shielding and Decoupling

Accessibility

Equipment Specifications

Holdup

Proximity and Placement

(ii) Establish management philosophy with input to key factors affecting MMA

A set of management decisions that must be made prior to development of the MMA system would include:

- Use of plant design information;

- Use of plant operation information (especially that accumulated by the MMAS);

- Definition of access areas and establishment of access authorization criteria;

- Commitment to a control philosophy (e.g., set point vs. automated control);

- Conditions for plant process interruption;

- Physical accessibility to plant process and material (e.g., contact vs. remote maintenance).

\section{(iii) Definition of Unit Process Accounting Modules}

An important element of the LASL program is the refinement of guidelines for the definition of unit process accounting modules (accounting envelopes containing one or more physical or chemical processes and/or an item storage area). While at this point the definition of these modules requires considerable judgment, a detailed description of how this process is carried out for a particular MOX fuel fabrication facility (Ref. 6 ) is available. The following are the principal

$$
\mathrm{B}-35
$$


factors used in that study to specify envelope boundaries:

- Smallest practical element of the process line

- Accessibility to measurement

- Accessibility to personnel

- Characteristics of material

- Characteristics of containment

It should be noted that circumstances may exist in which it is most efficient for the classical MBA to contain one and only one unit process accounting module.

In the subsequent analysis, each unit process is modeled separately. This permits a detailed description of process operations that are specific to each unit process. Because process variability, particularly in the levels of in-process holdup and material sidestreams, can have a significant effect on materials control, a very detailed baseline plant model is required for making quantitative estimates of MMA system sensitivity.

(iv) Simulate material flows in each unit process module

A model has been developed in which a schedule of material flow events is specified for each unit process. The model includes an initial event in which beginning inventories are set, a minimum of one type of process event, and a final event in which runouts and cleanups are performed. The process descriptions and the unit process event schedules are incorporated in a computer program called MOXSIM, described in

$$
B-36
$$


Reference 3, that simulates baseline plant operation one week at a time. In addition to timed events, it can schedule conditional events that arise during process operations; for example, stopping the flow of material when a tank has been filled.

The simulated process operation is defined in terms of true material flow data from each event. These data are saved for use by the measurement simulation computer program, MACSIM, which applies simulated measurements to flow data to produce measured material balance data.

(b) Preliminary System Design - Assume a practical and acceptable measurement system for each unit process module

A complete set of NDA and chemical instruments and methods are identified. The instrumentation needs for new safeguards functions should be included here. Uncertainty (error) distributions should be specified for each (the inclusion of anticipated performance specifications for future devices requires considerable judgment).

\section{(c) Determination of optimum system design}

The evaluation of a proposed measurement system is essentially a benefit-cost analysis where the benefits are assessed relative to the capability of the system to fulfill the design criteria:

- Regulations (existing and expected)

- Relationship of detection and false alarm levels

$$
\text { B-37 }
$$


- Feasibility

- Secondary (new safeguards) benefits

- Minimum facility, process, procedural changes

The initial measurement system is varied and reevaluated until a satisfactory solution is achieved. (It should be noted that no tests currently exist to distinguish between absolute and relative extrema.)

The principal tool for performing this evaluation is computer code MACSIM (Material Accounting and Control Simulation). This code simulates measurement of the true material flow data generated in MOXSIM described in Reference 3, and computes material balances and cumulative summations of material balances (cusums) appropriate to each of the unit processes considered.

Each material balance computed in MACSIM is a linear combination of measured quantities of plutonium. The uncertainty in the computer value of the material balance is produced by the combined effects of uncertainties in the contributing measured values. In MACSIM, the measurement results are assumed to be independent, and the variance associated with each material balance is the sum of the variances of the terms in the material balance equation.

A cusum is computed by MACSIM after each material balance period. It is the sum of all material balances for the unit 
process since the beginning of the accounting period. The cusum variance is a complex combination of the variances of individual material balances, as these balances usually are not independent. In most unit processes, there are one or more variables for which a single measurement value appears as output in one material balance period (i.e., this value has a negative sign in the material balance equation) and as input in the next. For example, this can be the result of accumulating material in a tank or scrap container and measuring the contents during each balance period. In such cases, only the first and last measurements of the container contents appear in the cusum, and only the corresponding variances appear in the cusum variances.

The code is sufficiently versatile to permit independent investigation of materials control sensitivity as a function of process variability, measurement variability and instrument configuration. Fixed sets of measurements are applied to different sets of material flow data, and a variety of measurement strategies applied to fixed sets of flow data. Design choices are based on the dual criteria of satisfactory sensitivity to both single theft and long-term diversion and minimal perturbation of anticipated process operation.

Sensitivity of the MMAS is determined quantitatively from relationships between parameters in the diversion detection algorithms and the dynamic material balance data. Algorithms 
for the detection of both short-term and long-term diversion of materials are discussed in Reference 3.

Short-term diversion refers to the sinqle theft of a relatively large amount of material. The sensitivity of the MMAS to short-term diversion depends on the measurement uncertainty (standard deviation, $\sigma$ ) associated with individual material balances. If unmeasured holdup or material sidestreams significantly affect the individual balances, that is, if an average positive bias on the order of $l \sigma$ is introduced by not making the measurements, the material probably should be measured and included in each dynamic balance.

Long-term diversion refers to repeated thefts of amounts of nuclear material, each too small to be detected in a single material balance because of measurement uncertainties. Repeated small thefts of SNM are indicated by the trend (positive slope they induce in the cumulative sum (cusum) chart of material balances). Detection of trends due to small sidestreams of material introduce similar trends in the cusum data. Analysis of trends is complicated by correlations between the cusum data and the variability of measurement errors in a sequence of material balances.

A technique for detecting trends is the cusum chart and V-mask method of control that is discussed in References 3 and 20 . By this approach, levels of sensitivity are set for small theft detection based on cusum uncertainties. 
The sensitivities to small-scale diversions are not necessarily indicative of the amount of SNM that a single person might steal. These sensitivities are detectability limits for average amounts of missing material per material balance period. For a single divertor to steal SNM at a rate equal to the average detectable amount, each theft would be a factor of three or four larger, with a corresponding increase in probability of detection.

(d) Develop detailed procurement specifications - Refine component and. system design parameters

Once the theoretical "optimum" system has been selected, a host of practical problems remain ranging from selection of isolation for data links to integration with the item operations control system. In principle, all of the analytic effort has been completed since all essential parameters were input to the benefit cost evaluation. Determination of significant unresolved areas would serve as an indication of serious deficiencies in Phase 4 . 
This section provides a brief overview of the activities employed in all phases of safeguards system design. It should be emphasized that the techniques used are not perfected but are evolving. Further, few details have been covered. However, the material included here, supplemented by information contained in the references, should acquaint the reader with the progress that has been made in developing a systematic method for designing physical protection systems and integrating them with material measurement and accounting systems.

Experience in applying these design techniques indicates that there is much to be gained by integrating safeguards features into plant designs as early as possible. In many cases, modifications to the plant can improve protection without increasing costs significantly. Adding safeguards elements to a plant designed without considering safeguards not only may be more costly, but adequate protection may not be possible. Therefore, it is strongly recommended that safeguards design be coordinated with new plant design as soon as the techniques are made available. 
1. Winblad, A. E., et al., Development of an Engineered Safeguards System Concept for a Mixed-Oxide Fuel Fabrication Facility, SAND76-0180, Sandia Laboratories, August 1976.

2. Winblad, A. E., et al., A Concept and Preliminary Definition of an Engineered Safeguards System for a Mixed-Oxide Fuel Fabrication Facility (U), SAND76-0528, Sandia Laboratories, September 1976, Confidential.

3. Shipley, J. P., et al., Coordinated Safeguards for Materials Management in a Mixed-oxide Fuel Facility, LA-6536, Los Alamos Scientific Laboratory, February 1977.

4. A Preliminary Assessment of Terrorist Threat to Nuclear Programs, Historical Evaluation and Research Organization (HERO), September 1975.

5. Estimate of Security Personnel Required to Protect Nuclear Fuel Cycle Components Against Theft of Special Nuclear Material and Sabotage, International Research and Technology Corporation (IR\&T), July 1975.

6. Burnham, S., et al., The Threat to Licensed Nuclear Facilities, The MITRE Corporation, September 1975.

7. Analysis of the Terrorist Threat to the Commercial Nuclear Industry, The BDM Corporation, September 1975.

8. Jenkins, Brian M., An Approách to the Study of Potential Threats to Nuclear Programs, Rand, WN-9366-SL, January 1976.

9. Johnson, Janera, et al., Sophisticated Crimes as Analogs to Potential Threats to the Nuclear Industry: $\underline{A}$ Preliminary Assessment, Rand, WN(L)-9367-SL, January 1976.

10. Strauch, Ralph, Symbolic Bombing as an Analog Threat to the Nuclear Industry (A Preliminary Assessment), Rand, WN (L) 9482-SL, JulY 1976. 
11. Wainstein, Eleanor S., Threats and Incidents Involving

Nuclear Material or Facilities, Rand, WN-9368-2-SL, September 1976 .

12. Keller, K. K. and Krofcheck, J., Nuclear Hoaxes, Preliminary Analysis, Rand, WN(L)-9420-1-SL, October 1976.

13. Safety and Security of Nuclear Power Reactors to Acts of Sabotage

Part I - Case Study of a Typical PWR Plant, SAND74-0069, Sandia Laboratories, March 1975, Secret

Part II - Case Study of a Typical BWR Plant, SAND75-0336, Sandia Laboratories, October 1975, Secret

Part II - Current U.S. LWR Plants, SAND76-0108, Sandia Laboratories, July 1976 (draft)

secret

Summary,

SAND75-0504, Sandia Laboratories, March 1976, Unclassified

14. Hickman, J. W. , Fault Tree Analysis in Nuclear Safety Assurance, SLA-73-0150, Sandia Laboratories, March 1973, specified distribution only.

15. Worre11, R. B., Using the Set Equation Transformation System in Fault Tree Analysis, SAND74-0240, Sandia Laboratories, September 1974.

16. Worrell, R. B., Instructions for Using the SETS Program, SLA-73-0908A, Sandia Laboratories, October 1974.

17. Chapman, L. D., A Model for isvaluating Alternative Fixed-Site Security Systems (U), SAND 75-0512, Sandia Laboratories, April 1976, Confidential. 
18. Boozer, D. D., and D. Engi, Simulation of Personnel Control Systems Using the Insider Safeguards Effectiveness Model (ISEM) (U), SAND76-0682, Sandia Laboratories, January 1977.

19. Bennett, H. A., A Security Force-Adversary Engagement Simulation, SAND75-0658, Sandia Laboratories, April 1976.

20. Cobb, D. D., D. B. Smith, and J.P. Shipley, "Cumulative Sum Charts in Safeguarding Special Nuclear Materials," submitted Technometrics 1976 . 


\section{B.2. Design Support}

The DOE safeguards design sequence requires effective

technical design support in three critical areas:

- Evaluation Techniques and Models. The models are used in the design sequence for estimating the relative effectiveness of alternative safeguards designs. These are being developed for both physical protection and material measurement and accounting systems. The techniques employ several different modeling concepts which vary considerably in their complexity. Some can be performed manually; however, most require extensive computer codes. The current state of the art does not include a single comprehensive algorithm to be used for all systems against all threats. System design planning requires a judicious selection of a mix of the models (Section B.2.1).

- Physical Protection Equipment Evaluation and Design Requirements. The design sequence and application of evaluation techniques and models can generate a set of system requirements that equipment used in actual safeguards systems must meet. This process is being exercised in the development of representative safeguards systems, and sets of preliminary design requirements are being identified. Equipment developed in both the private and public sector are tested relative to these design requirements (Section B. 2.2).

- Control, Coordination, and Communication Subsystems. Procedures and supporting hardware are being developed in the DOE program. These are discussed in sections B. 1, B. 3, B. 4, and B. 5 as appropriate.

B.2.1. Evaluation Techniques and Models.

The principal models used in the system design sequence developed by Sandia are:

- Adversary Sequence Diagram. This is an initial routine which structures routes of ingress and egress, identifies critical points, suggests placement of an initial set of safeguards devices, and enables preliminary evaluation of system effectiveness 
- Set Equation Transformation System (SETS). Fault tree analysis and event tree analysis are being used extensively for various safeguards studies. The Set Equation Transformation System is desighed to achieve a comprehensive and flexible capability to manipulate Boolean equations required by these analyses. Although such a capability is of general use, fault tree analysis was the methodology that provided the impetus for the development of SETS. Improvements being developed will allow calculation of the probability of success of a particular adversary attack. To this end, additional capabilities to be added to SETS are (1) the ability to both order and record event occurrences, and (2) a direct method in the code to calculate the probability of the various outcomes of selected scenarios.

- Safeguards Effectiveness Models. The Forcible Entry Safeguards Effectiveness Model (FESEM) has been continually modified since its development during the summer of 1975. During the safeguards design study for the Mixed Oxide Fuel Fabrication Facility (MOFFF), several worthwhile modifications were identified. These modifications, and others that develop with the growing number of applications, will be accomplished under this task.

The Insider Safeguards Effectiveness Model (ISEM) has been under development since February 1976. Although ISEM has been used to evaluate the MOFFF safeguards system, it has not been used by the MOFFF system designers themselves. It is anticipated that a number of useful ISEM modifications will be identified as the MOFFF and other safeguards system designers will utilize the program extensively. These modifications will also make ISEM easier to use. Data input and output from a graphics terminal will be evaluated and implemented if found to be feasible. It is anticipated that this activity will also have applications in the area of inspection model development.

Validation of both models will continue by conducting adversary simulation tests and by further study in areas such as force engagement. These activities should be completed by the end of 1977 .

The potential application of several other evaluation techniques and models is presented in the B.2.1 summary table and described in the data sheets which follow. 
B.2.1 Evaluation Techniques and Models

\begin{tabular}{|c|c|c|c|c|c|c|c|c|c|}
\hline \multirow[b]{2}{*}{ TECHNOLOGY } & \multicolumn{9}{|c|}{ FACILITY APPLICATION } \\
\hline & $\begin{array}{l}\text { Enrich- } \\
\text { ment }\end{array}$ & LWRs & FBRs & $\begin{array}{l}\text { Spent } \\
\text { Fuel } \\
\text { Storage }\end{array}$ & $\begin{array}{c}\text { Chemical } \\
\text { Repro. }\end{array}$ & $\begin{array}{l}\text { Mixed } \\
\text { Ox. Fuel } \\
\text { Fabrica. }\end{array}$ & $\begin{array}{c}\mathrm{PuO}_{2} \\
\text { Convers. }\end{array}$ & $\begin{array}{l}\mathrm{Pu} \\
\text { Storage }\end{array}$ & $\begin{array}{c}\text { Waste } \\
\text { Disposal }\end{array}$ \\
\hline FESEM & $x$ & $\mathrm{x}$ & $\mathrm{x}$ & $\mathrm{x}$ & $\mathrm{x}$ & $x$ & $\mathrm{x}$ & $\mathrm{x}$ & $x$ \\
\hline ISEM & $\mathrm{x}$ & $\mathrm{x}$ & $\mathrm{x}$ & $\mathrm{x}$ & $\mathrm{x}$ & $\mathrm{x}$ & $\mathrm{x}$ & $\mathrm{x}$ & $\mathrm{x}$ \\
\hline MACSIM & $\mathrm{x}$ & & & & $\mathrm{x}$ & $\mathrm{x}$ & $\mathrm{x}$ & & \\
\hline MOXSIM & & & & & & $x$ & & & \\
\hline $\begin{array}{l}\text { Diversion Path } \\
\text { Analysis }\end{array}$ & $\mathrm{x}$ & $\mathrm{x}$ & $\mathrm{x}$ & $\mathrm{x}$ & $\mathrm{x}$ & $\mathrm{x}$ & $\mathrm{x}$ & $\mathrm{x}$ & $\mathrm{x}$ \\
\hline MUFMOD & & & & & $\mathrm{x}$ & $\mathrm{x}$ & $\mathrm{x}$ & & \\
\hline PROTMOD* & $\mathrm{x}$ & $\mathrm{x}$ & $\mathrm{x}$ & $\mathrm{x}$ & $\mathrm{x}$ & $\mathrm{x}$ & $\mathrm{x}$ & $\mathrm{x}$ & $\mathrm{x}$ \\
\hline
\end{tabular}

* Model currently includes

theft language--could be

modified for sabotage. 
1. Model - FESEM : Forcible Entry Safeguards Effectiveness Model

2. Developer - Sandia Laboratories, Leon D. Chapman, systems Analysis Division (505-264-9158)

3. Status/Estimated Availability - The code has evolved through several iterations and is complete. It has been used in safeguards analysis for several DOE facilities, a few mixed facilities, and has been used to produce and evaluate upgrade plans for existing DOE facilities and for conceptual designs such as the mixed oxide fuel fabrication facility. Procedures for making the code available to other users will be defined by the Nuclear Regulatory Commission. A user's manual for the latest version of the code is now being written and will be available after acceptance by the NRC.

4. Estimated Unit Cost - Undetermined

5. Principles of Measurement - The computer model provides a Monte Carlo simulation of a fixed site safeguard security system considering the inter-relationships of barriers, alarms, on-site and off-site response forces, alarm assessment and communication against a forcible adversary attack whose intention is to create an act of sabotage or theft. The purpose of the model is to provide a framework for performing inexpensive experiments on fixed site security systems for testing alternative decisions and to determine the relative effectiveness associated with these decision policies. The output consists of summaries and detailed histograms describing the response of the safeguards system to the defined level of adversary threat.

6. Design and Operation

(a) FESEM is a FORTRAN Code consisting of approximately 2250 cards including many comments. It requires the GASP IV Simulation library which provides executive and program control functions.

(b) The user must provide data appropriate for a specific adversary path of attack. All input is from data cards which define the site, barrier, response force and adversary attributes for the path chosen. 
(c) The code currently runs in a batch made on the CDC 6600 computer and requires about 100,000 octal words memory. Five minutes of CPU time is usually adequate to perform one thousand trials upon the safeguards system.

7. Operating History - The simulation code has evolved over the past two years to include additional simulation capability to encompass the variety of security systems observed at existing facilities as well as to provide a framework to study new concepts.

8. References - "Fixed-Site Physical Protection System Modeling," L. D. Chapman, Sandia Laboratories, SAND75-6061.

"Effectiveness Evaluation of Alternative Fixed-Site Safeguards Security Systems" L.D. Chapman, Sandia Laboratories, SAND75-6159. 
1. Model - ISEM: Insider Safeguards Effectiveness Model

2. Developer - Sandia Laboratories; Drayton D. Boozer, Safeguards Evaluation Division (505-264-6926) and Dennis Engi, Systems Analysis Division I (505-264-4831)

3. Status/Estimated Availability - The computer code is complete and verified. Available after January 1, 1978 .

4. Estimated Unit Cost - Undetermined

5. Principle of Measurement - ISEM is used to simulate, via Monte Carlo techniques, the temporal interaction among adversary (usually authorized facility personnel) and safeguards system events along a specified adversary path within a nuclear facility. The safeguards system events - detection, assessment, communications, response, and neutralization are modeled for the general adversary strategy which includes degradation of safeguards system elements followed by an attempt by one adversary to steal or disperse radiological material. ISEM generates a set of summary statistics and histograms for use by safeguards system analysts. The most often used performance measure is the estimated probability of adversary success given a specified set of adversary actions.

6. Design and operation - ISEM requires an initial specification of facility and safeguards system data. Once these data are available, only adversary path specific parameters are modified to simulate any adversary path. ISEM exists in both batch and time-sharing versions for the CDC6600 computer. The GASP-IV simulation packagel (ANSI Fortran) is required. The batch version requires minimal changes to conform to ANSI standard Fortran; however, the time sharing version is specific to the CDC NOS time sharing system. The transfer of the time sharing version to other computer manufacturer's time sharing systems would not be trivial.

7. Operating History - ISEM has been used in the analysis of the safeguards system of a mixed oxide fuel fabrication facility, several ERDA facilities, and a research reactor.

8. References - 1) Pritsker, A. A. B, The GASP IV Simulation Language,"Wiley 1974. 2) SAND76-0682 "Simulation of Personnel Control Systems with the Insider Safeguards Effectiveness Model (ISEM) "April 1977 3) SAND77-0043 "Insider Safeguards Effectiveness Model - ISEM- Sandia User's Guide" To be published. 4) SAND77-0075C "Nuclear Facility Safeguards System Modeling Using Discrete Event Simulation" April 1977. 5) SAND77-0410C "The Use of ISEM In Studying the Impact of Guard Tactics on Facility Safeguards system Effectiveness, July 1977. 
1. Model - MACSIM: Measurement, Accountability and Control Simulator.

2. Developer - Los Alamos Scientific Laboratory, Darryl B. Smith, Integrated Safeguards systems and Technology Transfer Group. (505-667-6141).

3. Status/Estimated Availability - The computer code is complete and has been applied to the conceptual design of a material measurement and accounting system in a mixed-oxide fuel fabrication facility (see Reference). The code is in ANSI standard FORTRAN. Procedures for making the code available to other users have not been specified; however, output data have been supplied to other DOE contractors with DOE/SS approval.

4. Estimated Unit Cost - Undetermined.

5. Principle of Measurement - Model takes as input facilityspecific flow data (see MOXSIM) and measurement variances. A Monte Carlo simulation of measurements is performed, with statistical propagation of measurement variances and computation of simulated material balances and cusum along with their associated uncertainties.

6. Design and Operation - The model consists of approximately 500 lines of ANSI Standard FORTRAN coding. All data are facility-specific structure of the measurement and accountability strategy is supplied as a subprogram. The code is designed to run in batch mode on a CDC 6600.

7. Operating History - The model has been used in the design and evaluation of the measurement system in a mixed-oxide fuel fabrication facility.

8. Reference - "Courdinated Safeguards for Materials Management in a Mixed-oxide Fuel Facility," J. P. Shipley et al." Los Alamos Scientific Laboratory Report LA-6536 (1977). 
1. Model - MOXSIM: Mixed-Oxide Fuel Fabrication Simulator.

2. Developer - Los Alamos Scientific Laboratory, Donald D. Cobb, Integrated Safeguards Systems and Technology Transfer Group. (505-667-6141).

3. Status/Estimated Availability - The code is complete. It has been debugged and used in safeguards systems design studies at LASL. The output data have been comparea with estimates made by westinghouse for the Recycle Fuel Plant, which is the baseline model facility incorporated in the code. Procedures for making the code available to other users have not been specified. However, output data have been supplied to other DOE contractors with DOE/SS approval.

4. Estimated Unit Cost - Undetermined.

5. Principles of Measurement - The computer code provides a Monte Carlo simulation of the mixed-oxide fuel fabrication process based on the westinghouse Recycle Fuel Plant design. The output consists of true material flow and inventory quantities which serve as input to a materials measurement and accounting simulator (see MACSIM).

6. Designs and Operation

(a) MOXSIM is a FORTRAN code consisting of 2000 cards. It requires the availability of the GASP IV Simulation Package which provides the executive and control functions.

(b) At present, the MOX process is divided into 11 unit processes. The unit process subprograms are facility-specific, and require $\sim 1200$ cards. Each output data set contains about 15,000 decimal numbers representing one week of process operation.

(c) The code currently is set up to run in batch mode on a CDC 6600 computer. It requires $\sim 150,000$ octal storage locations including the GASP IV and plotting packages. About 50 seconds of $\mathrm{CP}$ time is required per week of simulated time.

7. Operating History - About 6 months of simulated process operation used in the conceptual design of a materials measurement and accounting system for a MOX facility.

8. Reference - "Coordinated Safeguards for Materials Management in a Mixed-Oxide Fuel Facility," J. P. Shipley et al., Los Alamos Scientific Laboratory Report LA-6536 (1977). 
1. Evaluation Methodology - Diversion Path Analysis (DPA).

2. Developer - National Bureau of Standards, J. C. Schleter (301-921-2551).

3. Status/Estimated Availability - Methodology has been field tested and is available for commercial application.

4. Estimated Unit Cost - Depends on size of facility to be analyzed and skill of analyst. (For average size facility, estimated to be about \$150R.)

5. Principle and Application - DPA is a methodology for systematically analyzing existing or proposed internal controls of a facility in order to identify potential vulnerabilities to successful diversion of SNM by an adversary.

6. Description - The facility is divided, for purposes of analysis, into unit processes. The diversion paths, or modi operandi, that might be used for removing SNM from a unit process and concealing the fact of removal are identified. Analysis includes consideration, from the adversary viewpoint, of potential attractiveness of material in the area under scrutiny and complexity of possible diversion paths. Complexity parameters include records alteration and falsification, multiple removals of sub-threshold quantities, substitution, collusion and type of individual. Indicators, or data elements and information of significance to detection of unprevented theft, are identified by means of DPA. Indicator sensitivity is developed in terms of mass, time and space, i.e., the threshold quantity of material necessary for indication, the elapsed time between removal and indication, and the degree of localization of facility area and personnel given by the indicator. Evaluation of facility internal controls in light of these sensitivities defines capability of interrupting identified adversary action sequences related to acquisition of material at fixed sites associated with the identified potential vulnerabilities. Corrective measures can, in many cases, also be prescribed for management consideration and action.

7. Operating History - Initial field testing proved both the feasibility and practicality of the methodology. Follow-on implementation testing verified the ability of facility personnel to perform DPA, provided insight into techniques for transferring the methodology to the field, and led to finalization of a Handbook detailing implementation procedures $[1,2]$.

8. References - [1] M.D.K. Maltese, K.E. Goodwin and J.C. Schleter, Diversion Path Analys is Handbook, Volume I (Methodology), Division of Safeguards and Security, ERDA, october 1976.

[2] K.E. Goodwin, M.D.K. Maltese and J.C. Schleter, Diversion Path Analysis Handbook, Volume II (Example), Division of Safeguards and Security, ERDA, October 1976. 
1. Model - MUFMOD - Nuclear Material Flow and Measurement Model

2. Developers - Alan M. Bieber, Jr. and Sylvester Suda, Technical Support Organization, Brookhaven National Laboratory

3. Status/Estimated Availability - The computer code is complete and has undergone preliminary debugging and testing. The results of the first field test suggested certain modifications which are being incorporated in the model at this time. The code is in ANSI standard FORTRAN. The model could not be made available without prior DOE/SS approval.

4. Estimated Unit Cost - Not known.

5. Principle of Measurement - Model takes as input facilityspecific data on inventory and average flow rates and variances. A Monte Carlo simulation of flows and measurement is performed, with statistical propagation of measurement errors and calculation of simulated material balances. See reference 1.

6. Design and Operation - Model consists of approximately 650 lines of ANSI standard FORTRAN code. All data are facilityspecific and are supplied as input to the program. The code is designed for interactive execution via a remote time-sharing terminal, but may also be run in batch mode.

7. Operating History - One field test at a DOE facility. Report on results is classified, but the test revealed some faults in the model which are now being corrected.

8. References - (1) "MUFMOD - A code for Simulation of Nuclear Material Flow and Measurement," Alan M.Bieber, Jr., TSO/BNL, April 1, 1976. 
1. Model - PROTMOD - A Computer Model of Overt Attacks on Nuclear Facilities

2. Developers - Joseph P. Indusi, William Marcuse, and Alan M. Bieber, Jr. Technical Support Organization, Brookhaven National Laboratory.

3. Status/Estimated Availability - Computer code is complete, debugged, and field tested. Barrier penetration data files are complete. Neither the code nor the data files can be made available without prior DOE/SS approval. If released, the model could be run on virtually any computer capable of compiling ANSI standard FORTRAN IV.

4. Estimated Unit Cost - Not known.

5. Principle of Measurement - Comparison of facility response times with attacker barrier penetration times. See reference 2 .

6. Designs and Operation -

a. Model consists of 1200 line ANSI standard FORTRAN code. Code is designed for interactive execution via a remote time-sharing terminal, but may also be run in batch mode.

b. Barrier penetration data were compiled from unclassified sources and are stored in one data file external to the program. Data are in the form of card images, and may be stored and used on disk or tape.

7. Operating History - Model has been applied at all major DOE facilities and two mixed DOE/NRC facilities. Reports on results are classified, but this experience has allowed complete debugging and field testing.

8. References - (1) "TSO Physical Protection Simulation Model," no date, TSO file \#5.8.3

(2) "PROTMOD - A Computer Model for Evaluating Physical Protection of Special Nuclear Material," no date, TSO file \#5.8.3

(3) "Simulating Physical Protection Against Overt Attacks at Facilities Using, Processing, or Storing Nuclear Materials," William Marcuse and Joseph P. Indusi, Journal of the Institute of Nuclear Materials Management IV (3):233-245, fall 1975. 
B.2.2. Physical Protection Equipment Evaluation

The representative ESS designs are based on a strategy of detection, delay, and response. The components and equipment which will be required for a safeguards system are identified during the evolution of the system design. Much commercial equipment is available but complete data concerning its performance or the effects of various environments on its performance have not been available. Therefore, concurrent with the development of the ESS designs, a major program to evaluate and characterize commercial equipment is being conducted.

Evaluation tests are being conducted under controlled laboratory environments and in various field locations where the range of physical conditions and environments is typical of operational use. The following types of safeguards equipment are being evaluated:

1. Intrusion detection and assessment equipment

2. Integrated entry control equipment (contraband detectors and personnel identification systems)

3. Barriers--barrier materials, activated delay barriers, vaults, doors, locks, and vehicle perimeter barriers

The intrusion detection testing program being conducted by Sandia Laboratories, which has been in progress since January 1975, is designed to gain a basic understanding of the various available commercial systems, establish their capabilities and limitations, and, in cooperation with the manufacturers,

$$
\text { B-54 }
$$


upgrade the system capabilities to provide a family of sensors for use at DOE facilities. Sandia is evaluating alarm systems at the Sandia Alarm Development Laboratory (SADL) in Albuquerque, New Mexico, and the Rocky Flats Plant in Colorado. The SADL site provides generally mild climate conditions but also, at certain times of the year, high winds and numerous electrical storms. The terrain is flat, and there are no nearby structures or roads. Electrical noise includes signals from nearby airport surveillance, air route traffic control, and airborne radars. Rocky Flats, on the other hand, presents severe weather environments including severe cold, extremely high winds, deep snow, frost, and electrical storms. The terrain is highly irregular, and the test area contains many buildings, roads, sidewalks, fence lines, and narrow corridors between structures. Electrical noise is high as a result of a network of power lines in the area. Another facility, dedicated to interior intrusion detection evaluation and development, is loizted at Manzano Base, Albuquerque, New Mexico, and is referred to as the Sandia Interior Alarm Development Laboratory (SIADL). Alarms that have been evaluated include buried line sensors (magnetic and seismic), free-standing sensors (infrared, microwave, electric-field), fence-mounted vibration, and tilt sensors, and electromagnetic point sensors. Closed-circuit TV with automatic motion detection alarms is a particularly attractive assessment technology and is also being evaluated. 
In the evaluation of integrated entry control equipment, special attention is being given to positive personnel identification systems (fingerprint, voice print, hand geometry, handwriting), as opposed to credential verification (locks, badges, code/card systems). Detection systems for deterring and detecting the unauthorized movement of SNM or contraband materials through designated entry and exit points are also required for safeguards systems. Commercial instruments have been developed to detect, with varying degrees of success, contraband items such as explosives and guns. Where the sensitivity, reliability, or vulnerability of commercial instruments is inadequate, Sandia is investigating alternative techniques. The goal is to define prototype instruments suitable for commercial production which can be integrated into the entry control system. Low cost, ease of maintenance, reliability, low false alarm rate, and system compatibility and effectiveness are the criteria for development activities.

Material containment and passive and active barriers are being developed to provide a cumulative delay which permits detection, assessment, response, and attack neutralization by security forces. Effort is underway to improve the resistance of doors to explosive attack in order to match that of massive walls. Vehicle barriers are being designed and evaluated. Delay and denial materials which can be dispensed on command are being developed to complement passive physical barriers.

$$
\text { B-56 }
$$


Information exchange has been established with the various government and military agencies involved in safeguards technology to avoid duplication of effort and to insure a comprehensive data base. To aid industry in the selection, procurement, installation and maintenance of safeguards equipment, user-oriented, handbooks have been published, seminars or workshops will be made available, and representative procurement specifications will be prepared.

The "Intrusion Detection Systems Handbook" (SAND76-0554) has been published and is available on request to DOE/SS. The handbook provide recommendations for the: (a) selection, procurement, installation, test, and maintenance of intrusion detection sensor systems, both for exterior and interior use; (b) assessment of alarms generated by the detection system; and (c) information collection and display systems.

Additional handbooks cover barrier technology and hardware, and personnel identification, metal detecting, and explosivesdetecting technologies and hardware. These handbooks are also available through DOE/SS. All reports will be updated as significant additional information is obtained.

Initial seminars or workshops are being considered for industry representatives in FY78. These programs are being organized 
to aid the engineering staffs of industry who will design and operate the safeguard systems for fuel cycle facilities.

Initial procurement specifications for specific items of safeguards equipment will be issued during FY78 and FY79. 


\section{B.3. Representative System and Subsystem Designs}

The principal safeguards system design activity is being conducted by Sandia with major support in MMA by Los Alamos. The format for presenting the systems resulting from this process is yet to be determined. A detailed presentation of current results from the mixed oxide fuel fabrication study can be found in the reports by A. E. Winblad et al., Development of an Engineered Safeguards System Concept for a Mixed-Oxide Fuel Fabrication Facility ${ }^{*}$ and in R. B. Walton et al., Coordinated Safeguards for Materials Management in a Mixed-Oxide Fuel Facility. * *

A proposed control, coordination, and communications system to be used in the system design concept is described in (2). Other systems and subsystems developed in the DCE program are presented in the B. 3 summary chart and subsequent text.

\section{(1) Representative ESS Designs for Fuel Cycle Facilities.}

The Design Methodology described in Section B.I is being used to develop representative ESS designs for the fuel cycle facilities.

\footnotetext{
*SAND76-0180, Sandia Laboratories, August 1976. **LA-6536, Los Alamos Scientific Laboratory, September 1976. 
Each representative design will include the plant layout, the safeguards system specifications and operating procedures, and response force requirements.

Each representative design can be used by the design staffs of industry to assist in the development of the specific safeguards system for their facility.

\section{(2) Engineered Safeguards Central Control System}

This system consists of a data gathering and transmission network and a central control module. The data gathering network includes the subsystem that transmits information from ESS transducers and sensors, material accountancy units, item operation control elements and assessment units to the central processing units. The central processing units are general purpose digital computers used to consolidate, process, and store this information, and to generate appropriate reports.

Major project goals are:

- to provide system exercise and "state of health" monitoring for safeguards elements; 
- to provide alarm interpretation which will lead to optimum responses;

- to provide data storage and display; and

- to provide management information and system performance verification data for in-plant and offsite use.

As presently envisioned the Central Control Module will consist of three major elements. The Security Operations center controls admittance of personnel into and within the facility and provides response action in threat situations. The Item Operations center contributes to the protection of SNM during item-handling operations involving facility personnel. This is accomplished through centralized closed-loop control of each step in the monitored operations. The Material Accountancy Center receives on-line material measurements data and supplies information on location and status of SNM and computes material balances. If improper action is detected, operations can be adjusted, if necessary, and appropriate response initiate ${ }^{7}$.

Subsystem concepts and preliminary design of the Central Control system are currently under development. During FY78, Engineering Evaluation of Hardware and Software will be performed. In FY79, a detailed description and specification for a representative information processing and display system will be available.

$$
E-61
$$


1. System - Integrated Safeguards System for Nuclear Fuels Processing Plants.

2. Developer - Allied Chemical, Idaho Chemical Programs (Idaho National Engineering Laboratory) G. L. Booman (208-526-0111 Ext. 3322).

3. Status - The concept is established. Components suited to system needs are being tested, developed or defined.

4. Estimated Unit Cost - The exact cost is dependent on the plant and equipment configurations. Installation costs on the order of 5 percent of plant capital cost have been suggested.

5. Principle - The safeguards system is computer-driven and uses on-line sensors in the plant data from analytical lab, plant staff and physical security sensors. It provides online diversion detection, and on-line accountability, an $\bar{d}$ physical security functions.

6. Description - The system consists of one or more "secure" computers with associated terminals and sensors in the process plant and fence areas. These computers provide alarms and initiate appropriate response when improper or suspicious actions are detected. The system provides: (a) Control of access to SNM; (b) Control and a record of personnel within the area; (c) Monitoring of the process and plant equipment for the "signature" of a diversion attempt, and (d) on-line verification of its proper operation.

7. Operating History - None--the complete system has not yet been demonstrated although most component functions (access control, on-line accountability, automated security functions) have a history of satisfactory operation. 


\section{B. 4 Physical Protection Equipment Development}

A fundamental principle of DOE planning is to intervene in commercial development only when technologies necessary for meeting the five national policy objectives for energy would not otherwise be developed. Where private sector development appears likely (as is the case with respect to most physical protection equipment), the DOE role is to assure that candidate equipment meet the rigorous system requirements of the safeguards program (see B.2). Where technical risk, exceptional design requirements, small potential market size, or other factors preclude commercial development, the DOE program will take the initiative. Representative products being developed under this category are presented in the B.4 summary table and the following data sheets.

$B-63$ 
B.4 Physical Protection Equipment

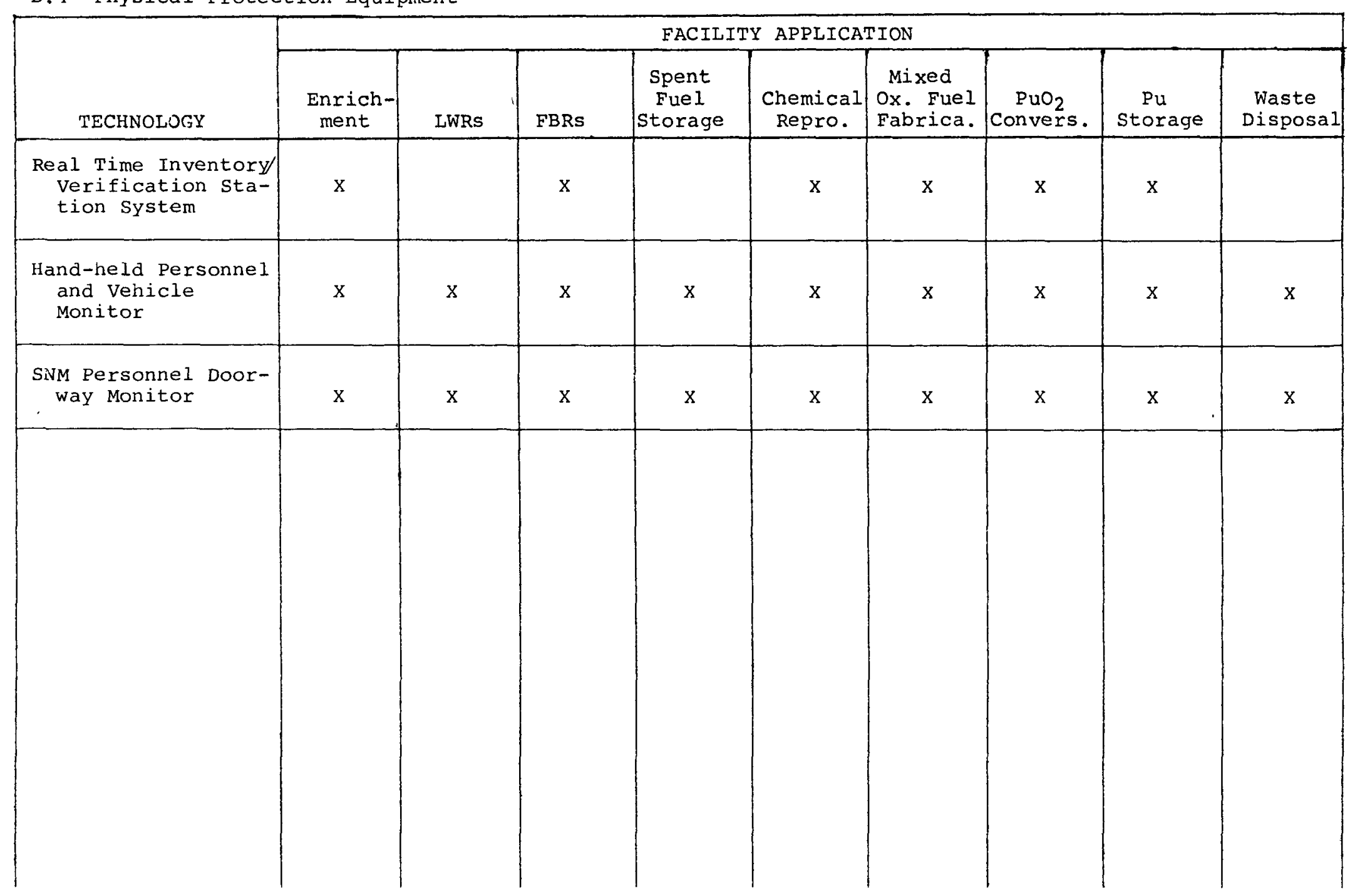


1. Equipment - Real Time Inventory/Verification Station System

2. Developer - Los Alamos Scientific Laboratory

3. Status/Estimated Availability - under development. Prototype system will be tested in vault environment by fall 1977; possible contractor availability 1978.

4. Estimated Cost -

(a) Verification station and computer - \$90-\$100 K

(b) Shelf detectors in quantity

- $\$ 125 /$ detector

5. Principle and Application - separate portals are provided for personnel and SNM. The personnel portal is monitored by a gamma sensitive doorway monitor that detects the gamma rays emitted from the SNM and a metal detector doorway monitor that is designed to detect potential shielding material. The SNM portal is a verification chamber containing an accurate scale, gamma and neutron detectors, whose outputs are fed to a mini-computer. A composite signature is obtained of the entering material, which is then compared to a second signature obtained when the material is removed from the vault. This signature comparison verifies that no material has been diverted during its stay in the vault. To further insure that the SNM is not tampered with while in storage, shelf detectors constantly monitor the SNM on the shelf. These detectors consist of a collimated geiger tube which is detecting a gamma count rate, and should be constant once the material is placed on the shelf. In addition, a parallel plate weight sensor monitors the weight of the can and further insures that the can is not tampered with. Both the weight and gamma sensors are interrogated by the computer as often as once a second or as infrequently as required by other demands on the computer.

6. Description - the verification chamber is shielded by $10 \mathrm{~cm}$ of 5 percent borated polyethylene and $1.27 \mathrm{~cm}$ of lead. Four $5 \mathrm{~cm}$ diameter ${ }^{3} \mathrm{He}$ tubes surround the pan of the scale and a $5 \mathrm{~cm} \times 5 \mathrm{~cm}$ NaI detector is looking down at the pan from the top of the chamber. The shelf detectors contain a geiger tube, $4 \mathrm{~cm}$ long $\times 0.8 \mathrm{~cm}$ in diameter, and operates at 425 volts. The weight sensor is made of two parallel conductive plates separated by an array of springs. When weight is placed on the plates, the capacitance changes which changes the frequency of an oscillator.

7. Operating History - under development.

8. References - none. 
1. Monitor for Special Nuclear Materials - Hand-Held Personnel and Vehicle Monitor

2. Developer - Los Alamos Scientific Laboratory

3. Status/Estimated Availability - Evaluation complete. Commercially available.

4. Estimated Unit Cost - $\$ 600$ to $\$ 1,000$

5. Principle of Measurement - Passive gamma rays from special nuclear materials are detected by a NaI (TI) detector, producing pulses that are integrated for a preset counting interval (typically $0.3 \mathrm{~s}$ ). If the counts in the interval exceed the trip level, which is a preset multiple of the stored background, an audible alarm is produced.

6. Description - The monitor contains a 38-mm diameter by 38-mm long NaI(TI) scintillator/photomultiplier, a pulse amplifier, a lower level discriminator, and a digital logic system. The photomultiplier high voltage supply is a battery pack of twenty-four $30 \mathrm{~V}$ batteries, with taps for each electrode of the photomultiplier. Because there is little current drain (there is no resistor string), the batteries essentially have normal shelf life. Low voltage is supplied by rechargeable nickel-cadmium batteries with a capacity for approximately 120 hours of continuous operation between recharges.

7. Operating History - Earlier versions of the monitor have been used by the Protective Force at LASL for SNM searches of personnel and vehicles for about $2-1 / 2$ years. The monitor is capable of detecting at $>95$ percent confidence level a $10-\mathrm{g}$ sphere of highly enriched $235 \mathrm{U}$ with the distance of closest approach $0.25 \mathrm{~m}$ and sweep speed of $0.5 \mathrm{~m} / \mathrm{s}$ in a $25 \mathrm{\mu R} / \mathrm{h}$ background.

8. References - W. E. Kunz, W. H. Chambers, C. N. Henry, S. W. France, D. R. Millegan, R. D. Hastings, and G. M. Worth, "Hand-Held Personnel and Vehicle Monitors," Los Alamos Scientific Laboratory report LA-6359 (Sept. 1976). 
Physical Protection Equipment

1. Monitor for Special Nuclear Materials - SNM Personnel Doorway Monitor

2. Developer - Los Alamos Scientific Laboratory

3. Status/Estimated Availability - The monitor was developed to determine a reasonable compromise between cost and sensitivity. The monitor would have to be updated somewhat to comply with current DOE requirements. Subsequent logic designs could be substituted to greatly reduce the number of integrated circuits used. Currently available commercial monitors achieve comparable sensitivity.

4. Estimated Unit Cost - $\$ 12,000$

5. Principle of Measurement - Gamma ray radiation is detected by an array of NaI or plastic scintillation detectors. The background count rate is averaged and used to determine the alarm level. If the count exceeds the alarm level while the monitor is occupied, a visual and audible alarm signal is activated.

6. Description - The detector array consists of four $12.7 \mathrm{~cm}$ $\mathrm{x} 2.5 \mathrm{~cm} \mathrm{NaI}$ scintillators or four $5 \mathrm{~cm}$ diameter $\mathrm{x} 91.4$ $\mathrm{cm}$ long plastic scintillators that are collimated by 0.3 $\mathrm{cm}$ lead shielding. The detectors, photomultiplier tubes, tube bases, and two preamplifiers are located in a portal. High voltage supply, amplifier, single channel analyzer, and logic module are located in a NIM bin.

7. Operating History - The two monitors, one with NaI and one with plastic scintillators, were evaluated at LASL for sensitivity, operational stability, and cost. The monitors have since been used at demonstrations and one has been in use at the LASL Plutonium facility in a long term demonstration for about $1-1 / 2$ years.

8. Reference - T. Sampson, et al, "Portal Monitor for Diversion Safeguards," Nuclear Technology, Vol. 23 (2), 124 (August 1974).

9. Other Remarks - The sensitivity of the monitor meets the requirements of the DOE doorway monitors standard. The difference between this monitor and commercial monitors lies in the tradeoff between detector cost and logic cost. This monitor lists a minimal detector array and sophisticated logic. 
The material measurement and accounting field includes both the systems, software, and communications necessary to collect, store, and analyze data on material flows, and the instruments and techniques being developed to generate this data. Because of the relatively narrow technical requirements that must be met and the relatively small commercial market for these products, much of the basic RD\&D is performed within the DOE program. It should be noted, however, that commercialization of these products within the private sector is a goal of the DOE program and, as seen in A.2, partial success has already been achieved.

The focus of the MMA system development activity is the LASL design sequence (discussed briefly in B.1.3). The DOE program to develop instruments and techniques to generate basic data from all elements of the fuel cycle is being conducted by LASL, LLL, NBS, NBL, ICPP, and Mound Laboratories.

Because of the large number of products in the NDA area, these are presented separately in B.5.1. Other physical and analytical chemistry techniques used for bulk and sample measurement are presented in $\mathrm{B} .5 .2$ and B.5.3, respectively. Storage vaults and seals are presented in B.5.4. 
B.5.1 NDA Instrumentation

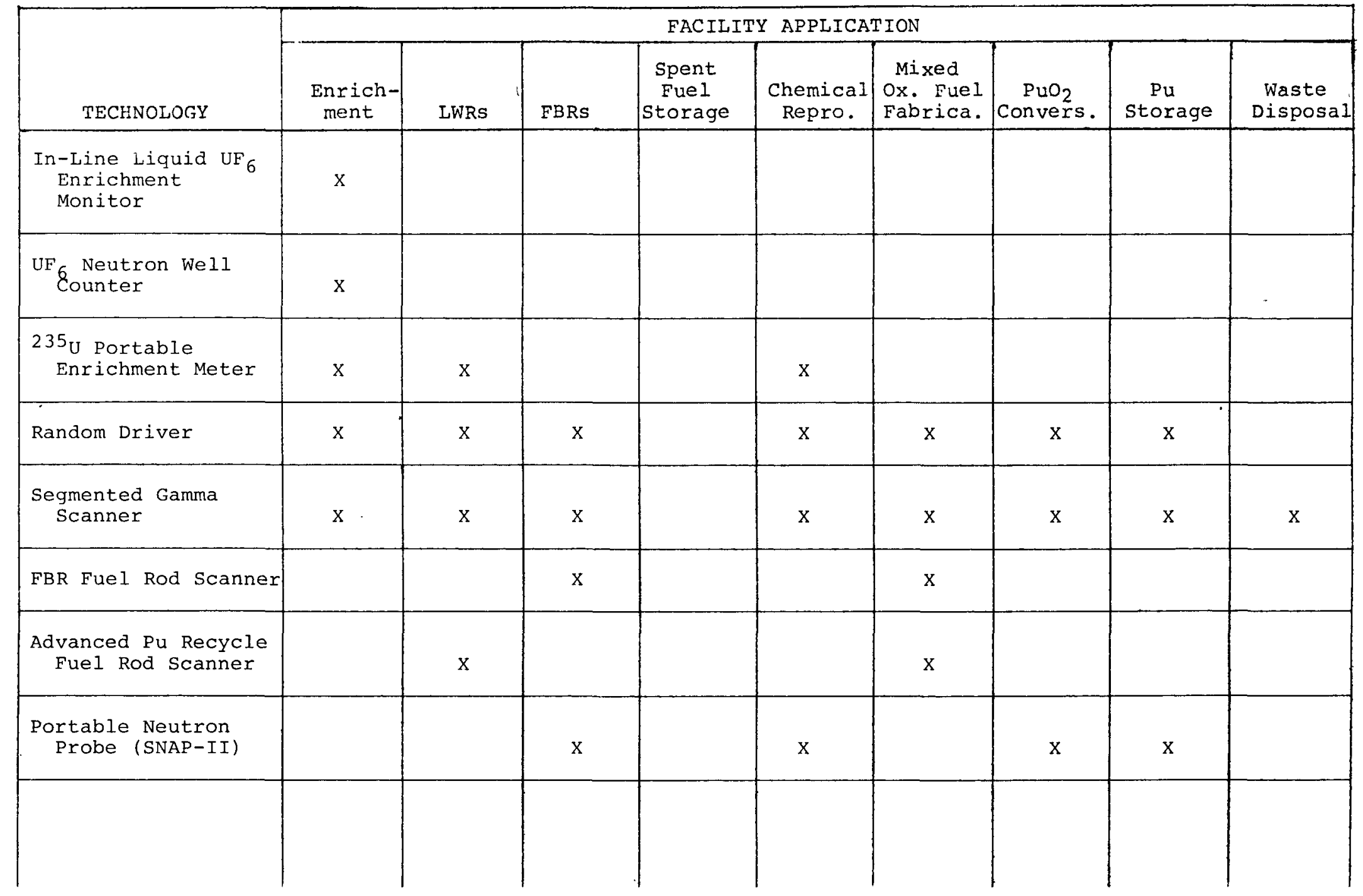


B.5.1 NDA Instrumentation, continued

\begin{tabular}{|c|c|c|c|c|c|c|c|c|c|}
\hline \multirow[b]{2}{*}{ TECHNOLOGY } & \multicolumn{9}{|c|}{ FACILITY APPLICATION } \\
\hline & $\begin{array}{c}\text { Enrich- } \\
\text { ment }\end{array}$ & LWRS & FBRs & $\begin{array}{l}\text { Spent } \\
\text { Fuel } \\
\text { Storage }\end{array}$ & $\begin{array}{c}\text { Chemical } \\
\text { Repro. }\end{array}$ & $\begin{array}{l}\text { Mixed } \\
\text { Ox. Fuel } \\
\text { Fabrica. }\end{array}$ & $\begin{array}{c}\mathrm{PuO}_{2} \\
\text { Convers. }\end{array}$ & $\begin{array}{l}\text { Pu } \\
\text { Storage }\end{array}$ & $\begin{array}{l}\text { Waste } \\
\text { Disposal }\end{array}$ \\
\hline $\begin{array}{c}\text { Thermal Neutron Coin } \\
\text { cidence Counter }\end{array}$ & & & & & $\mathrm{x}$ & $\mathrm{x}$ & $\mathrm{x}$ & $\mathrm{X}$ & \\
\hline $\begin{array}{l}\text { Photoneutron Assay } \\
\text { System for } \\
\text { Irradiated Fuel }\end{array}$ & & $\mathrm{x}$ & $\mathrm{x}$ & $\mathrm{x}$ & $\mathrm{X}$ & & & & \\
\hline $\begin{array}{c}\text { Portable Active Neu- } \\
\text { tron Assay System }\end{array}$ & $\mathrm{x}$ & $\mathrm{x}$ & & & & & & & \\
\hline $\begin{array}{l}\text { Portable Monitor for } \\
\text { Liquid Wastes }\end{array}$ & $\mathrm{x}$ & $\mathrm{x}$ & & & $x$ & $\mathrm{x}$ & & & $\mathrm{x}$ \\
\hline $\begin{array}{l}\text { Advanced Portable } \\
\text { Assay Electronics }\end{array}$ & $\mathrm{X}$ & $x$ & $x$ & $\mathrm{x}$ & $\mathrm{x}$ & $\mathrm{x}$ & $\mathrm{X}$ & $\mathrm{x}$ & \\
\hline $\begin{array}{l}\text { Low Level Solid } \\
\text { waste Monitor }\end{array}$ & $\mathrm{x}$ & $\mathrm{x}$ & $\mathrm{x}$ & & $\mathrm{x}$ & $\mathrm{x}$ & $\mathrm{x}$ & & $\mathrm{x}$ \\
\hline $\begin{array}{l}\text { Absorption Edge } \\
\text { Densitometer }\end{array}$ & & $x$ & $\mathrm{x}$ & & $\mathrm{x}$ & $\mathrm{x}$ & $\mathrm{x}$ & $\mathrm{x}$ & \\
\hline 252 Cf Assay System & & & & $\mathbf{x}$ & $\mathrm{x}$ & $\mathrm{x}$ & $\mathrm{x}$ & $\mathrm{x}$ & \\
\hline & & . & & & & & & & \\
\hline
\end{tabular}


B.5.1 NDA Instrumentation, continued

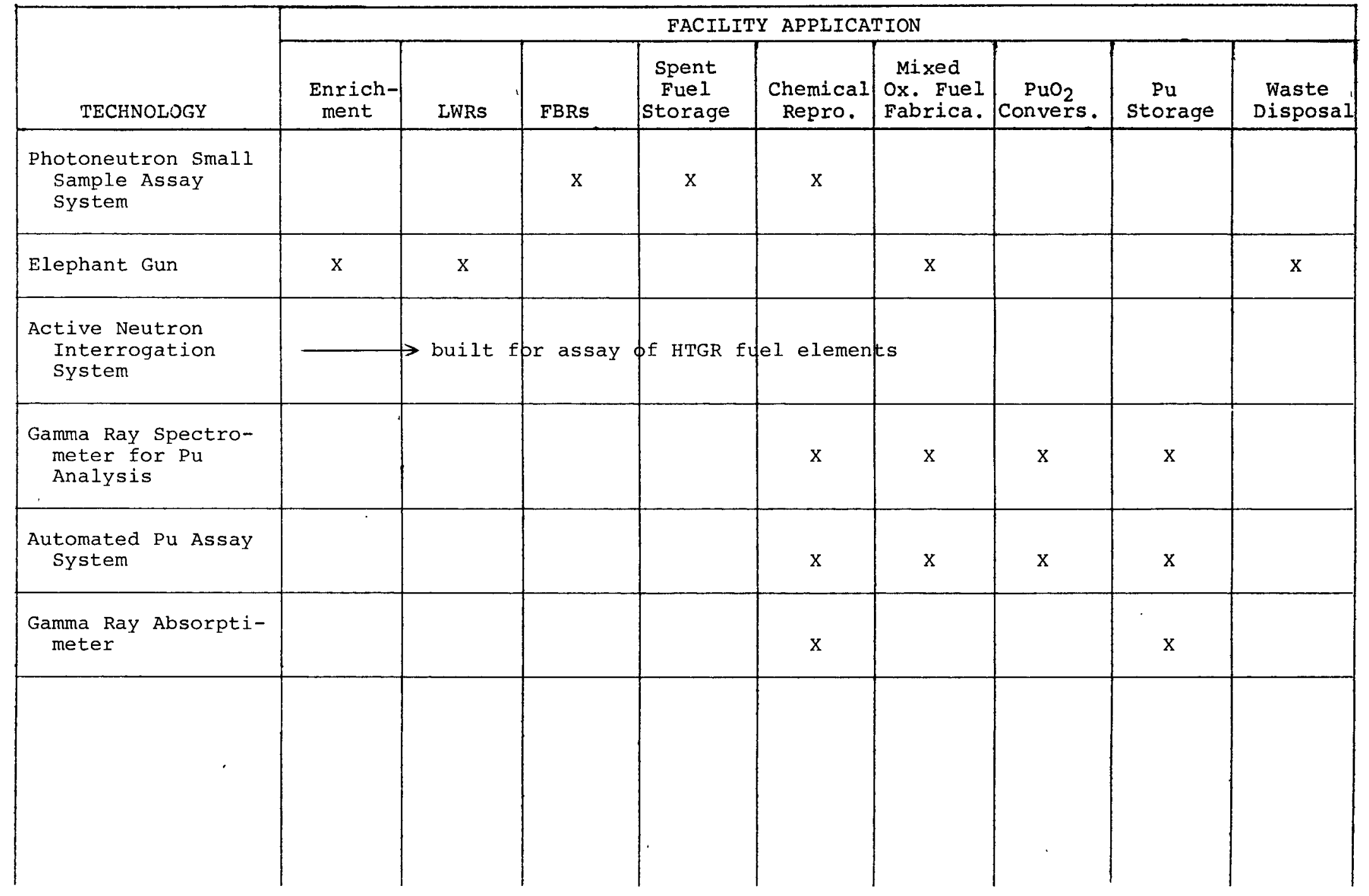


1. Assay Instrument - In-Line Liquid UF ${ }_{6}$ Enrichment Monitor.

2. Developer - Los Alamos Scientific Laboratory.

3. Status/Estimated Availability - Evaluation completed. Two units currently in operation. Commercial versions currently being produced.

4. Estimated Unit Cost - $\$ 20,000$ - gamma system only. $\$ 40,000$ - with neutron system.

5. Principle of Measurement $-{ }^{235} \mathrm{U}$ enrichment determined by passive gamma counting of $186-\mathrm{keV}$ gamma-ray from ${ }^{235} \mathrm{U}$. ${ }^{234} \mathrm{U}$ enrichment determined by gross neutron counting. Primary neutron source results from interaction of ${ }^{234} \mathrm{U}$ alpha particles on flourine $(F(\alpha, n) \mathrm{Na}$ reaction). These two signatures are measured for a fixed mass of $\mathrm{UF}_{6}$ in a continuous flow chamber.

6. Description - A 50-mm-diam. by 13-mm-thick NaI detector and two singlechannel analyzers are used for the gamma ray measurements. Sixteen ${ }^{3} \mathrm{He}$ proportional counters enclosed in a polyethylene annulus and wrapped around an enlarged section of pipe carrying UF 6 are used to detect neutrons. Hardwired arithmetic and control unit provides automatic calculation and alarm controls. Both visual display on the enrichment monitors and hardcopy output on a teletype are available. The assay cycles automatically at 2, 5 or 10 minute intervals, providing continuous copy of enrichment without operator intervention.

7. Operating History - Four years continuous operation at Goodyear Atomic Enrichment Facility. Measurement precision is $0.5 \%$ at $2 \sigma$ level for ${ }^{235} \mathrm{U}$ and $1 \%(2 \sigma)$ for ${ }^{234} \mathrm{U}$ enrichment. Accuracy is comparable to precision.

8. References

1. T. D. Reilly, E. R. Martin, J. L. Parker, L.G. Speir and R. B. Walton, "A Continuous In-Line Monitor for UF 6 Enrichment," Nuclear Technology, Volume 3, Number 3 (September 1974).

2. T. D. Reilly, E. R. Martin, and J. L. Parker, "UF 6 Enrichment Monitor: Operating Procedures Manual," LA-5485-M (1974) Los Alamos Scientific Laboratory.

9. Other Remarks - Materials measured are ${ }^{235} \mathrm{U}$ and ${ }^{234} \mathrm{U}$ enrichment in liquid $\mathrm{UF}_{6^{\circ}}$. Instrument is simple and inexpensive and measures all of the output on-line, rapidly and automatically. The instrument is capable of measuring all enrichment levels with adjustable alarms for low and high enrichments. The capability for essentially instantaneous isotopic analysis provides assurance of criticality safety during withdrawal into large cylinders and verification that the withdrawal selection meet target enrichment specifications. This technique can be easily adapted to many other liquid flows involving gamma radiation from nuclear materials. 


\section{Assay Instrument - UF 6 Neutron We11 Counter.}

2. Developer - Los Alamos Scientific Laboratory.

3. Status/Estimated Availability - Tests completed. All components are commercia11y available.

4. Estimated Unit Cost $-\$ 10,000-15,000$.

5. Principle of Measurement - This instrument measures the gross, passive neutron activity from a known mass of $\mathrm{UF}_{6}$. Since these neutrons are produced primarily by the interaction of alpha particles from $2{ }^{34} \mathrm{U}$ with flourine, the measurement is directly related to the ${ }^{234} \mathrm{U}$ isotopic abundance in the $\mathrm{UF}_{6}$ sample. If the ${ }^{235} \mathrm{U} /{ }^{234} \mathrm{U}$ ratio is known, the ${ }^{235} \mathrm{U}$ enrichment can also be determined.

6. Description - This instrument consists of a neutron well counter incorporating $14{ }^{3} \mathrm{He}$ proportional counters embedded in a polyethylene annulus which surrounds the sample cavity. The assembly weighs $250 \mathrm{~kg}$ with a 12-cm-thick neutron shield.

7. Operating History - Units have been successfully evaluated at the Goodyear Atomic Enrichment Facility (GAT) and the Oak Ridge Gaseous Diffusion Plant $(\mathrm{K}-25)$. For counting times of 1000 seconds and ${ }^{234} \mathrm{U}$ concentrations over a range of 0.001 to $1.0 \%$ (wt.) the method achieved accuracies better than $2.5 \%$ (10) for the depleted and $10 \mathrm{w}$ enriched $\mathrm{UF}_{6}$ and approximately $0.5 \%$ ( $1 \sigma$ ) for the highenriçhed $\mathrm{UF}_{6}$ (Ref. 1 ).

8. References

1. L. R. Steiff, et a1., "Neutron Measurements of ${ }^{234} \mathrm{U}$ Isotopic Abundance in $\mathrm{UF}_{6}$ Samples," Proc. 16th Annual INMM Meeting (June 1975) p. 180.

2. R. B. Walton and P. vanDieman, "Neutron Detector for Analysis of $\mathrm{UF}_{6}$ in $2 \mathrm{~S}$ Cylinders," LA5771PR, p. 4, Los Alamos Scientific Laboratory (1974).

9. Other Remarks - UF 6 in all enrichment ranges can be measured in quantities from 0.5 to $2.0 \mathrm{~kg}$. This instrument may provide a less expensive means for ${ }^{234} \mathrm{U}$ isotopic analysis with an accuracy comparable to a two-stage mass spectrometer. Three principal uses are (1) the neutron yield of $\mathrm{I}_{6}^{\prime}$ provides a simple signature for safeguards verification of UF cylinders in the field, (2) ${ }^{234} \mathrm{U}$ isotopic abundance is of key importance for the application of the MIST safeguards technique to enrichment facilities, (3) rapid $23{ }^{4} \mathrm{U}$ isotopic analysis is useful for enrichment process control. 
NDA INSTRUMENTATION

1. Assay Instrument - ${ }^{235} \mathrm{U}$ Portable Enrichment Meter.

2. Developer - Los Alamos Scientific Laboratory.

3. Status/Estimated Availability - Evaluation complete. Commercially available.

4. Estimated Unit Cost - $\$ 3,000-5,000$.

5. Principle of Measurement - Passive gamma-ray counting of ${ }^{235} \mathrm{U}$ 186-keV gamma rays. In "thick" samples the net count under this peak is proportional to the ${ }^{235} \mathrm{U}$ enrichment. The Compton background from higher energy gamma-rays must be subtracted and a correction for attenuation by the container wal1 must be applied.

6. Description - The gamma-ray probe consists of a 2-in. diam. by .5-in. thick NaI crystal and photomultiplier tube housed in a tungsten and lead collimator. Alpha-particle pulses from an $241 \mathrm{Am}$-doped NaI seed implanted in the crystal are used for gain stabilization. Pulses are sent through a commerical amplifier into one or two single channel analyzers. The two analyzer version allows an up-down scaling option for automatic background subtraction.

7. Operating History - The instrument has been evaluated at LASL, K-25 and GAT. Counting time is 100-300 seconds, depending on the material enrichment and precision required. For a 300 second counting period the precision is $4 \%$ ( $1 \sigma$ ) for natural uranium and $1 \%$ ( $1 \sigma$ ) for $3 \%$ enriched uranium. Accuracy is $0.5 \%$ to $5 \%$, depending on enrichment, containment and control of geometry.

8. References

R. B. Walton, T. D. Reilly, J. L. Parker, and J. H. Menzel, "Measurements of $\mathrm{UF}_{6}$ Cylinders with Portable Instruments," Nuclear Technology, Vol. 21 (February 1974).

9. Other Remarks - This instrument is used to measure ${ }^{235} \mathrm{U}$ enrichments in bulk materials of uranium metal, $\mathrm{UF}_{6}$, $\mathrm{UO}_{2}$, etc., having high concentrations of uranium. Measurements can be made in all enrichment ranges. The complete system can be battery operated and cart mounted for convenient mobility in field use. 
1. Assay Instrument - Random Driver

2. Developer - Los Alamos Scientific Laboratory

3. Status/Estimated Availability - In routine plant use for ${ }^{235} \mathrm{U}$; undergoing field testing for Pu. Similar units are commercially available.

4. Estimated Unit Cost $-\$ 40,000-60,000$

5. Principle of Measurement - Active interrogation with subthreshold neutrons from an $(\alpha, \eta)$ Am-Li source. Induced fission events are detected by coincidence counting of prompt fission neutrons and gamma rays using fast scintillation detectors. The neutron source energy and the degree of gamma ray sensitivity can be tailored to meet specific applications. Gamma ray discrimination is generally required when measuring kilogram quantities of $\mathrm{U}$ or $\mathrm{Pu}$ and is accomplished by the use of lead shielding and time of flight discrimination.

6. Description - Two vertically separated Am-Li neutron sources irradiate the sample from the rear while two or more lead shielded plastic scintillators view the sample from the sides. The sample is rotated during the measurement to average geometrical effects of a heterogeneous sample. ${ }^{3} \mathrm{He}$ detectors inside the cavity monitor the sample's flux perturbation. Temperature monitors and a load cell for measuring sample gross weight are also included. The electronics consist of fast NIM electronics interfaced to a small minicomputer via a CAMAC dataway.

7. Operating History - This instrument has been used in a wide variety of in-plant applications primarily for assay of uranium solids. Count times of 1000 's is normally required. Accuracy is $1-5 \%$ depending on the characterization of the sample with respect to matrix, homogeneity, fill height, impurities, etc. The applicability of a Random Driver for measurement of $\mathrm{Pu}$ salt residues having very high $(\alpha, n)$ background rates is currently under investigation at LASL.

\section{References}

1. T. L. Atwe11, L. V. East, and H. 0. Menlove, "Automated Random Driver Mod. ITI for NDA of HTGR in-Process Fue1," LA-5889-PR (1975) p. 3, Los Alamos Scientific Laboratory.

2. T. L. Atwe11, L. W. Cowder, T. R. Canada and D. A. Close, "Development and In-Plant Evaluation of Random Driver Mod IV for NDA of Highly Enriched U-Al Alloys, "LA-6040-PR (1975) p. 5, Los Alamos Scientific Lab.

3. R. N. Olsen, S. Untermeyer, H. Miller and J. Lung, "Random Driver for Al1 Sizes," Journal of Nuclear Materials Management, Vol, V, No. III (1976).

9. Other Remarks - This instrument is useful for high enrichment uranium or plutonium samples which have excessive gamma-ray absorption. It measures ${ }^{235} \mathrm{U}$ in quantities of $50-5000 \mathrm{~g}$, with a $1 \mathrm{~g}{ }^{235} \mathrm{U}$ sensitivity in the thermal mode. 
1. Assay Instrument - Segmented Gamma Scanner.

2. Developer - Los Alamos Scientific Laboratory

3. Status/Estimated Availability - Evaluation complete. Commercial versions currently available and in operation.

4. Estimated Unit Cost $-\$ 60,000$.

5. Principle of Measurement - Passive gamma radiation from the various isotopes is measured and related to fissile content by correcting for gamma transmission on a segment-by-segment basis, using a separate transmission source.

6. Description - A Ge(Li) detector, coupled through appropriate electronics to a dedicated minicomputer is used to take spectra for each sample segment of fissile peaks as well as the transmission peak. The sample table motion (rotation and vertical segmentation) is automatically controlled by the computer requiring the operator only to enter the sample identification and start the assay. The computer automatically makes the measurement on a segment-by-segment basis, and prints the results along with the statistical error estimates at the end of the cycle.

7. Operating History - LASL units have operated for 10,000 hours at Atlantic Richfield Hanford Company and General Atomic. The instrument is sensitive to quantities as low as one gram and up to any amount which will still yield a viable transmission measurement--generally around $300 \mathrm{~g}$ fissile. The assay requires 10 seconds per half-inch scan, or about 100 seconds for a 5-in. cylindrical sample. The precision is $1-5 \%$ depending upon sample size and transmission.

\section{References}

E. R. Martin, D. F. Jones and L. G. Speir, "Passive Segmented Gamma Scan Operation Manua1," LA-5652-M (1974) Los Alamos Scientific Laboratory.

9. Other Remarks - Materials measured includes ${ }^{235} \mathrm{U},{ }^{238} \mathrm{Pu},{ }^{239} \mathrm{Pu}$ and ${ }^{24} \mathrm{Pu}$. The instrument is fully engineered to measure either uranium or plutonium scrap and waste where the uniformity of the material and density are such that meaningful transmission measurements are possible. It is a complex measurement which is operationally simple, and whose results give a valid error estimate due to the attached minicomputer which handles the control and calculation and supplies hardcopy output for record purposes. 
1. Assay Instrument - FBR Fue1 Rod Scanner.

2. Developer - Los Alamos Scientific Laboratory

3. Status/Estimated Availability - Evaluation complete. Available for commercialization.

4. Estimated Unit Cost - $\$ 100,000-300,000$, depending on throughput and level of automation.

5. Principle of Measurement - Fast neutron interrogation with delayed gamma-ray counting for total fissile content. Passive gamma-ray counting for pellet-to-pellet uniformity.

6. Description - A ${ }^{252} \mathrm{Cf}$ source is located inside annular regions of $\mathrm{W}, \mathrm{Be}, \mathrm{N} i$ and $\mathrm{Pb}$ which serve as shields, moderator and reflectors. Two 127-mm by 127-mm thick NaI detectors with through-holes for passage of fuel rods are positioned near the ${ }^{252} \mathrm{Cf}$ source. A group of fuel rods are placed on a loading tray and are automatically fed into the irradiation-counting region at a rate of $4 \mathrm{~min} . / \mathrm{rod}$.

7. Operating History - Instrument system has been in operation at the Westinghouse-HEDL plutonium fuel facility for $\sim 4$ years. The individual rod precision is $0.6 \%(2 \sigma)$. HEDL measured over 36,000 FFTF fuel pins and observed a $0.1 \%$ agreement between this NDA technique and chemical analysis.

8. References

1. H. 0. Menlove, R. A. Forster, J. L. Parker and D. B. Smith, 1252 Cf Assay System for FBR Fuel Pins: Description and Operating Procedures Manual," LA-5071-M (1972) Los Alamos Scientific Laboratory.

2. H. O. Menlove, R. A. Forster, J. L. Parker and D. B. Smith, "Californium-252 Assay System for FBR-Type Fue1 Pins," Nuclear Technology, Vo1. 20, November 1973.

9. Other Remarks - This instrument is used to measure total fissile content and pellet-to-pellet uniformity $\left({ }^{241} \mathrm{Am}\right.$ and $\left.\mathrm{Pu}\right)$ in FFTF type fuel rods. Advanced versions of the instrument can measure the entire throughput of a production plant. 
1. Assay Instrument - Advanced Pu Recycle Fuel Rod Scanner.

2. Developer - Los Alamos Scientific Laboratory

3. Status/Estimated Ava1lability - Under development. Plant tests expected in 1978. Estimated commercialization 1978-1979.

4. Estimated Unit Cost - $\$ 100,000-300,000$ depending on throughput and level of automation.

5. Principle of Measurement - Thermal neutron interrogation with prompt neutron counting for total fissile content. Either passive or delayed gamma-ray counting for pellet-to-pellet uniformity.

6. Description - A shielded ${ }^{252} \mathrm{Cf}$ source in a $\mathrm{D}_{2} \mathrm{O}$ moderator is used with 1-4 NaI delayed gamma-ray detectors for each fuel rod channel.

7. Operating History - Under development.

8. References - none

9. Other Remarks - This instrument will be used for total fissile content and pellet-to-pellet uniformity measurements on $\mathrm{Pu}$ recycle fuel rods. Whereas present LWR fuel rod scanners give combined amount of ${ }^{235} \mathrm{U}$ and ${ }^{239} \mathrm{Pu}$, this instrument will separate these components. Fissile enrichments from natural to $7 \%$ will be measurable. 
1. Assay Instrument - Portable Neutron Probe (SNAP-II)

2. Developer - Los Alamos Scientific Laboratory

3. Status/Estimated Availability - Commercially available. Currently in field and plant use.

4. Estimated Unit Cost $-\$ 3,000-5,000$

5. Principle of Measurement - Passive neutron counting. The observed neutron count rate is proportional to the sum of spontaneous fission (generally ${ }^{240} \mathrm{Pu}$ ) and $(\alpha, \eta)$ neutron yields. For high purity Pu-metal the $(\alpha, \eta)$ yield is negligible and the count rate gives direct measurement of effective ${ }^{240} \mathrm{Pu}$ in the sample. A correction factor for neutron multiplication is required for large samples (>1kg.). Knowledge of isotopic composition will allow determination of various plutonium isotopes. For oxides or other non-metallic compounds, the sample must be well characterized with respect to light element impurities and matrix materials so that counts can be corrected for $(\alpha, n)$ contributions.

6. Description - A 19-mm I.D. x 127-mm 0.D. x 305-mm long Cd 1ined, polyethylene core houses two ${ }^{3} \mathrm{He}$ detectors. Small samples such as LWR or FBR fuel rods can be counted internally. To achieve directional sensitivity and good background discrimination, a removable $240^{\circ}$ annular polyethylene shield $(241-\mathrm{mm}$. diam.) surrounds the core. A simple turntable mechanism is usually added to rotate samples in front at the detector during data collection. The assoclated electronics uses the Eberline SAM-II Assay Meter.

7. Operating History - Users of this instrument include the DOE Richland Operation Office, IAEA and ARHCO. For well characterized Pu metal buttons and ingots the instrument will yield precisions of $1-3 \%$ and accuracies of $3-4 \%(1 \sigma)$ for 30 second count periods. Oxides, mixed oxides and other matrix bearing or less well defined samples generally require longer counting times (up to 300 seconds) and yield accuracies of $2-15 \% . \mathrm{PuO}_{2}$ process holdup has been measured to estimated accuracies of $50 \%$.

8. References

1. T. L. Atwe11, D. B. Smith, and A.C. Walker, "Assay of Plutonium Metal Buttons with a Portable Neutron Counter, "LA-5431-PR (1973), Los Alamos Scientific Laboratory.

2. H. O. Menlove, T. L. Atwe11 and A. Ramalho, "Upgrading of SNAP Neutron Detector-SNAP II, " LA-6316-PR (1976) Los Alamos Scientific Laboratory

3. C. H. Kindel, "In Site Measurement of Residual Plutonium, "Proc. 17th Annual INMM Meeting,'(1976) p. 540.

9. Other Remarks - This instrument is useful for measuring neutron yields when portability is important. It is useful for measuring $10 \mathrm{~g}$ to $2500 \mathrm{~g}$ of plutonium in the form of metal, well characterized $\mathrm{PuO}_{2}$ or mixed oxides and holdup in process areas. SNAP-II is an improved, upgraded version of the SNAP I Probe previously developed at LASL. 
1. Assay Instrument - Thermal Neutron Coincidence Counter.

2. Developer - Los Alamos Scientific Laboratory

3. Status/Estimated Avallability - Well counters have been commercially available for several years. One version of the associated readout electronics (shift register) is also currently commercially available. Improved versions of the shift register have been developed at LASL and field tested. Latest version will be available for commercialization in 1977.

4. Estimated Unit Cost $-\$ 30,000-50,000$.

5. Principle of Measurement - Coincidence neutrons from the spontaneous fissions of ${ }^{240} \mathrm{Pu}$ are counted in the passive mode. Coincidence counting allows this technique to be used even in the presence of fairly large backgrounds produced by $(\alpha, \eta)$ reactions in the matrix material.

6. Description - The instrument consists of ${ }^{3} \mathrm{He}$ or $\mathrm{BF}$ detectors mounted in a polyethylene annular moderator which complestely surrounds the sample measurement cavity. The coincidence logic unit is an improved design shift register which exhibits very small deadtime.

7. Operating History - LASL instruments have been used for 2 years in plutonium recovery operations at Los Alamos and at ARHCO. Measurement time ranges from 30-1000 seconds depending on sample size and desired precision. Precision is $1 \%$ for 100 grams of $240 \mathrm{Pu}$ for a 200 second count time. The accuracy is $1-10 \%$ depending on how well the sample matrix and isotopic composition are known. Commerclal versions are in use at HEDL, NUMEC nad GE-Vallecitos.

\section{References}

1. R. Sher, "Operating Characteristics of Neutron We11 Coincidence Counters," BNL 50332 (1972) Brookhaven National Laboratory.

2. M. M. Stephens, J. E. Swansen, and L. V. East, "Shift Register Neutron Coincidence Module, "LA-6121-MS (1975) Los Alamos Scientific Laboratory.

9. Other Remarks - The instrument measures effective ${ }^{240} \mathrm{Pu}$ in metal, oxide or mixed oxides. If the plutonium isotopic composition is known this instrument gives accurate results over a wide range of loadings (from 1 to 2000 gram plutonium a $20 \%{ }^{240} \mathrm{Pu}$ ), and is relatively insensitive to gamma-ray contamination. 
1. Assay Instrument - Photoneutron Assay System for Irradiated Fuel.

2. Developer - Los Alamos Scientific Laboratory

3. Status/Estimated Availability - Evaluation complete. Ready for commercialization - 1977 .

4. Estimated Unit Cost $-\$ 40,000-60,000$.

5. Principle of Measurement - Active neutron interrogation of sample and detection of induced prompt fission neutrons. Counts are related directly to ${ }^{235} \mathrm{U}$ mass via a calibration curve.

6. Description - A photoneutron source, $\mathrm{Ra}(\gamma, \eta)$ Be is used to produce subthreshold neutrons. The induced prompt fission neutrons are detected by $12{ }^{4} \mathrm{He}$ gas proportional counters. Two fission chambers are incorporated to correct for matrix and self-absorption effects. The samples are scanned through the irradiation detection region using a pusher driven by a stepping motor. Because of relatively high radiation levels of the fuel, the irradiation-detection portion of the system is located inside a hot cell with fuel handling performed by manipulators. Acquisition, analysis and printing functions are controlled by programmable calculator with extended memory.

7. Operating History - Instrument system has been in operation 3 years at the Nuclear Rocket Development Station in Nevada. An assay time of 150 seconds provides a measurement precision of $\sim 2 \%(2 \sigma)$ for a $400 \mathrm{~g}$ uranium sample. Accuracy is comparable to precision.

8. References

R. H. Augustson, et. al., "An Automated Nondestructive Assay System for the Measurement of Irradiated Rover Fue1," Proc. 16th Annual INMM Meeting (June 1975) p. 152.

9. Other Remarks - This instrument system is used to assay ${ }^{235} \mathrm{U}$ content in irradiated reactor fuel from the Nuclear Propulsion (ROVER) program. Photoneutron active assay systems of this type are being studied for future applications to automated NDA of other high-fissile content fuels such as HTGR, mixed $\mathrm{PuO}_{2}-\mathrm{UO}_{2}$, etc. 
1. Assay Instrument - Portable Active Neutron Assay System

2. Developer - Los Alamos Scientific Laboratorv

3. Status/Estimated Availability - Enrichment plant evaluation complete. LWR plant tests in 1977. Expected commercial availability - 1977.

4. Estimated Unit Cost $-\$ 10,000-15,000$

5. Principle of Measurement - Active interrogation with low energy neutrons and detection of prompt (fast) neutrons from induced fissions.

6. Description - The interrogating thermal neutrons are produced by an Am-Li source embedded in a polyethylene moderating assemb1y. Biased ${ }^{4} \mathrm{He}$ proportional counters are used to detect prompt fission neutrons. A cadnium subtraction technique is used to obtain a net response from thermal-neutron fission only.

7. Operating History - Instrument tested at $\mathrm{K}-25$ and GAT. Counting times of 5-10 minutes are required to obtain a precision of about $3 \%(1 \sigma)$. Accuracies are typically $5 \%$.

8. References

R. B. Walton, et. al., "Measurement of UF 6 Cylinders with Portable Instruments," Nuclear Technology, Vol. $21^{6}$ (February 1974) p. 133.

9. Other Remarks - This assay system provides a direct measure of ${ }^{235} \mathrm{U}$ enrichment which is relatively insensitive to high energy neutron backgrounds. The problem of attenuation by container walls is much less severe than in the 186-keV gamma assay method. 
1. Assay Instrument - Portable Monitor for Liquid Wastes.

2. Developer - Los Alamos Scientific Laboratory.

3. Status/Estimated Availability - Two years of successful field experience. Available for commercial production.

4. Estimated Unit Cost - \$5,000-7,000 (excluding multichannel analyzer).

5. Principle of Measurement - Concentration of ${ }^{235} \mathrm{U},{ }^{238} \mathrm{U}$ and thorium are determined by measuring intensities of naturally occurring (passive) gamma rays (186-keV gamma ray from ${ }^{235} \mathrm{U}, 63 \mathrm{keV}$ gamma ray from ${ }^{2}{ }^{3} \mathrm{U}$, and $238-\mathrm{keV}$ gamma ray from the thorium complex). Since both ${ }^{235} \mathrm{U}$ and ${ }^{2}{ }^{38} \mathrm{U}$ concentrations are measured, the enrichment can also be determined. However, because of interference from a ${ }^{234} \mathrm{U} 53-\mathrm{keV}$ gamma ray with the $63-\mathrm{keV}{ }^{2}{ }^{3} \mathrm{U}$ gamma ray, accurate enrichment measurements can be made only up to $\sim 25 \%$.

6. Description - A 127-mm-diam. by 20-mm-thick NaI detector with a $0.25-\mathrm{mm}-$ thick beryllium entrance window are housed in a 22-mm-thick annular lead shield and enclosed in 3-mm-thick inner and outer brass tubes. Water samples are contained in $250-\mathrm{ml}$ plastic bottles placed in a sample-counting well. A multichannel analyzer is used to simultaneously assay for thorium, ${ }^{235} \mathrm{U}$ and ${ }^{238} \mathrm{U}$. This instrument has also been produced in a stationary version.

7. Operating History - Portable version in use at Oak Ridge for approximately 2 years. Stationary systems used $\sim 2$ years by NRC Atlanta Regional Office and $\sim 1 \frac{1}{2}$ years at LASL Group CMB-8. A standard 250-ml sample of liquid is assayed for 1000 seconds and compared to a known standard. Detectability limits $(3 \sigma, 1000 s)$ are $\psi 3 \mathrm{ppm}(.2 \mathrm{MPC})$ for thorium, $280 \mathrm{ppb}(0.00 \mathrm{i} \mathrm{MPC})$ for ${ }^{2}{ }^{35} \mathrm{U}$ and $\sim 3 \mathrm{ppm}(.03 \mathrm{MPC})$ for ${ }^{238} \mathrm{U}$. The accuracy is $10 \%$ for uranium and $40 \%$ for thorium.

\section{References}

1. C. J. Umbarger and L. R. Cowder, "Portable Radioactivity Monitor for Liquid Effluents, Surface Contaminations, and Bulk Solid Wastes," Nuclear Instruments and Methods 121 (1974) 491-498.

2. C. J. Umbarger, et al., "NDA Measurement of Low-Level U and Pu Waste," Proc. 15th Annual INMM Meeting (1974) p. 140.

9. Other Remarks - This instrument is used as portable, low level 1iquid monitor to measure ${ }^{235} \mathrm{U},{ }^{238} \mathrm{U}$ and thorium. 
1. Assay Instrument - Advanced Portable Assay Electronics.

2. Developer - Los Alamos Scientific Laboratory

3. Status/Estimated Availability - Under development, available for field testing of prototype units--fa11, 1977. Expected commercial availability-1978.

4. Estimated Unit Cost $-\$ 3,000-5,000$.

5. Principle of Measurement - Passive gamma-ray detection.

6. Description - Portable dual single channel analyzer (SCA) stabilized assay instrument for use with $\mathrm{CdTe}, \mathrm{NaI}(\mathrm{T} 1)$ or intrinsic Ge detectors. Two separate SCA's are provided to enable the operator to set data windows around gamma peaks of interest, and to optionally subtract one from the other or use them separately. Error estimates are given on all counts. Computation is automatic and final assay values are visually displayed on LCD's.

7. Operating History - Under development. 
1. Assay Instrument - Low Level Solid Waste Monitor

2. Developer - Los Alamos Scientific Laboratory

3. Status/Estimated Availability - Evaluation completed. In process of being commercialized.

4. Estimated Unit Cost $-\$ 40,000-70,000$.

5. Principle of Measurement - Passive gamma-ray detection. Measures 17-keV $x$-rays for low level samples ( $<10 \mathrm{nCi} / \mathrm{g}$ ) subsequently crossing over to progressively higher energy gamma-rays as activity level increases. Can be calibrated to measure ${ }^{235} \mathrm{U}$, ${ }^{238} \mathrm{Pu},{ }^{239} \mathrm{Pu},{ }^{241} \mathrm{Am}$ or fission products in low density solid wastes.

6. Description - A 127-mm-diam. x 50-mm-thick NaI(T1) crystal views a rotating $.06 \mathrm{~m}^{3}$ cardboard box through a $25-\mathrm{mm}$-wide $\times 100-\mathrm{mm}$-high iron collimator. The full gamma-ray spectrum is analyzed by a computerized pulse-height analyzer. The computer provides not only the spectral analysis, but also complete control of the assay operation and printout of the results. The box is automatically weighed by a computer-coupled load cell, which then permits a direct comparison for the 10-nCi/g fiducial.

7. Operating History - The fully computerized unit has been operating for $\sim 2$ years at the LASL Plutonium Processing Facility. The instrument sensitivity is $\sim 1 \mathrm{nCi} / \mathrm{g}$ for transuranics, fission products, ${ }^{235} \mathrm{U}$ and ${ }^{239} \mathrm{Pu}$ for count times of 240 seconds. Accuracy is about $50 \%$ at the $1 \mathrm{nCi} / \mathrm{g}$ level.

\section{References}

1. C. J. Umbarger and L. R. Cowder, "Measurement of Transuranic Solid Wastes at the 10-nCi/g Level, "LA-5904-MS (March 1975) Los Alamos Scientific Laboratory.

2. D. F. Jones, L. R. Cowder, and E. R. Martin, "Computerized Low-Leve1 Waste Assay System Operationa1 Manua1," LA-6202-M (February 1976) Los Alamos Scientific Laboratory.

9. Other Remarks - ERDA Chapter 0511 requires separation of low density wastes into retrievable and non-retrievable storage at the 10-nCi/g level. This instrument provides a timely method of meeting this requirement and significantly reducing the material which must be stored at retrievable storage sites. An upgraded version of this system incorporating germanium detectors is being developed. The new system will have improved accuracy and will be able to assay samples containing both transuranic and fission product contamination. 
1. Assay Instrument - Absorption Edge Densitometer.

2. Developer - Los Alamos Scientific Laboratory

3. Status/Estimated Availability - Under development. In plant evaluation expected 1977-1978. Commercial availability estimated 1978.

4. Estimated Unit Cost $-\$ 20,000-40,000$.

5. Principle of Measurement - This instrument will determine elemental density within a sample by means of photon transmission measurements which utilize the unique signature of the respective $K$ or $L$ absorption edges.

6. Description - High resolution detector (Ge(Li) or $\mathrm{Si}(\mathrm{Li})$ ) signals are stored in a multichannel analyzer which is interfaced to a minicomputer. Either natural radioisotopes or an X-ray generator is used as the transmission source.

7. Operating History - Under development. Trial program presently underway assaying $U$ in solutions. Accuracies of $0.5-1.0 \%$ are attainable in many applications.

8. References

T. R. Canada, J. C. Parker and T. D. Reilly, "Total Plutonium and Uranium Determination Using Gamma-Ray Densitometry," ANS Transactions, $\underline{22}$ (1975) 140 .

9. Other Remarks - A number of instruments using the absorption edge transmission technique are under development to measure $\mathrm{U}$ and $\mathrm{Pu}$ in solutions and solids containing SNM concentrations $\geqslant .01 \mathrm{~g} / \mathrm{cm}^{3}$. 
NDA INSTRUMENTATION

\section{Assay Instrument - ${ }^{252}$ Cf Assay System ("Shuffler).}

2. Developer - Los Alamos Scientific Laboratory.

3. Status/Estimated Availability - Currently undergoing lab tests. In-plant evaluation expected 1977-1978. Estimated commercial availability - 1979 .

4. Estimated Unit Cost $-\$ 60,000-100,000$.

5. Principle of Measurement - A ${ }^{252} \mathrm{Cf}$ neutron source is used to interrogate fissile isotopes and the induced delayed neutrons are counted. Can also use coincident counting in the well detector to measure ${ }^{240} \mathrm{Pu}$.

6. Description - A $0.2-1.0 \mathrm{mg}{ }^{252} \mathrm{Cf}$ neutron source is transferred between the irradiation chamber and a shielded position via a teleflex cable with a stepping-motor drive or a pneumatic system. The induced delayed neutrons are counted using radiation resistant ${ }^{3} \mathrm{He}$ detectors.

7. Operating History - Undergoing lab tests. The irradiation time depends on the type of sample being assayed and will vary between 1 and 15 minutes. The precision is expected to be $0.25 \%$ for $1 \mathrm{~g}{ }^{235} \mathrm{U}$ in a $100-s$ measurement. The accuracy should be better than $1 \%(2 \sigma)$ for wel1 characterized samples.

\section{References}

1. M. M. Stephens, "System Control for the Modulated ${ }^{252}$ Cf Source 'Shuffler'," LA-6007-MS (1975) Los Alamos Scientific Laboratory.

2. H. 0. Menlove, "Applications of ${ }^{252} \mathrm{Cf}$ in the Nuclear Industry," LA-UR-76-859 (1976) Los Alamos Scientific Laboratory.

9. Other Remarks - Bulk samples of product, scrap and waste in both solid or liquid form can be assayed for ${ }^{2}{ }^{5} \mathrm{U},{ }^{2}{ }^{39} \mathrm{Pu}$ and ${ }^{240} \mathrm{Pu}$. The instrument is used for high accuracy measurements on low level samples of mixed oxide or irradiated fuels. The instrument has been developed to a completed system for uranium detection at the $1 \mathrm{mg}$ to $1 \mathrm{~kg}$ fissile content leve 1 . 
1. Assay Instrument - Photoneutron Small Sample Assay System.

2. Developer - Los Alamos Scientific Laboratory.

3. Status/Estimated Availability - Undergoing lab tests. In-plant evaluation expected 1977-1978. Expected commercial availability - 1979.

4. Estimated Unit Cost $-\$ 40,000-60,000$.

5. Principle of Measurement - The sample is interrogated by sub-threshold neutrons from a $\mathrm{Sb}-\mathrm{Be}$ source. The fast fission neutrons induced in the assay sample are detected by biased "He detectors.

6. Description - A Sb-Be neutron source is located at the sample position. Biased ${ }^{4} \mathrm{He}$ detectors surround the sample and count fast neutrons from induced fissions.

7. Operating History - Undergoing 1ab tests. Counting time is 1-15 minutes depending upon fissile content. For a 7 minute measurement of an HTGR fuel rod containing $0.2 \mathrm{~g}$ of ${ }^{23} \mathrm{U}$, the precision of the measurement is $1.0 \%(1 \sigma)$. Accuracy of the instrument $1 s \sim 1 \%$ for fired HTGR fuel rods.

8. References

H. O. Menlove, R. A. Forster, and D. L. Matthews, "A Photoneutron Antimony-- 124 Beryllium System for Fissile Materials Assay," Nuclear Technology, Vo1. 19, September 1973.

9. Other Remarks - Materials measured include product, scrap and irradiated fuel in small samples containing ${ }^{235} \mathrm{U},{ }^{23} \mathrm{U}$ and ${ }^{239} \mathrm{Pu}$. Fissile content from $0.01 \mathrm{~g}$ to $100 \mathrm{~g}$ can be measured. The instrument is used for accurate assays of samples which require good penetrations and can be applied to spent fuel assay with only minor modifications. The laboratory model is currently being upgraded to a fully engineered field instrument. 
1. Assay Instrument - Elephant Gun.

2. Developer - Los Alamos Scientific Laboratory

3. Status/Estimated Availability - Evaluation complete. Commercially available.

4. Estimated Unit Cost - $\$ 8,000$ to 10,000 .

5. Principle of Measurement - Passive gamma rays from ${ }^{234} \mathrm{~Pa}(.767$ and $1.001 \mathrm{MeV}$ ) are detected by a NaI detector. Providing the daughter activity $\left({ }^{2}{ }^{4} \mathrm{~Pa}\right)$ is in equilibrium with the uranium (which requires an aging period of $>3$ months) the amount of ${ }^{238} \mathrm{U}$ can be related to this measurement. Counting the high energy daughter gamma-rays gives greater penetrability than the lower energy uranium gamma-rays.

6. Description - The detection system consists of a 5-in, by 5-in. NaI crystal enclosed in a 2-in.-thick lead shield and collimator. The detector is connected to a power supply, amplifier, scaler, single channel analyzer and timer. Either NIM bin or portable electronic units may be used.

7. Operating History - This instrument has been in use for 4 years at the GE Wilmington, N.C. LWR fuel fabrication plant. Measurement time is 5 minutes or less. The precision is $3 \%$ for a 5 minute count on a sample containing $1 \mathrm{~kg}$ of ${ }^{238} \mathrm{U}$ with a background rate of 300 counts/min. The accuracy is $12 \%(2 \sigma)$ for combustible waste in large containers. Detectability limits $(3 \sigma)$ is $\sim 30 \mathrm{~g}{ }^{238} \mathrm{U}$ at sea level for a 5 minute count.

8. References

R. B. Walton, E. I. Whitted and R. A. Forster, "Gamma-Ray Assay of Low Enriched Uranium Waste, "Nuclear Technology, Vo1. 24 (October 1974).

9. Other Remarks - The elephant gun may be used for the management of waste generated in LWR fuel fabrication facilities or to measure holdup in enrichment plants. It measures depleted, natural and low enriched uranium. This instrument will measure ${ }^{238} \mathrm{U}$ in amounts greater than $30 \mathrm{~g}$ in large containers of combustible waste, e.g., 55-gallon drums or p1ywood boxes. 
1. Assay Instrument - Active Neutron Interrogation System.

2. Developer - Los Alamos Scientific Laboratory

3. Status/Estimated Availability - Instrument has been tested under laboratory conditions. No plans to adapt to plant operations until such need is identified.

4. Estimated Unit Cost - $\$ 75,000$.

5. Principle of Measurement - Active interrogation with source neutrons and counting of delayed neutrons from induced fissions. The sample is irradiated with neutron spectra of two different average energies.

6. Description - A sealed-tube $14 \mathrm{MeV}$ neutron generator with and without a moderating assembly produce the interrogating neutron spectra. Data are collected by moderated ${ }^{3} \mathrm{He}$ tubes and two fission chambers connected to discriminators and scalers. Data analysis is currently done on a PDP-9 computer, but can be hand calculated. Sample is rotated and translated during data collection.

7. Operating History - This instrument has been used in a laboratory environment; there has been no commercial engineering development to date. Total time for two-spectra assay is 30 minutes. Measurement precision is $5-10 \%$ for ${ }^{2}{ }^{35} \mathrm{U}$, and $4-6 \%$ for ${ }^{232} \mathrm{Th}$. Sufficient data is not available to state accuracy.

8. References

R. H. Augustson and J. J. Malanify, "Investigation Into Assay Techniques for HTGR Fuel E1ements, "LA-5675 PR (1974) P. 9, Los Alamos Scientific Laboratory.

9. Other Remarks - Instruments measure ${ }^{235} \mathrm{U}$ (fissile) and thorium (fertile) in HTGR fuel elements. This material is difficult to measure any other way. The multi spectra irradiation technique is also applicable to other large samples. The possibility of using a radioactive source instead of the $14 \mathrm{MeV}$ generator is being investigated. 
1. Assay Instrument - Gamma Ray Spectrometer for Plutonium Analysis

2. Developer - Lawrence Livermore Laboratory, R. Gunnink (415-447-1100, x8730)

3. Status/Estimated Availability - Laboratory development and testing at LIL since 1973; prototype at Savannah River Plant since 1973, prototype II at Allied General Nuclear Services, Barnwell, 1976. Hardware components commercially available.

4. Estimated Cost - $\$ 50,000$ (includes detector and computer/analyzer)

5. Principle of Measurement - Gamma rays emitted during radioactive decay of plutonium isotopes are measured to determine amounts of individual isotope present or the attenuation of externally located gamma rays by the solution is used to determine the total amount of plutonium present.

6. Design and Operation -

6.1 Physical Layout - The spectrometer is a stand-alone system. The material to be analyzed is placed in close proximity to the detector. For analysis of solutions, any uniform container or counting cell of cylindrical shape can be used. The average plutonium concentration expected must be considered when selecting container size or volume. Samples containing 10-100 $\mathrm{mg}$ of plutonium are optional.

6.2 Detector and Electronics - A small ( $1 \mathrm{cc}$ ) germanium detector with high resolution ( $<500 \mathrm{eV}$, FWHM, at $122 \mathrm{keV})$ is used. Electronics included preamplifier, amplifier, live-time corrector, pulse-light stabilizer and mini-computer. The hardware components are all commercially available.

6.3 Data Interpretation and Readout - Special computer codes are used to analyze the spectral data. Calibration parameters are stored in data files and accessed by the codes as required. Computer output includes disintegration rates, number of atoms and isotopic concentrations of the various isotopes of interest at both time of count and a designated zero time.

7. Operating History - Gamma Ray spectrometry systems have been in routine operation for the analysis of weapons grade plutonium at LLL and the Savannah River Plant since 1973. A second prototype system to be used for joint experiments with Allied General was shipped to Barnwell in 1976. A comparison of the accuracy of gamma spectrometric isotopic measurements with those by mass spectrometry is given in the table.

\begin{tabular}{|c|c|c|c|}
\hline Isotope & Abundance (q) & $\begin{array}{l}\text { Standard Deviati } \\
\gamma \text {-spec. from Mas }\end{array}$ & $\begin{array}{l}\text { of } \\
\text { spec. }\end{array}$ \\
\hline $\begin{array}{l}238 \\
239 \\
240 \\
241\end{array}$ & $\begin{array}{c}0.01 \\
93 . \\
5 . \\
0.6\end{array}$ & $\begin{array}{c}\text { Recent1y Processed } \\
3.08 \\
0.04 \\
0.6 \\
1.0\end{array}$ & $\begin{array}{l}\text { Aged } \\
5.08 \\
0.05 \\
1.0 \\
0.7\end{array}$ \\
\hline
\end{tabular}

8. References

R. Gunnink, J. B. Niday, P. Siemans, "A system for Plutonium

Analysis by Gamma Ray Spectrometry," UCRL-51577 (1974).

Part I: Techniques for Analysis of Solutions

Part II: Computer Progress for Data Reduction and Interpretation 
1. Equipment: Automated Plutonium Assay system

2. Developer: Mound Laboratory, C. L. Fellers and M. F. Duff 513-866-7444

3. Status/Estimated Availability: System evaluation, including reliability and accuracy test results, as well as engineering design recommendation will be available by late 1977.

4. Estimated Unit Cost: This prototype assay system is being developed for demonstration and evaluation purposes. Unit cost will be system dependent.

5. Principle of Measurement: A nondestructive analysis of the total plutonium content in a discrete container is made by measuring the heat output of the sample in a calorimeter and the material isotopics in a gamma-ray spectrometer. The assay instrumentation is located in a closed boxline and supplied with samples by means of a three-axis transport system interfaced to a computer. The assay system is totally automated and can operate without operator intervention.

6. Description: The prototype [1] system consists of three glove boxes housing two twin-resistance bridge calorimeters (space is available for six calorimeters), one high resolution germanium gamma-ray spectrometer, six temperature controlled buffer storage wells and a three-axis transport system. A central process computer located externally to the boxline controls the movement of the samples in the boxline, collects and analyzes data from the calorimeters and spectrometer and generates a final assay report.

This prototype assay system is being developed to allow for concept evaluation and demonstration. The system design recommendation and the test results will be available to commercial manufacturers for incorporation of automated assay systems in future fuel processing plants.

7. Operating History: Preliminary tests [2] indicate that the calorimeters have a precision of 0.068 based on 10 replicate measurements on a 3-watt $\mathrm{Pu}-238$ heat standard and an equilibrium time of approximately 40 minutes.

8. References:

(1) J. F. Lemming, J. H. Birden and R. A. Neff, "An In-Line Automated Plutonium Assay System," Proceedings of the Seventeenth Annual Meeting of the Institute of Nuclear Materials Management, Seattle, Washington, June 22-24, 1976, pp. 156-163.

(2) J. F. Lemming et al., "An Automated Nondestructive Assay System," Proceedings of the 1976 Nuclear Science Symposium. 
1. Instrument - Gamma Ray Absorptimeter

2. Developer - Allied Chemical-Idaho Chemical Programs, Idaho National Engineering Laboratory. F. O. Cartan (208-526-0111, ext. 3323)

3. Status/Availability - Second version of instrument is ready for in-plant testing; drawings of instrument are available.

4. Estimated Cost - $\$ 20 \mathrm{~K}-\$ 30 \mathrm{~K}$ (estimated)

5. Principle of Measurement - The instrument measures the concentration of streams of pure uranyl or plutonium nitrate dissolved in water- $\mathrm{HNO}_{3}$ mixtures by determining the attenuation of gamma rays passing through layers of the solution. Attenuation is measured at two energies, $59.6 \mathrm{kev}$ and $661 \mathrm{kev}$ (to correct for variations in the nitric acid content).

6. Description - The uranium or plutonium solutions flow through a titanium cell with liquid paths of $4 \mathrm{~mm}$ and $3 \mathrm{~cm}$. Collimated gamma sources of Am-24l (60 kev) and Cs-137 (662 kev) are mounted in line with NaI (Tl) detectors arranged so the gamma beams pass either through the flow cells or through reference adsorbers. Both sources can be shuttered to correct for solution activity.

A remote enclosure contains the counting electronics and a controlling mini-computer.

7. Operating History - The absorptimeter has been tested in the laboratory. The tests indicate a precision of $0.5 \%$ or better (1 std dev) for concentrations of 100-300 $\mathrm{g} / \mathrm{L}$. 
B.5.2 Other Physical Techniques for Bulk and Sample Measurement

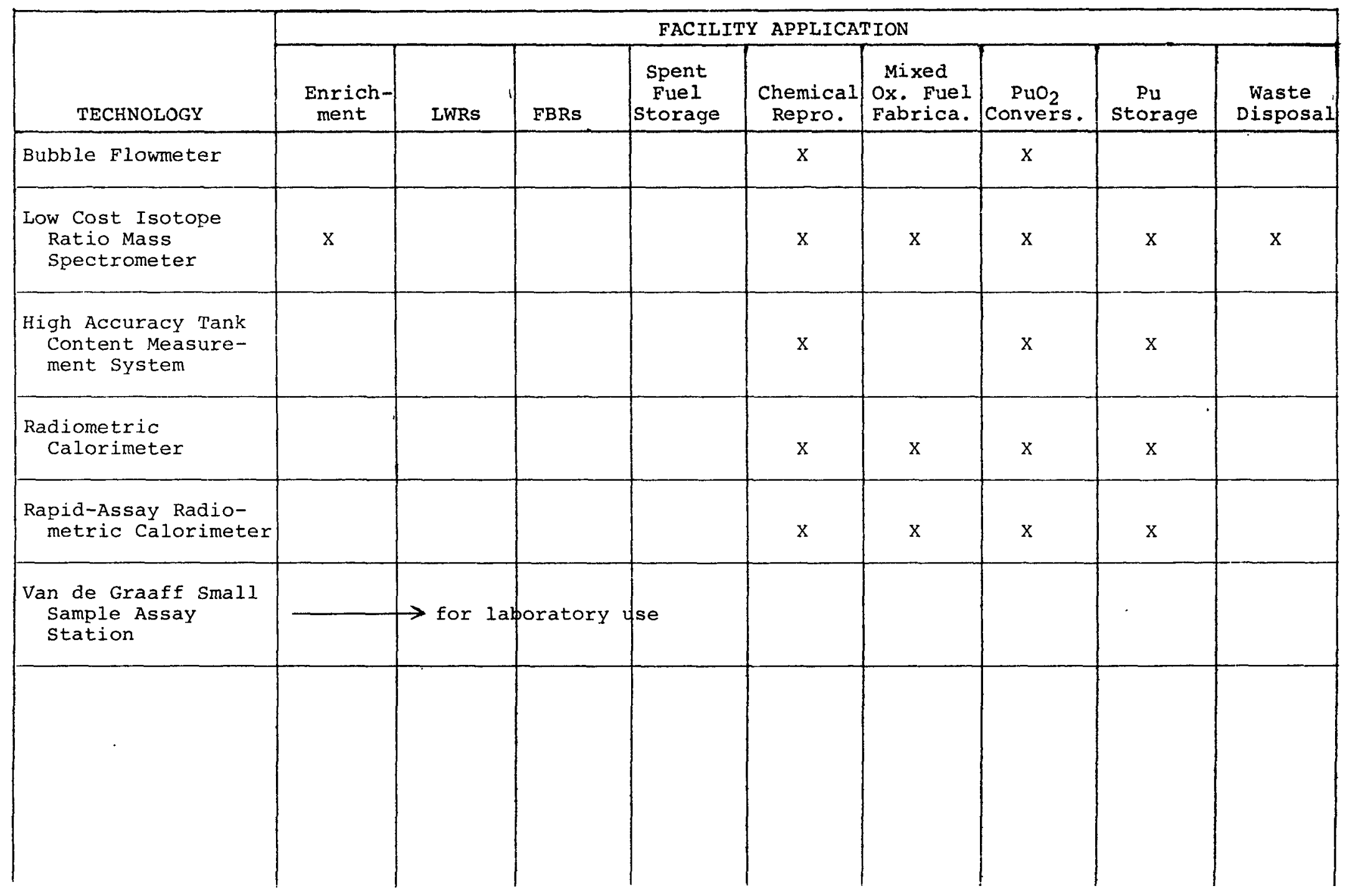


1. Instrument - Bubble flowmeter

2. Developer - Allied Chemical-Idaho Chemical Programs Office (Idaho National Engineering Laboratory) H. R. Deveraux (208-526-0111 Ext. 3324)

3. Status/Availability - Initial development tests are complete. A prototype is ready for in-plant testing summer 1977.

4. Estimated Cost - Not determined. Estimated to be $\$ 5 \mathrm{~K}$ to $\$ 7 \mathrm{~K}$ exclusive of remote computer.

5. Principle - The instrument measures the transit time of a bubble between two ultrasonic sensors mounted on a pipe.

6. Operation - On command a bubble is injected into the flow moving thru a horizontal stretch of line. The bubble is detected by the first ultrasonic sensor, starting a timer. The timer is shut off when the bubble is detected by a second sensor. The flow rate is calculated from elapsed time and knowledge of flow path geometry. A remote computer is normally used to initiate the measurement sequence and to read the timer.

7. Performance - Development experience only - The instrument has demonstrated an accuracy of $0.5 \%$ for water flows of roughly 1 liter $/ \mathrm{min}$. The instrument is suited to low flows and low viscosity corrosive or radioactive liquids. Periodic calibrations are unnecessary.

8. Reference - None 
1. Instrument - Low Cost Isotope Ratio Mass Spectrometer

2. Developer - Allied Chemical-Idaho Chemical Programs Office (Idaho National Engineering Laboratory) F. O. Cartan (208526-0111 Ext. 3323)

3. Status - Completing development tests - In plant use scheduled for fall 1977 .

4. Unit Cost - $\$ 60 \mathrm{~K}(30-40 \mathrm{~K} \$$ estimated for production models) for development model

5. Principle - The isotope ratio of uranium or plutonium is measured with a quadrupole mass spectrometer. A dual filament thermal emission source is used.

6. Design/Operation - The machine is designed specifically for moderate accuracy $\mathrm{U}$ or $\mathrm{Pu}$ isotope ratio measurements. The mass spectrometer and its electronics are mounted in two cabinets with wheels for mobility. The system could also be mounted in a light van for use by NRC or IAEA inspectors. The instrument cabinet contains the mass filter, the vacuum system and a sample glove box surrounding the source. The electronics cabinet contains the electronics, and a microcomputer used to control the instrument and calculate the isotope ratios.

The selected ions are connected by an ion multiplier allowing samples of $1 \mu \mathrm{gm}$ or less to be used.

7. Operating History - Developmental History - An 8-day test showed satisfactory operation and sample rate of $3 / \mathrm{hr}$. Resolution of 233 and an abundance sensitivity of 3500 were obtained.*

8. References - *F. E. Jones and F. O. Cartan, "A Preliminary Evaluation of a Quadrupole Mass Spectrometer for Safeguards Isotope Ratio Measurements, ICP-1085 (May 1976). 
1. Instrument - High Accuracy Tank Content Measurement System

2. Developer - Allied Chemical-Idaho Chemical Programs (Idaho National Engineering Laboratory) F. O. Cartan (208-526-0111 Ext. 3323)

3. Status - Development is near complete. The system will be tested in the plant during 1977.

4. Estimated Unit Cost - Dependent on number of tanks to be measured and the degree of multiplexing permitted. Estimated cost range $(\$ 2,000-\$ 15,000 /$ tank $)$

5. Principle - The system uses high-accuracy pressure transducers connected to conventional tank bubbler probes to measure level, density and weight of liquid in tank.*

6. Description - High accuracy pressure transducers $(0.01 \%)$ are arranged to read the pneumatic output of the level and density bubbler pairs. The transducer outputs are read by a remote computer. Several tanks can be read with the same transducers by pneumatic valving.

7. Operating History - A previous development system operated for 3-4 months and demonstrated the expected accuracy, but had minor problems with pneumatic multiplexer. Present system should not have this fault.

8. References $-*_{F}$. M. Groth and F. O. Cartan, "Evaluation of Instrumentation for Nuclear Fuels Reprocessing Plant Input Weight Measurements," ICP-1014 (1972) 
1. Equipment: Radiometric Calorimeters

2. Developer: Mound Laboratory, C. L. Fellers and J. H. Birden, 513-866-7444

3. Status/Estimated Availability: Currently available.

4. Estimated Unit Cost: $\$ 30,000-\$ 50,000$.

5. Principle: The calorimeters measure the amount of heat generated by the radioactive decay of nuclear materials [1]. The quantity of heat is determined by measuring the temperature rise caused by the sample power and comparing it to the temperature rise caused by a known amount of power supplied to an electric heater in the calorimeter. If the isotopic content of the sample is known, the quantity of nuclear material in the sample can be determined from the measured heat output.

6. Description: The calorimeters which are of the twin-resistance bridge design are immersed in a temperature-controlled environmental water bath. The larger calorimeter accommodating samples up to 4-3/4" diam and 8-3/4" high with a power output between 0.1 watt and 20 watts is servo-controlled [2]. The smaller calorimeter can accommodate analytical samples up to 1" diam and 3" high with a power output between 10 milliwatts and 3 watts and is operated by the replacement method.

7. Operating History: Accuracies relative to a calibrated Pu-238 heat standard of $0.1 \%$ can be obtained within one to two hours in the 4-3/4" by 8" calorimeter operating in a servo-controlpreequilibration mode [2].

The 1" by 3" analytical calorimeter has a demonstrated accuracy relative to a $\mathrm{Pu}-238$ heat standard of $+0.01 \%+2$ microwatts in times ranging from two to four hours.

8. References:

1. W. W. Rodenburg, "Fundamentals of Calorimetric Assay," Proceeding of the Symposium on the Calorimetric Assay of Plutonium, October 24-25, 1973, MLM-2177.

2. F. A. O'Hara, J. D. Nutter, W. W. Rodenburg, M. L. Dinsmore, "Calorimetry for Safeguards Purposes," MLM-1798, 1972. 
1. Equipment: Rapid-Assay Radiometric Calorimeters

2. Developer: Mound Laboratory, C. L. Fellers and J. R. Wetzel 513-866-7444

3. Status and Estimated Availability: The calorimeters are currently available but associated software and hardware are in development. Complete system will be available by the end of FY78.

4. Estimated Unit Cost: $\$ 45,000-\$ 55,000$.

5. Principle: The rapid-assay calorimeters measure the amount of heat generated by the decay of radioactive material, but they perform the analysis more rapidly than calorimeters operated by the replacement or analog servo-control modes [1]. A mathematical technique which allows for prediction of a final equilibrium value in advance of actually obtaining an equilibrium condition can be applied to a conventionally operated calorimeter or may be combined with a digitally controlled mode of operation.

6. Description: The calorimeters which are of the twin-resistance bridge design are immersed in a temperature-controlled water bath. The larger calorimeter can accommodate samples up to 4-3/4" diam and 8-3/4" high with a power output between 0.1 watt and 20 watts. The smaller calorimeter can accommodate samples up to 1 " diam and 3" high with a power output between 10 milliwatts and 3 watts. Digital servo instrumentation including a high impedance digital voltmeter and a microprocessor will be interfaced to the calorimeter to provide servo control, data collection and data reduction. The mathematical prediction technique will be incorporated in a microprocessor interfaced directly to the calorimeter or combined with the servo instrumentation.

7. Operating History: Reductions in calorimeter assay time ranging from $40 \%$ to $70 \%$ have been obtained using a single exponential mathematical prediction technique [2].

8. References:

I. W. W. Rodenburg, "Fundamentals of Calorimetric Assay," Proceedings of the Symposium on the Calorimetric Assay of Plutonium, October 24-25, 1973, MLM-2177.

2. C. L. Fellers and P. W. Seabaugh, "Prediction of Calorimeter Equilibrium," Proceedings of the Seventh Annual Meeting of the Institute of Nuclear Materials Management, Seattle, Washington, January 22-24, 1976, pp. 179-188. 
1. Assay Instrument - Van de Graaff Smal1-Sample Assay Station.

2. Developer - Los Alamos Scientific Laboratory.

3. Status/Estimated Availability - Tested in 1aboratory. Ready for commercialization.

4. Estimated Unit Cost - $\$ 25,000$ for assay related equipment exclusive of Van de Graaff or other neutron source.

5. Principle of Measurement - Active neutron interrogation based on counting of delayed neutrons from fissions induced by neutrons of selectable energy. The neutron beam is pulsed on for $40 \mathrm{~ms}$ and off $60 \mathrm{~ms}$ repetitively. Delayed neutrons are counted during part of the off periods. Assays are normalized to appropriate standards.

6. Description - Neutrons for active interrogation are produced using the Van de Graaff generator for $(p, \eta)$ and $(\alpha, \eta)$ reactions. Delayed neutrons are counted using $39{ }^{3} \mathrm{He}$ detectors in polyethylene. A fission chamber is used to normalize the delayed neutron count. Samples are shielded from lower energy neutrons by $a \cdot 75-i n$. pressed $B_{4} C$ shield.

7. Operating History - This technique has been used in the laboratory for 10 years. Counting statistics and attenuation and/or multiplication effects determine precision and are tailored to specific samples. A $600 \mathrm{~s}$ counting time yields a $1 \%$ accuracy measurement for $300 \mathrm{mg}$ of ${ }^{235} \mathrm{U}$. Forty of these measurements can be performed per day. Accuracy has been established as . $1 \%$ to $.2 \%$ under good conditions.

8. References

A. E. Evans, "The Expanding Role of the Small Van de Graaff in Nuclear Nondestructive Analysis," IEEE Transactions on Nuclear Science," Vo1. NS-20, No. 3, June 1973.

9. Other Remarks - This technique measures fissile content of small samples and small standards in the form of dry solids. It is applicable to a wide range of materials, but considerable research and testing are necessary to assure good results for the assay of each new type of material. It provides rapid assay of inventory verification, samples, precision intercomparison of standards for other systems, and normalization of "round robin" results. 
B.5.3 Analytical Chemistry Techniques for Bulk and Sample Measurement

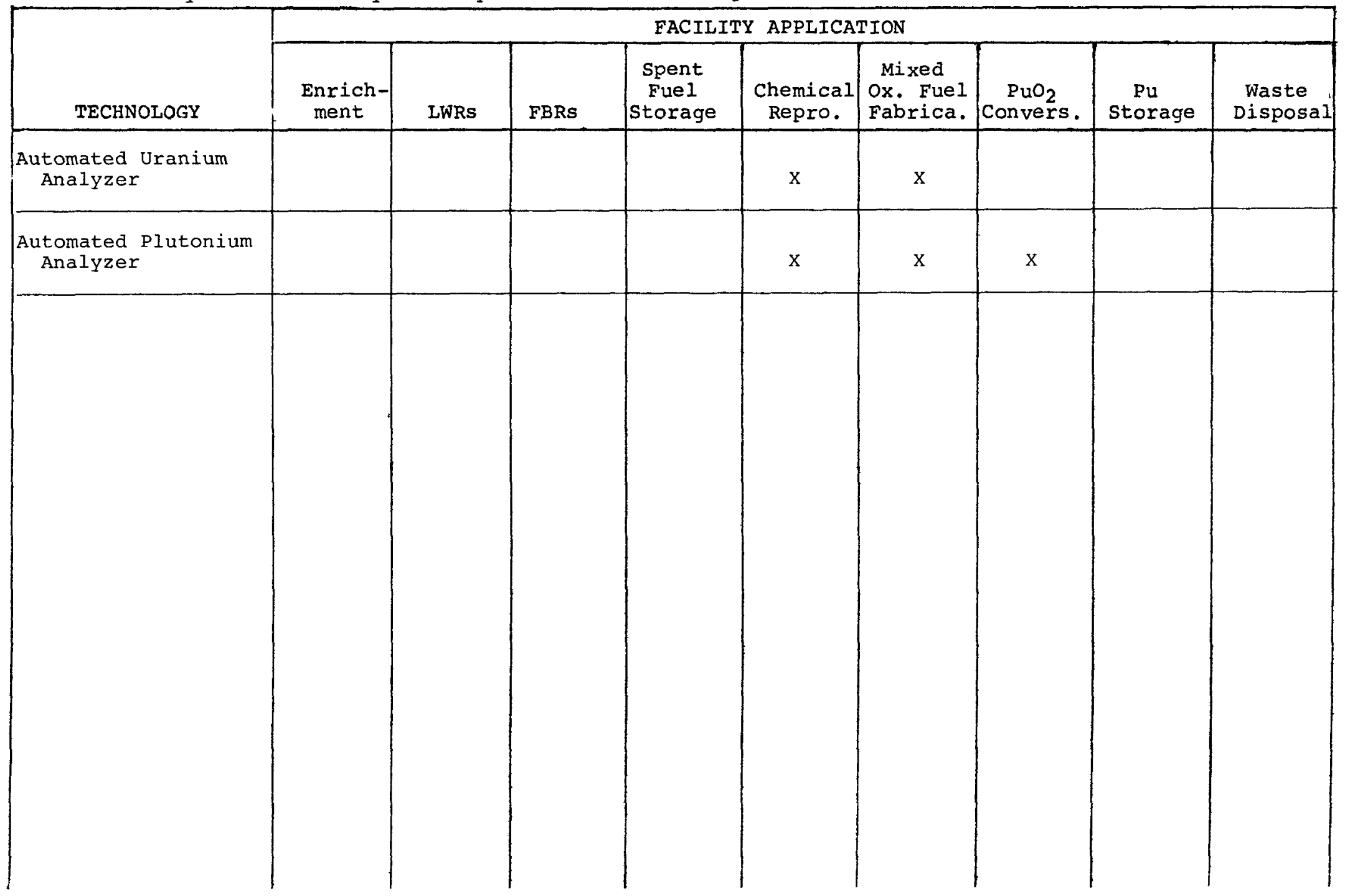


1. Assay Instrument - Automated Plutonium Analyzer

2. Developer - DOE, New Brunswick Laboratory (Ref.1,2)

3. Status/Estimated Availability - Undergoing laboratory prototype testing. Commercialization possible by 1979.

4. Estimated Unit Cost $\sim \$ 50,000$.

5. Principle of Operation - Up to ten solutions of a dissolved sample or reference material are treated by selective addition of reagents to adjust the plutonium valence. The plutonium is purified by ion-exchange separation, aliquoted into beakers and mechanically sequenced into position for analysis by controlled-potential coulometry.

6. Design and Operation

At the present time, separate mechanized prototype modules (AUTOSEP for the ion-exchange purification, AUTOALIQUOT for transferring solution aliquots and AUTOCOULOMETER for the movement and measurement of purified sample solutions) exist and have been tested on the bench and in the glove box. These modules will be appropriately interfaced, mechanical timers and controllers replaced by microprocessor control and subjected to intensive system evaluation.

7. Operating History

On plutonium standards and synthetic samples, system recovery data (transfer, purification and mesurement) show a mean and standard deviation of $99.98 \pm 0.058$.

8. References

1. G. E. Peoples, S. A. Malone, J. R. Weiss, A. W. Wenzel and C. E. Pietri, NBL-277

(February 1976), pp. 80-85.

2. R. J. Greer, C. E. Pietri, J. R. Weiss and

A. W. Wenzel, NBL-277 (February 1976),

pp. 89-92. 
1. Assay Instrument - Automated Uranium Analyzer

2. Developer - Lawrence Livermore Laboratory/DOE New Brunswick Laboratory (Ref.1,2).

3. Status/Estimated Availability - Undergoing final testing and evaluation. Commercialization possible in late 1977 or early 1978.

4. Estimated Unit Cost - $\$ 50,000-80,000$ (depending upon configuration and software).

5. Principle of Measurement - Up to 44 prepared solutions each containing 50-120 $\mathrm{mg}$ of uranium are titrated with electrogenerated vanadium(V) by constant-current coulometry. The end-point is computer-calculated based upon potentiometric measurements stored by the computer during the titration. The uranium content of the weighed sample solution aliquot is calculated from the Faraday relation.

6. Design and Operation

a. Physical Layout - The system consists of a digital electronic semi-micro balance, a sample handling system, a reagent delivery system, a precision constant-current source, an electrode potential monitori.ig system, a control panel and a digital keyboard - all controlled by a PDP-8e minicomputer. The physical layout can be adapted to space available - approximately $75 \mathrm{sq}$. ft. are required.

b. Operation - Sample weight, sample solution weight and/or sample solution aliquot weight can be entered into the computer via the digital balance and the keyboard. Sample identification $A-X X X X-X-X(A=$ letter, $X=$ numeral $)$ is related to a location number $(1-44)$ on the sample changer by the operator and entered into the computer. An optical reader senses the position number. A prepared solution or reference standard solution containing 40-120 $\mathrm{mg}$ of uranium in $<15 \mathrm{ml}$ of solution is brought into position and necessary reagents added in timed intervals. After all re- 
agents have been added and completion of reactions has occurred, an oxidant vanadium(V) is electrogenerated at constant-current (initially $400 \mathrm{~mA}$ ) at a gold mesh working electrode. The potential of the solution, a function of the $V^{5} / V^{4}$ and $U^{6} / U^{4}$ ratios, relative to a standard reference electrode is monitored by the computer. At a preselected slope of the potential-coulomb curve, generation of the oxidant is switched to a lower rate $(\sim 10 \mathrm{~mA})$ and titration through the end-point proceeds. From the potentiometric data, the computer calculates the end point, the coulombs expended in the titration, and the quantity of uranium present. If the titrated sample was a reference sample, the computer prints an error message based on the value stored for that reference standard.

c. Data Readout - Data are read out at a DEC writer. The titration curve can be displayed on a recorder.

d. Fault Detection - Failure of the titration beaker to seat properly, failure of reagent flow or flow at wrong time, improper potential at generator or reference electrode, inability to detect or compute an end point, or an observed value for a standard outside of prescribed limits will result in a local alarm and a printed fault message.

7. Operating History

On several hundred prepared uranium standard solutions over the 40-120 $\mathrm{mg}$ U range, a mean relative difference of $-0.05+0.09 \%$ has been observed (uncertainty is one standar d deviation). On a limited number of actual samples the titrator exhibited a mean and standard deviation of the relative difference from reported values of $-0.01 \pm 0.14 \%$.

8. References

1. J. E. Harrar, et.al., Nuclear Materials Management, 5, No.3, 199-210, (1976).

2. C. G. Goldbeck and M. W. Lerner, Anal. Chem., 44, $594(1972)$. 
B.5.4 Storage Vaults and Seals

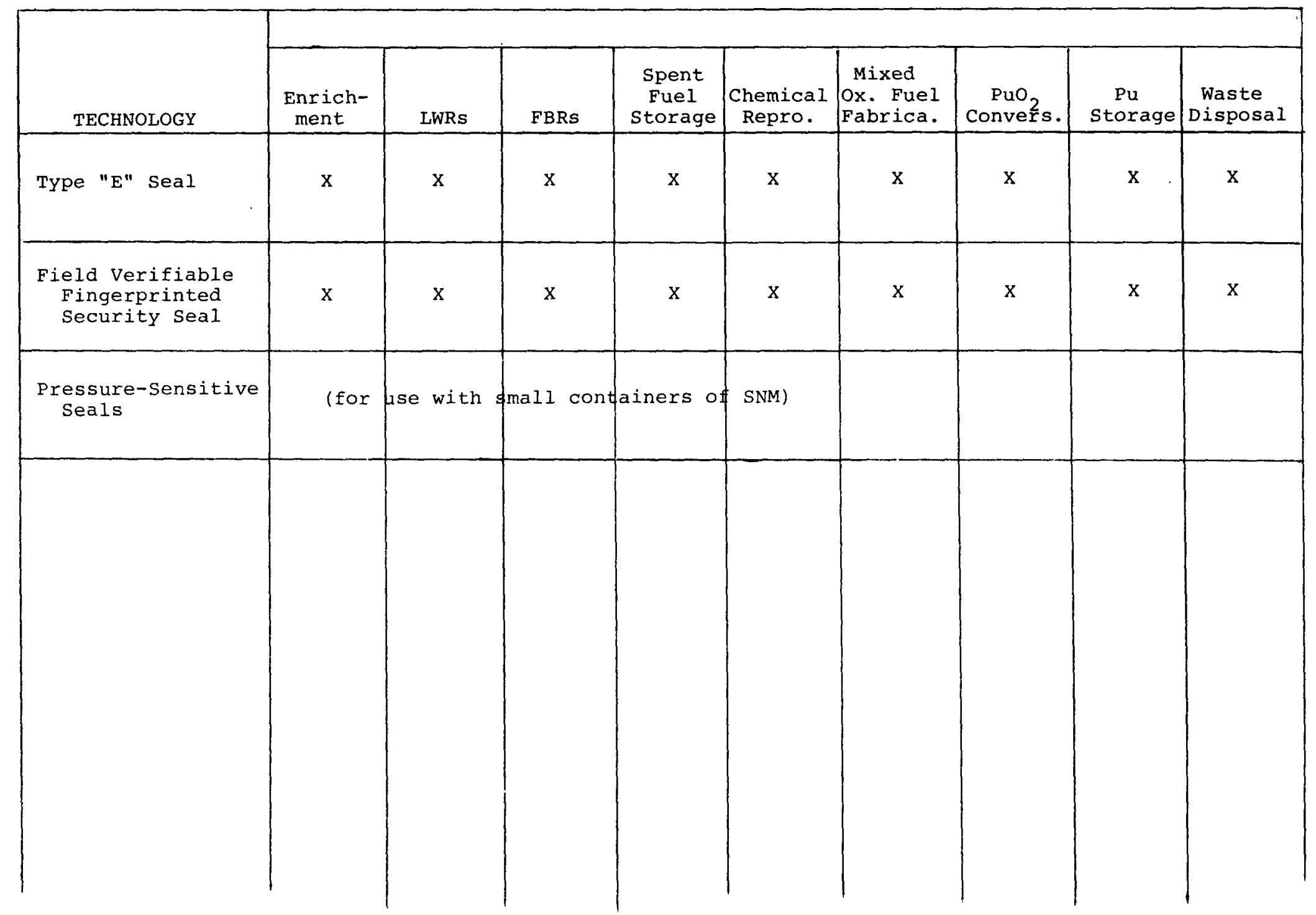


1. Equipment - Type "E" Seal

2. Developer - Brookhaven National Laboratory, C. Sastre (516) 345-4077, L. Green (516) 345-2944.

3. Status/Estimated Availability - Brookhaven National Laboratory and Sandia Laboratories have a capability for preparing, fingerprinting and examining seals. This sealing system is ready for commercial development.

4. Estimated Unit Cost - $\$ 10$ to $\$ 20$ for application and examination.

5. Principle and Application - This sealing system is based on the modification of a seal that is manufactured by American Casting and Manufacturing Corporation. After modification, the seals are uniquely marked to permit verification after use. Seals may be applied to hasps on container closures, doors or gates. Other applications could include reactor heads, valve handles and control handles. Seals and wire are returned to a laboratory for examination for tampering.

6. Description - Formed by two parts (top and bottom) through which the ends of a multistrand cable used for securing some objects are fastened. The seal parts are formed from sheet copper and brass.

7. Operating History - Three separate laboratories have tested the sealing system for operability and vulnerability. The system has been recommended for use in NUREG Guide 5.15.

8. References - Report BNL-1340 dated March 8, 1969, The Use of Seals as a safeguards Tool.

Task Paper 2.1-2 dated July 1969, on testing type E security seals.

Task Paper 2.13 dated April 28, 1971, on use of tamperindicating containers for shipment of unirradiated reactor fuel.

Manual \#1, Preparation and Examination of High Security Type E Seals, August 30, 1971.

Manual \#2, Field Use and Application of Type E Seals, October 24, 1974 . 
1. Equipment - Field Verifiable Fingerprinted Security Seal.

2. Developer - Brookhaven National Laboratory, C. Sastre, (516) 345-4077.

3. Status/Estimated Availability - A small number of seals have been hand-crafted. Commercial development is possible by 1978 .

4. Estimated Unit Cost $-\$ 1.00$ to $\$ 5.00$ for application and verification.

5. Principle and Application - Seal contains a random pattern fingerprint that is readable in the field. Seals may be applied to hasps on container closures, doors or gates. other applications could include valve handles and control handles.

6. Description - A seal consists of a cylinder of thermosetting clear plastic with two tapered holes on one face to receive matching tapered plugs which cover the ends of a segment of multistrand cable used to secure the opening to be sealed.

In the body of the plastic are suspended particles of colored plastic. The fingerprint is the set of coordinates of the positions of a selected number of particles, measured against an integral reference system.

7. Operational History - Test of vulnerability and operability were performed at Brookhaven National Lab. No field use to date.

8. Reference - C. Sastre - Security Seals for Safeguards, BNL 18553, January 4, 1974. 
1. Equipment - Pressure-Sensitive Seals.

2. Developer - Brookhaven National Laboratory, C. Sastre (516) 345-4077, L. Green (516) 345-2944.

3. Status/Estimated Availability - A set of specifications have been developed to permit commercial purchase.

4. Estimated Unit Cost $-\$ .50$ to $\$ 1.00$ for application and verification.

5. Principle and Application - Seal is a label printed on special pressure sensitive adhesive material. The seal is used for tamper-safing containers of SNM in storage. Visual examination for tampering is made in the field.

6. Description - Seals are constructed of sheet vinyl or paper with pressure sensitive adhesive backing. The seal material will tear if attempts are made to peel it. Attempts to remove the seal using solvents will cause the ink to run or will destroy the seal material.

7. Operational History - A number of DOE and commercial facilities are using the seal. NUREG Guide 5.10 recommends use of these seals.

8. References - TSO File 5.3.51.5 - Specifications for Pressure Sensitive Seals, February 11, 1976. 


\section{B.6 Inter-Facility Transportation}

Because the fuel cycle facilities are located at different sites, transportation links are necessary to move spent fuel, solidified waste, and fresh fuel between the various installations. Link requirements are poorly defined at present due to uncertainties in material forms, container configurations, radiation activity, thermal properties, optimum shipment size, economic constraints, and sabotage/theft sensitivity. Many of the unknowns are interdependent, and their degree of definition is directly proportional to the maturity of other LWR fuel cycle concepts.

\section{Plutonium Oxide Transportation Vehicle and Shipping Container}

Sandia Laboratories is completing the concept definition for a commercially-operated vehicle for the safe, secure transport of large-quantity shipments of plutonium oxide. The primary objective of this program was to define advanced, cost-effective physical protection measures for the transportation vehicle and associated shipping container designs, while maintaining compatibility with facility designs and operations. To accomplish this objective, close coordination has been maintained with the fuel cycle industry.

Initial effort consisted of design, analysis, and modeling activities leading to a conceptual design definition of the transportation vehicle and shipping container. Data from this test program will be used to establish a representative design.

$$
\text { B-109 }
$$


B.7. Inspection, Assessment and Verification

The experience of the DOE program in the area of inspection, assessment and verification is being documented in report form. The set of reports available in the near term is indicated in the B.7 summary table and the data sheets which follow.

The value of these reports in the safeguards planning program is the development of an awareness of potential inspection requirements that may be levied and inspection options that could be used for internal management control. These provide guidance not only on performance levels (especially when accuracy of a particular measurement may be somewhat arbitrary, e.g., .001 vs .002 , within the context of the whole system), but also enable the facility design to be developed compatible with inspection access needs. 
B. 7 Inspection, Assessment and Verification

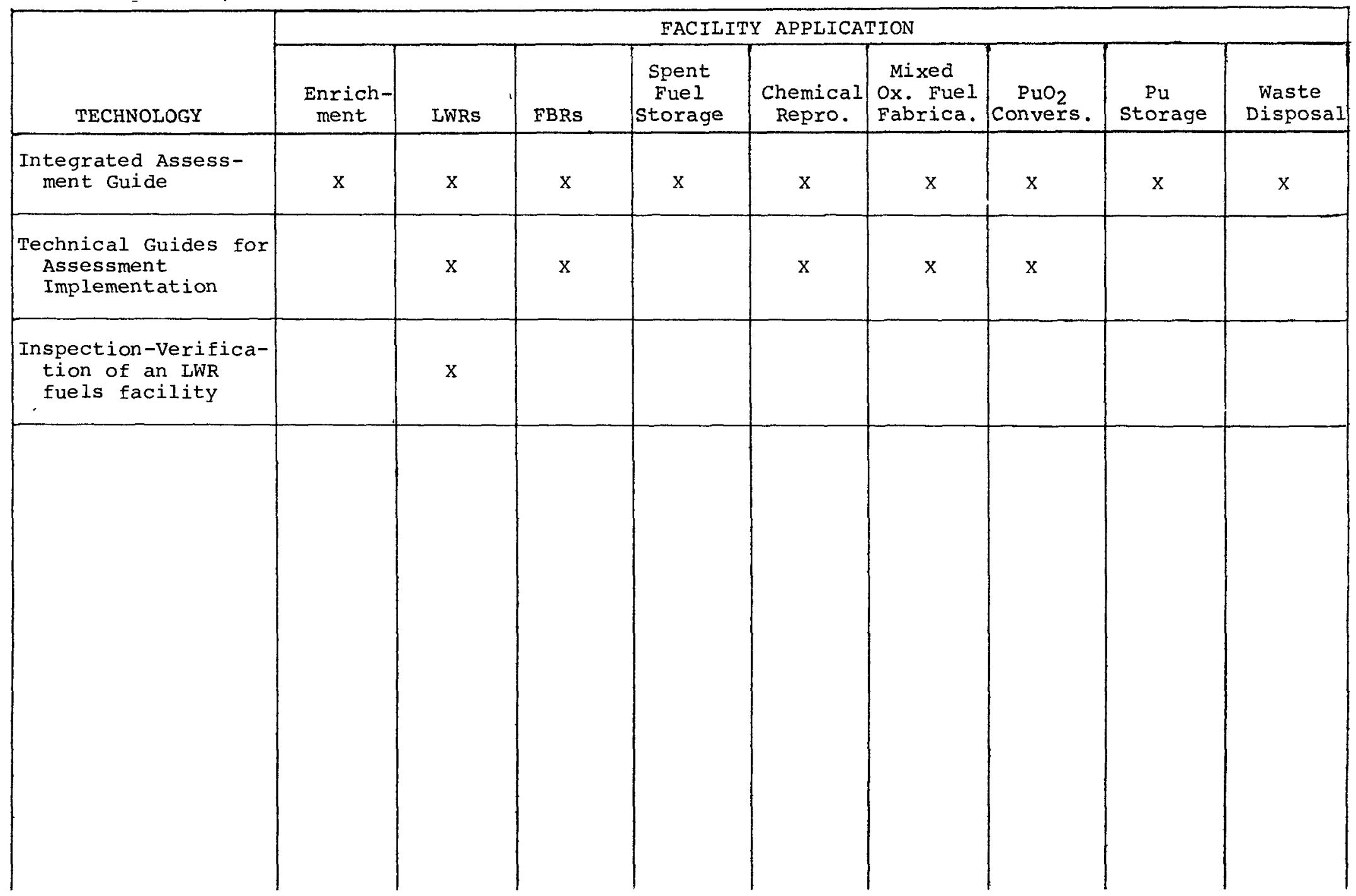


1. Inspection Plan - a report describing inspection-verification of operator materials accounting data in a LWR fuel fabrication facility.

2. Developer - Battelle-Northwest, R. J. Sorenson (509-946-2372), and Brookhaven National Laboratory, L. Green (516-345-2123).

3. Status/Availability - A draft of the report has been prepared. It is in the review process and is expected to be issued by Fall, 1977 .

4. Estimated Unit Cost - Not known.

5. Principle - (not applicable).

6. Description - The report describes the application of a systematic assessment and verification procedure to the materials accounting system of a specific type of licensed facility. The key parameters are the number and types of independent samples and measurements required to achieve various defined degrees of confidence that the operator's stated material balance is correct.

7. Operating History - The inspection procedure is patterned after the procedure developed in previous studies for DOE and IAEA application (references 1, 2).

8. References - (1) Hough, C. G., Schneider, R. A., Stewart, K. B., Jaech, J. L., and Bennett, C. A., Example of Verification and Acceptance of Operator Data-Low Enriched Uranium Fabrication, BNWL-1852, August 1974 .

(2) Stewart, K. B. and Schneider, R. A., "Verification Sampling Techniques in a Safeguards Situation," Nucl. Mater. Manage., Vol. III, No. I, Spring 1974. 
1. Inspection Plan - an integrated assessment guide for safeguards and security (a report).

2. Developer - Battelle-Northwest, R. J. Sorenson (509-946-2372).

3. Status/Availability - Comprehensive outline complete; report for ERDA/DSS review is expected to be available by July 1977 . Technical appendices scheduled for four to six months later.

4. Estimated Unit Cost - Not known.

5. Principle - (not applicable).

6. Description - The guide will describe the roles and responsibilities for both planning and administering assessment systems for safeguards and security at DOE field offices and contractor facilities. It will also describe general approaches and reference specific sources of methodology for assessment. The technical appendices will contain sufficient technical detail to meet the needs of field offices' personnel.

7. Operating History - The safeguards materials accounting assessment methodology was developed for DOE in previous work on the program (references $1,2,3$ ).

8. References - (1) Hough, C. G., Schneider, R. A., Stewart, K. B., Jaech, J. L., and Bennett, C. A., Example of Verifification and Acceptance of Operator Data-Low Enriched Uranium Fabrication, BNWL-1852, August 1974 .

(2) Stewart, K. B. and Schneider, R. A., "Verification Sampling Techniques in a Safeguards Situation," Nucl. Mater. Manage., Vol. III, No. I, Spring 1974.

(3) Sorenson, R. J., Stewart, K. B., and Schneider, R. A., "A Structural Approach to Inspection," Nucl. Mater. Manage., Vol. V, No. III, pp. 580-591, fall $19 \overline{76 .}$ 
1. Inspection Plan - technical guides for implementation of safeguards assessment methods (a report).

2. Developer - Battelle-Northwest, R. J. Sorenson (509-946-2372).

3. Status/Availability - Drafts of guides on several subjects related to assessment of materials accounting systems are prepared. The work on additional guides on this subject will be completed by December 1977. Guides in the physical protection area of safeguards and in personnel and document security are expected to be the subject of program efforts in FY 1978 .

4. Estimated Unit Cost - Not known.

5. Principle - (not applicable).

6. Description - The guides give the procedures and analysis methods recommended for use by DOE inspectors of safeguards systems. They will help ensure uniform application of principles by inspectors at all field offices.

7. Operating History - The bases of these guidelines were developed over several years in prior work for ERDA at this laboratory (references $1,2,3$ ).

8. References - (1) Hough, C. G., Schneider, R. A., Stewart, K. B., Jaech, J. L., and Bennett, C. A., Example of Verification and Acceptance of Operator Data-Low Enriched Uranium Fabrication, BNWL-1852, August 1974 .

(2) Stewart, K. B. and Schneider, R. A., "Verification Sampling Techniques in a Safeguards Situation," Nucl. Mater. Manage., Vol. III, No. I, Spring 1974. (3) Sorenson, R. J., Stewart, K. B., and Schneider, R. A., "A Structural Approach to Inspection," Nucl. Mater. Manage., Vol. V, No. III, pp. 580-591, fall 1976. 


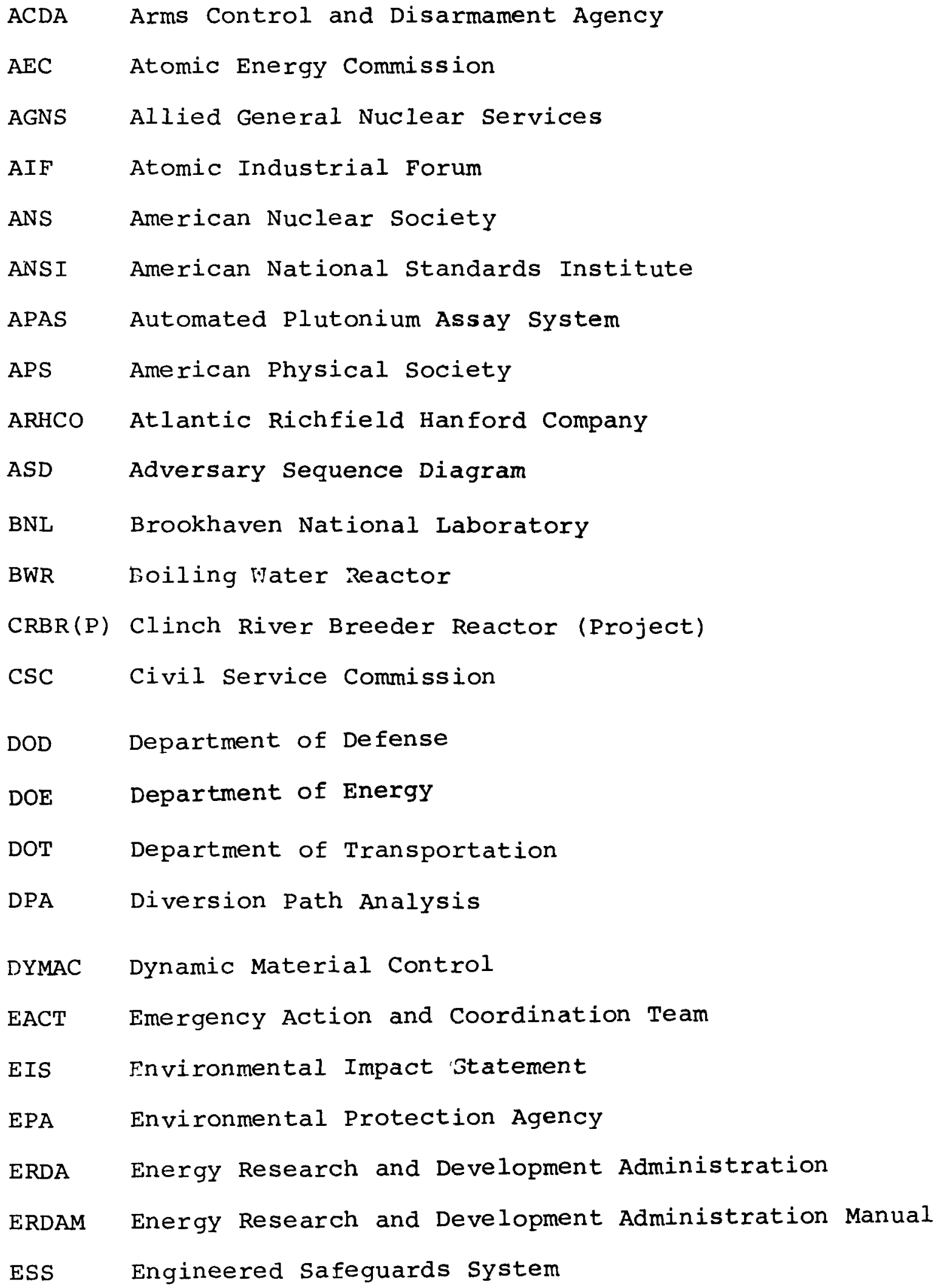


FBI Federal Bureau of Investigation

FBR Fast Breeder Reactor

FESEM Forcible Entry Safeguards Effectiveness Model

FFTF Fast Flux Test Facility

FPA Federal Preparedness Agency

FY Fiscal Year

GA General Atomic

GAO General Accounting office

GE General Electric

GESMO Generic Environmental Statement on Mixed Oxide

GSA General Services Administration

HEDL Hanford Engineering Development Laboratory

HEW Health, Education and Welfare (Department of)

HPFL High Performance Fuel Laboratory

HTGR High Temperature Gas Reactor

HUD Housing and Urban Development (Department of)

IAEA International Atomic Energy Agency

ICPP Idaho Chei-ical Processing Plant

ID Inventory Difference

IEEE Institute of Electrical and Electronics Engineers

INEL Idaho National Engineering Laboratory

INMM Institute of Nuclear Materials Management

ISEM Insider Safeguards Effectiveness Model

LASI. Los Alamos Scientific Laboratory

LLL Lawrence Livermore Laboratory

LMFBR Liquid Metal Fast Breeder Reactor

LWR Light water Reactor 


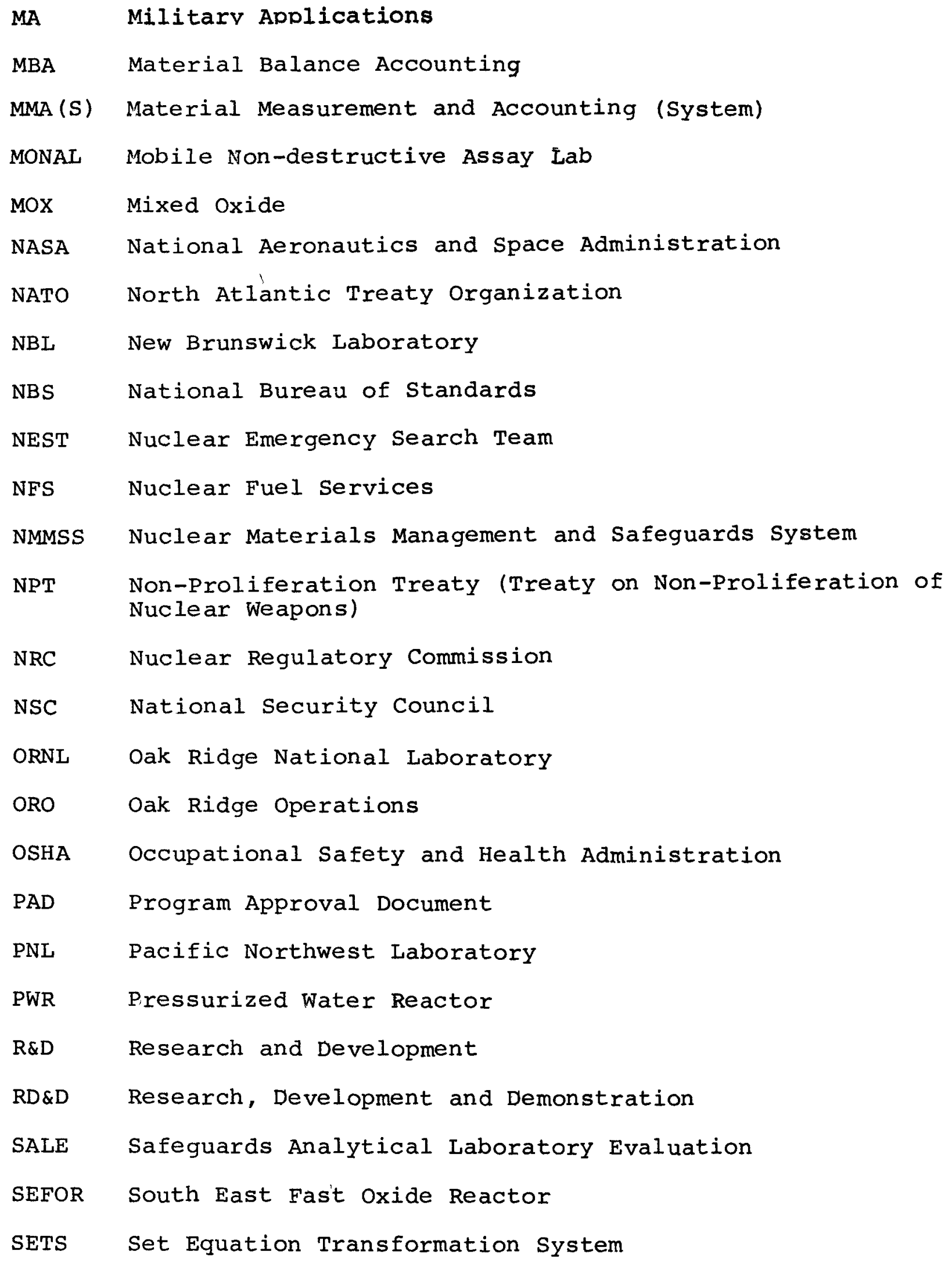


SIS Safeguards Information System

SNM Special Nuclear Material

SRM Standard Reference Material

SRP Savannah River Plant

TID Technical Information Division

TSO Technical Support Organization

USDA United States Department of Agriculture 